NBER WORKING PAPER SERIES

\title{
THE FEDERAL RESERVE'S CURRENT FRAMEWORK FOR MONETARY POLICY: A REVIEW AND ASSESSMENT
}

\author{
Janice C. Eberly \\ James H. Stock \\ Jonathan H. Wright \\ Working Paper 26002 \\ http://www.nber.org/papers/w26002 \\ NATIONAL BUREAU OF ECONOMIC RESEARCH \\ 1050 Massachusetts Avenue \\ Cambridge, MA 02138 \\ June 2019
}

Prepared for the Conference on Monetary Policy Strategy, Tools, and Communication Practices, June 4-5, 2019, Federal Reserve Bank of Chicago. The authors thank Gadi Barlevy, Regis Barnichon, Ben Bernanke, Gabe Chodorow Reich, Jordi Galí, Michael Kiley, Ed Nelson, John Taylor, and Mark Watson for helpful discussions, Ben Austin for econometric assistance, and John Coglianese, Don Kim, and Marco Del Negro for providing data. The views expressed herein are those of the authors and do not necessarily reflect the views of the National Bureau of Economic Research.

At least one co-author has disclosed a financial relationship of potential relevance for this research. Further information is available online at http://www.nber.org/papers/w26002.ack

NBER working papers are circulated for discussion and comment purposes. They have not been peer-reviewed or been subject to the review by the NBER Board of Directors that accompanies official NBER publications.

(C) 2019 by Janice C. Eberly, James H. Stock, and Jonathan H. Wright. All rights reserved. Short sections of text, not to exceed two paragraphs, may be quoted without explicit permission provided that full credit, including $\odot$ notice, is given to the source. 
The Federal Reserve's Current Framework for Monetary Policy: A Review and Assessment Janice C. Eberly, James H. Stock, and Jonathan H. Wright

NBER Working Paper No. 26002

June 2019

JEL No. C22,E43,E52

\begin{abstract}
$\underline{\text { ABSTRACT }}$ consistent with a higher inflation target coming into the financial crisis recession.

Janice C. Eberly

Department of Finance

Kellogg School of Management

Northwestern University

2211 Campus Drive

Evanston, IL 60208

and NBER

eberly@kellogg.northwestern.edu

James H. Stock

Department of Economics

Harvard University

Littauer Center M26

Cambridge, MA 02138

and NBER

James_Stock@harvard.edu

Jonathan H. Wright

Department of Economics

Johns Hopkins University

3400 N. Charles Street

Baltimore, MD 21218

and NBER

wrightj@jhu.edu
\end{abstract}

We review and assess the monetary policy framework currently used by the Federal Reserve, with special focus on policies that operate through the slope of the term structure, including forward guidance and large scale asset purchases. These slope policies are important at the zero lower bound. We study the performance of counterfactual monetary policies since the Great Recession in the framework of a structural VAR, identified using high-frequency jumps in asset prices around FOMC meetings as external instruments. The intention is to give guidance to policymakers responding to future downturns. In our counterfactuals, we find that slope policies played an important role in supporting the recovery, but did not fully circumvent the zero lower bound. In our simulations, earlier and more aggressive use of slope policies support a faster recovery. The recovery would also have been faster, with the unemployment gap closing seven quarters earlier, if the Fed had inherited a higher level of inflation and nominal interest rates 


\section{Introduction and Summary}

The Humphrey-Hawkins Act of 1978 instructs the Federal Reserve Board to "promote effectively the goals of maximum employment, stable prices, and moderate long-term interest rates." The methods by which this dual mandate of maximum employment and price stability is to be achieved are left to the Fed. Those methods have evolved over time as the Fed and economists learned more about the theory and practice of monetary policy (Fuhrer et al. (2018)).

The current framework for monetary policy, formally adopted in 2012, consists of a symmetric $2 \%$ inflation target, a commitment to support maximum employment, and a suite of policy actions that Federal Reserve officials can take to achieve those goals. Those policy actions affect current and expected future interest rates and communicate the FOMC's intentions about monetary policy. A key element of this suite, setting the current level of the Federal funds rate from one FOMC meeting to the next, has been central to Fed policy for decades. The current monetary policy framework, however, also includes newer elements developed during this century to influence term premia and/or expectations of future Fed policy. One such element is forward guidance through measures such as statements accompanying FOMC meeting announcements, the Summary of Economic Projections, and speeches by Fed officials. Another such element is direct purchases of long-term assets (large-scale asset purchases, or LSAPs), which both directly affect the prices of long-term assets and convey information about future Fed policy. Collectively, these new policies affect the slope of the term structure of interest rates. We refer to these policies (forward guidance, LSAPs, maturity extensions, etc.) as slope policies, to differentiate them from traditional policy that sets the current level of the Fed funds rate. These new tools of slope policy are particularly relevant when conventional policy, that is, the current level of the Federal funds rate, is constrained by the floor on nominal interest rates, generally referred to as the zero lower bound.

This paper reviews and assesses the current monetary policy framework in the context of the experience of the expansion that began in the second quarter of $2009 .{ }^{1}$ Our assessment draws on the large literature examining the functioning and consequences of these policies, on a review of macroeconomic performance over the expansion, and on counterfactual simulations of alternative policies using the historical record. These alternative policies draw on the elements of the current framework but implement them in a way that allows us to consider alternative policy paths. We conduct these counterfactuals using an empirical model that combines the response of the unemployment gap

\footnotetext{
${ }^{1}$ Because our focus is on the current long-term monetary policy framework, we do not consider the special measures and facilities that provided liquidity during the financial crisis.
} 
to monetary policy shocks with a New Keynesian Phillips curve. Although this model is newly developed for this paper, comparisons with results from other papers indicate that the dynamics in our model are generally consistent with other, sometimes quite different, approaches.

Examining hypothetical counterfactuals overlaid on the actual experience of the expansion, as we do, has the advantage of making concrete the plusses and minuses of these counterfactuals, including possible unintended consequences. A disadvantage of this overlay is that it could be interpreted as second-guessing the Fed: It is not. Many of the counterfactuals we consider were not available in real time, at least in part because we are able to evaluate their effects with the benefit of hindsight. By using this evaluative method, our aim is to inform future options as the Fed evaluates its current monetary policy framework.

Our analysis leads us to six main conclusions.

First, the current monetary policy framework, in particular its new suite of slope policies, played an important role in supporting the recovery. Absent slope policy, the recovery of the labor market would have been slower, and the rate of inflation lower, than it was. The magnitude of the effect is substantial: absent slope policy, we estimate that the unemployment rate would have crossed the CBO's estimate of the natural rate more than one year later than it did, and the rate of inflation would have been approximately 0.2 percentage points lower than it was during the latter part of the recovery.

Second, the main forces behind the slow growth of GDP over this recovery are trends that predate the recession. These include the slowing of the growth of the labor force because of the retirement of the baby boom and the plateau of women entering paid work and the productivity slowdown that started in the early or mid-2000s. These trends and other factors, such as fiscal drag from 2012 to 2016, are outside the reach of monetary policy. To the extent that monetary policy could have sped up the recovery of the labor market, GDP growth would have been modestly faster, but even so the demographic and other headwinds would have produced a growth rate of GDP below that of the 2001-2007 expansion, and well below that of the expansions of the 1980s and 1990s.

Third, despite the efficacy of slope policy, the zero lower bound significantly restricted the scope of monetary policy during the recovery. Absent the zero lower bound, we (and others) estimate that normal Fed policy would have led to a Fed funds rate of approximately $-5 \%$. Our estimates suggest that Fed slope policies were able to offset perhaps one percentage point of the zero lower bound constraint. Multiple authors have pointed to a high probability of hitting the zero lower bound again during future downturns, and our simulations suggest that, when this happens, it meaningfully limits the efficacy of Fed policy. 
Fourth, small changes in policy would have produced small changes in realized outcomes. For example, speeding up or delaying liftoff of the Fed funds rate by one year would have changed the unemployment gap, relative to actual, by a few tenths of a percentage point, and would have had a negligible effect on the inflation rate.

Fifth, of the counterfactuals we consider, the policies with the largest effect are ones with early and aggressive slope policy, undertaken roughly when the Fed funds rate hits the zero lower bound. We estimate that "stronger sooner" slope policies have a relatively rapid effect on the economy, so early aggressive action to flatten the term structure could substantially speed the recovery in the labor market and support reflation. This said, more aggressive use of slope policy comes with a number of concerns and potential channels that we do not model, which could constrain the Fed's ability to implement them in practice.

Sixth, the current suite of policies would have led to a substantially faster recovery and a rate of inflation closer to target had the Fed inherited higher nominal interest rates and inflation rates consistent with a higher inflation target. For example, we estimate that inheriting interest rates, inflation rates, and an inflation target one percentage point higher than actual, combined with the slope policies actually used over the expansion, would have resulted in the unemployment rate falling below the $\mathrm{CBO}$ natural rate of unemployment seven quarters earlier than it did. With inherited nominal rates, inflation, and an inflation target two percentage points higher than actual, we estimate that the unemployment rate would have crossed the $\mathrm{CBO}$ natural rate 10 quarters earlier than it did, allowing liftoff to occur in 2014.

Our results also have implications for fiscal policy. Even though adjustments to the long-run framework, including "stronger sooner" policies and a higher inflation target, could enhance the Fed's efforts to stabilize the economy in a future recession, as we discuss there are limits to the Fed's use of forward guidance and LSAPs. Moreover, the Fed funds rate is at historic lows for this late stage of the business cycle. These observations underscore the importance of complementary countercyclical fiscal policies, especially automatic stabilizers, in future recessions.

The remainder of the paper is organized as follows. We begin in Section 2 with an overview of the current monetary policy framework, including a timeline of major events in its evolution and development. There is now a large literature that has examined the effect of slope policies on long-term interest rates and on economic outcomes, and we review that literature in Section 3. Section 4 reviews macroeconomic performance during the expansion. Section 5 presents our simulation model, Section 6 presents the counterfactuals, and Section 7 provides caveats and conclusions. 


\section{The Current Framework for Monetary Policy}

The current monetary-policy framework was put in place in January 2012 and while subsequently refined operationally, remains largely unchanged. This framework has two objectives: keeping the rate of price inflation, as measured by the personal consumption expenditure (PCE) price index, close to two percent, and keeping the unemployment rate close to the long-run full-employment rate, sometimes called the natural rate of unemployment or the non-accelerating inflation rate of unemployment (NAIRU). There is an explicit numerical objective for inflation, whereas there is no corresponding numerical objective for unemployment, because the natural rate is seen as time-varying, not directly measurable, and driven by nonmonetary factors. In two subsequent meetings, in 2014 and 2016, respectively, FOMC statements clarified that that inflation outcomes above and below the 2 percent goal were equally costly, then explicitly referred to the inflation objective as a "symmetric inflation goal".

The historical path to the current framework reflects a trend toward greater transparency in central banking, as well as greater resolution about the use of new tools over time.

As part of the trend toward greater transparency, the January 2012 monetary-policy framework integrated and expanded the Summary of Economic Projections (SEP), which had been in place since October 2007. From the start, the SEP numbers were released quarterly, and covered real GDP growth, the unemployment rate, PCE and core PCE inflation at horizons out to three years. In 2009, projections were expanded to include long-run real GDP growth, the unemployment rate, and headline inflation. The January 2012 monetary-policy framework made additional changes. Notably, it included numerical forecasts of the future path of the federal funds rate at year-end and in the longer run by individual FOMC participants, the so-called "dot plots". This change is notable for publishing numerical forecasts of future policy, not only economic conditions.

In addition to the over-arching framework describing monetary policy objectives, the FOMC has provided guidance about the implementation of monetary policy, or its operating policy. These operating policies govern the use of the tools to achieve the objectives. The current monetary policy framework uses short-term interest rates as the primary tool for influencing aggregate demand, but can also use forward guidance, long-term asset purchases, and other measures that affect the maturity 
composition of the Fed's balance sheet. As documented by Fuhrer et al. (2018), Fed operating policies have changed historically, and the FOMC has used several approaches over the last 10 years. ${ }^{2}$

Figure 1 summarizes the evolution of forward guidance from 2007 through $2018 .^{3}$ When the FOMC lowered its target for the federal funds rate to a range of 0 to $1 / 4$ percent in December 2008 , it

Figure 1. FOMC Timeline Exhibit - Interest Rate Forward Guidance

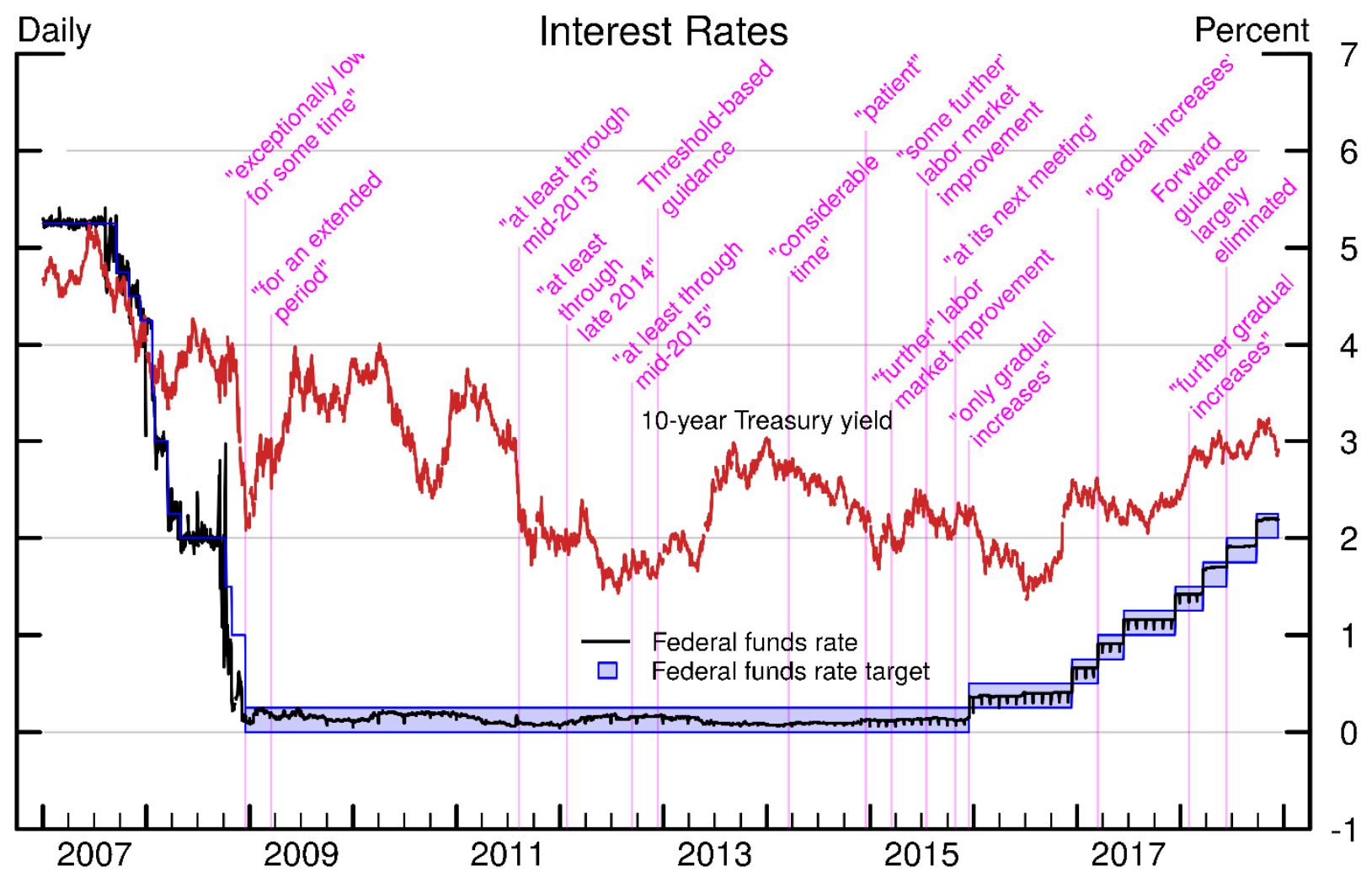

Source: Board of Governors of the Federal Reserve System

communicated that conditions were likely to warrant exceptionally low levels of the rate "for some time." In addition to moving the current federal funds rate, this forward guidance potentially affects expectations of future interest rates, and hence longer horizon interest rates: the slope of the yield

\footnotetext{
${ }^{2}$ We take a longer perspective for this section, as the FOMC has these tools available to it, even if not currently in use, and they are relevant for the counterfactual analysis in Section 6.

${ }^{3}$ Forward guidance predates the financial crisis recession. FOMC statements in 2003-2005 contained early forms of forward guidance. For example, at several meetings in 2003, the FOMC statement said that "policy accommodation can be maintained for a considerable period." Gürkaynak, Sack and Swanson (2005) document that even before the crisis, much of the news from FOMC announcements came in the form of news about the path of future policy rather than news about the target level of the federal funds rate. However, forward guidance assumed a much greater role since the financial crisis.
} 
Figure 2. FOMC Timeline Exhibit - LSAP Policies

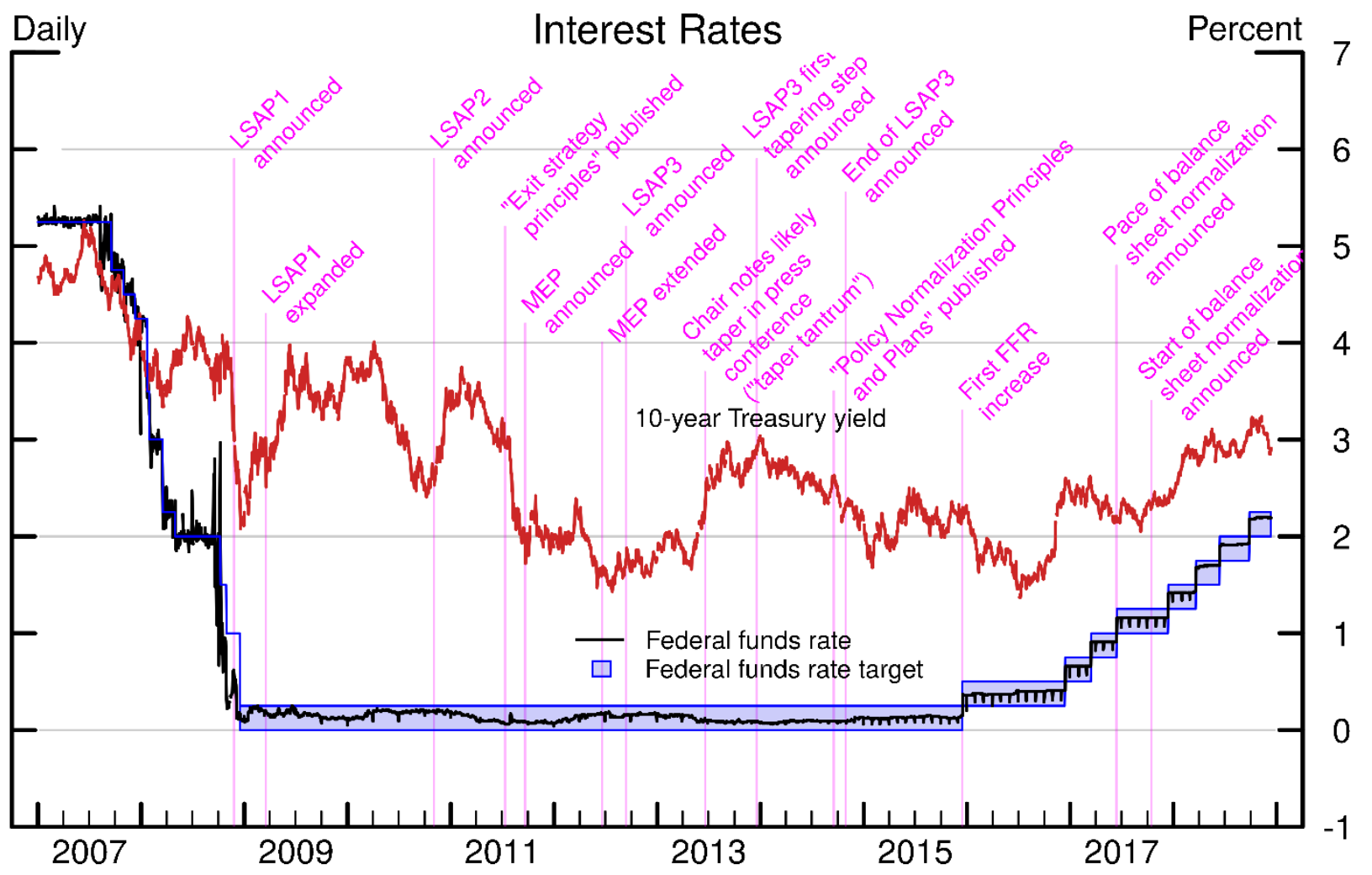

Source: Board of Governors of the Federal Reserve System

curve. In March of 2009, the language "for some time" was replaced with "for an extended period". In August 2011, this qualitative language was replaced with a calendar threshold of "at least through mid2013," which was then extended to 2014 and 2015 in January and September of 2012, respectively. The calendar-based guidance was replaced by outcome-based thresholds starting in December 2012, stating that the low range would be maintained "at least as long as the unemployment rate remains above $6 \frac{1}{2}$ percent, inflation between one and two years ahead is projected to be no more than a half percentage point above the Committee's 2 percent longer-run goal, and longer-term inflation expectations continue to be well-anchored." Threshold-based guidance continued until the unemployment rate reached $61 / 2$ in 2014. These three periods represent three approaches to operating policy: qualitative guidance, calendar-based guidance, and outcome- or threshold-based guidance.

As shown in Figure 2, the Fed's balance sheet policies also have evolved since 2007. Starting in November 2008, the Federal Reserve's Balance Sheet programs were announced with both quantitative amounts of asset purchases and a time horizon for the transactions. As the programs were completed, 
Figure 3. FOMC Timeline Exhibit - SEP and Consensus Statement

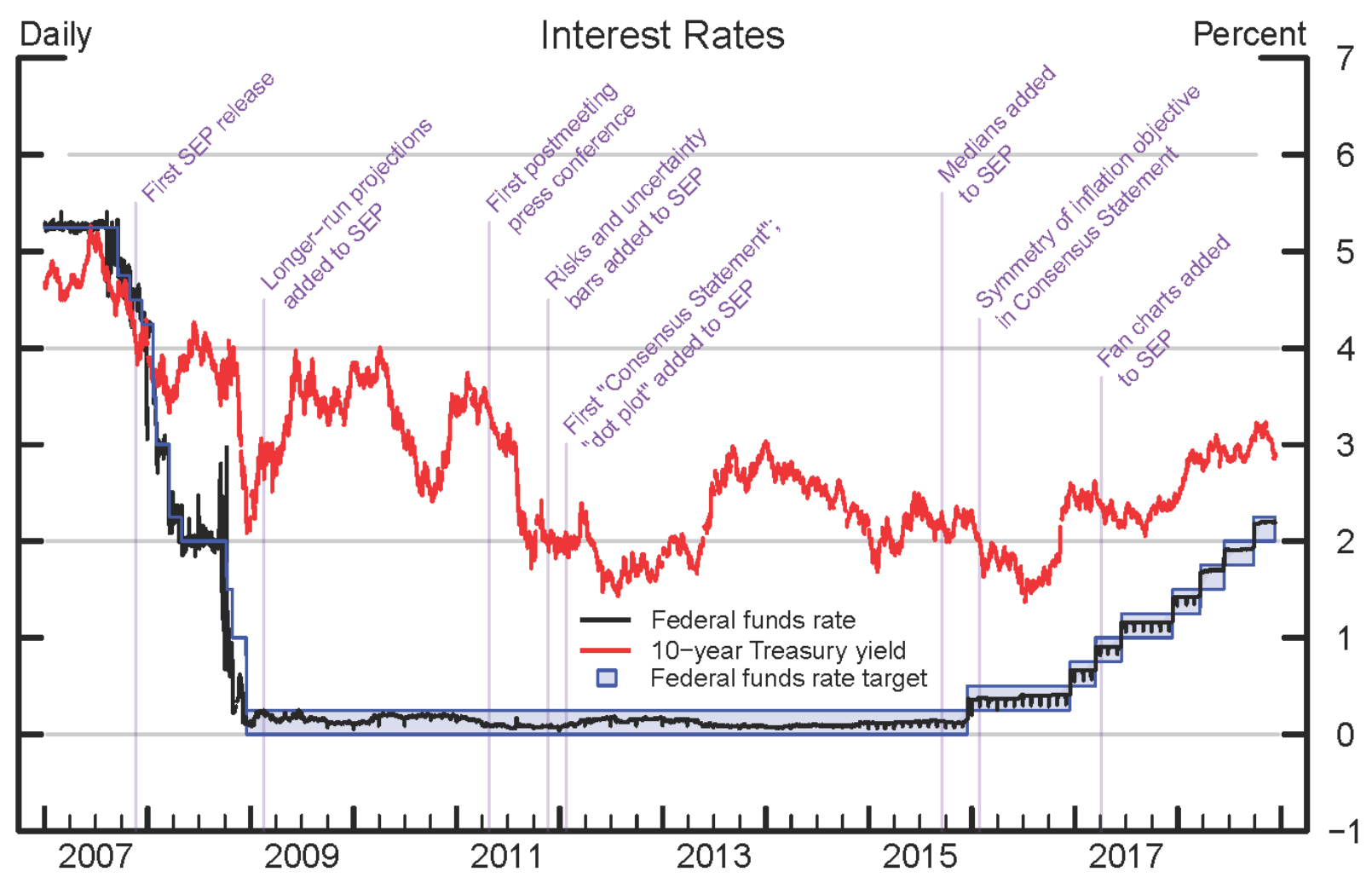

Source: Board of Governors of the Federal Reserve System

the FOMC clarified reinvestment policies and its commitment to use policy tools to meet its economic objectives, for example in September 2010, "to provide additional accommodation if needed to support the economic recovery and to return inflation, over time, to levels consistent with its mandate." This commitment was renewed throughout the LSAP and MEP implementation periods. While no explicit outcome-based thresholds were introduced, the policy was conditional on economic outcomes ${ }^{4}$.

The statement of a possible calendar time for slowing purchases was first broached in 2013 and announced in December 2013. A formal policy statement governing balance sheet normalization was published in September 2014. This statement was refined in the interim, and an Addendum was issued in June 2017 with quantitative steps to govern balance sheet normalization. In addition to guidance for principal reinvestment, this addendum included the statement that the Committee would be prepared to resume reinvestment of principal payments if there were a "material deterioration in the economic outlook" that would warrant a sizable reduction in the target federal funds rate. The Committee

\footnotetext{
${ }^{4}$ See, for example, the FOMC statements of September 2012, March 2013, and May 2013.
} 
affirmed that it was prepared to use "its full range of tools," including the size and composition of the balance sheet, "if future economic conditions were to warrant a more accommodative monetary policy than can be achieved solely by reducing the federal funds rate." The Federal Reserve thus retains economic conditionality for future balance sheet policies.

The Summary of Economic Projections added median forecasts starting in September 2015 and included fan charts in the expanded version of the projections that is published with the minutes, starting in March 2017. The Federal Reserve Chairman gives a press conference after every meeting, starting in 2019. Figure 3 summarizes the evolution of the SEP and the Consensus statement.

Since 2012, the monetary policy framework has remained essentially unchanged, with the committee reaffirming its statement of longer-run goals and monetary policy strategy each January with some adjustments. As noted at the outset of this section, the minutes to the October 2014 FOMC meeting noted that the committee discussed changes to the goals and strategy statement including clarification that the inflation objective is symmetric, which was made explicit in the January 2016 update. The unemployment objective has neither a numerical goal nor a statement that it is symmetric. Many models of Federal Reserve policy include an estimate of the unemployment goal, typically the natural rate or the NAIRU. However, stated policy does not specify the goal, nor does it state that operating policy is symmetric around this goal. ${ }^{5}$

\section{Effects of LSAPs and Forward Guidance on Yields and the Macroeconomy}

The existing monetary policy framework treats short-term interest rates as the primary tool of monetary policy, but also uses forward guidance and large-scale asset purchases (LSAPs) and related maturity policies, such as the maturity extension program and reinvestment of principal policy at the zero lower bound (ZLB). Kuttner (2018) gives a recent review of the experience of unconventional monetary policy since the financial crisis recession. In this section, we review evidence on their effects on yields and on macroeconomic outcomes.

\subsection{Asset Purchases}

Much of the evidence for the efficacy of LSAPs comes from event study evidence, which was particularly apparent in the first round of purchases, QE1, because these announcements came as complete surprises and were immediately followed by sharp drops in yields. Gagnon et al. (2011) and

\footnotetext{
${ }^{5}$ This approach allows for uncertainty in the observation of labor market conditions, as well as conditioning the response to labor market conditions on other economic conditions and shocks.
} 
Krishnamurthy and Vissing-Jorgensen (2011) find that QE1 announcements were followed by immediate drops in Treasury yields that added up to around a percentage point.

The event study approach only measures the short-run effect of the announcement. There have been studies on trying to estimate the persistence of the effects (Wright (2012), Swanson (2017), Greenlaw et al. (2018)) but confidence intervals are very wide, and results are sensitive to the inclusion of the March 2009 FOMC announcement. This announcement came as a complete surprise that caused a sharp drop in yields, that was however reversed over the next couple of months. LSAP announcements subsequent to the first QE1 round were better anticipated by markets, making the event study methodology less operative.

Federal Reserve purchases of Treasury securities reduce the effective supply of these assets to market participants. Several authors have studied the effects of overall Treasury supply on yields, including Hamilton and Wu (2012), Krishnamurthy and Vissing-Jorgensen (2012) and Greenwood and Vayanos (2013). These papers all frame the question slightly differently, but nonetheless end up with consistent results---changes in the supply of Treasuries have a small but significant impact on yields. Belton et al. (2018), reviewing the existing literature, conclude that adding to 1 percent of GDP (or around $\$ 200$ billion today) to the supply of ten-year equivalent Treasuries raises the term premium by about 6 basis points. A rule of thumb like this is market conventional wisdom, and close to what was found by Hamilton and Wu (2012). Li and Wei (2013) estimate supply effects in an affine term structure model, and get a somewhat larger estimate in which a 1 percent of GDP increase in the supply of Treasuries raises the term premium by about 10 basis points. They conclude that the total effect of QE1, QE2 and Operation Twist was to lower ten-year yields by about a percentage point. Note that these estimates relate yields to the stock of asset purchases, not the flow of asset purchases. Some of the QE1 announcements had announcement effects that were bigger than can readily be explained by changes in the stock of Treasuries. In particular, the March 2009 announcement of $\$ 300$ billion in Treasury purchases lowered ten-year yields by 40 to 70 basis points, depending on the time window used for the event study. This is a far bigger impact than would be predicted by any of the conventional elasticities, but it happened at a time of severe market disruption when flows might have had a large, though transitory, effect.

Another question about the effects of LSAP purchases on Treasury yields is the potential for Treasury to offset the effect by issuing more of the securities that the Federal Reserve is going to buy, leaving the net supply to the market unchanged. The Treasury did indeed substantially lengthen the maturity of its issuance during the LSAP period. 
There is also evidence of LSAP effects on credit markets, which is crucial since affecting Treasury yields is not an end in itself. Di Maggio, Kermani and Palmer (2016) document that MBS purchases increased mortgage refinancing activity, at least among households who were not underwater and thus eligible to refinance. This also underscores a limitation of MBS purchases: many homeowners were simply unable to refinance, because they were underwater or for other reasons, and so they could not benefit from the reduction in mortgage rates. Rodnyanski and Darmouni (2017) and Foley-Fisher, Ramcharan and $\mathrm{Wu}$ (2016) use differences-in-differences approaches to argue that asset purchases increased bank lending.

LSAPs had an effect on bond markets, but it is less clear through what channels this was working. There are broadly two possibilities. One is that it worked by reducing term premia on longerterm bonds as investors have demand for specific long duration assets, as in the preferred habitat model of Vayanos and Vila (2009). The other is that it signals that the Federal Reserve will keep policy rates low for longer. There can be elements of both. But the view that LSAPs worked only through expectations and left term premia unchanged should imply that near term yields fell, but long-term yields should be little changed ${ }^{6}$ unless one views the commitment to lower policy rates to last beyond a few years, which does not seem credible given FOMC turnover. However, the announcements of LSAPs lowered ten-year yields by substantially more than two-year yields (Gagnon et al. (2011)). Moreover, the announcements of asset purchases had the greatest impact on the specific securities being purchased relative to others with similar maturity that were not being purchased (D'Amico et al. (2012), D'Amico and King (2013)), which also points to the importance of preferred habitat or local supply mechanisms. A similar indicator that asset purchases operated significantly through the impact of asset supply is the fact that announcements of MBS purchases had large effects on MBS rates, but announcements of Treasury purchases alone had much more muted effects on MBS rates (Krishnmaurthy and Vissing-Jorgensen (2011)).

\subsection{Forward guidance}

As noted in Section 2, from March 2009 until June 2011 the post-meeting FOMC statements declared that exceptionally low levels of rates would be warranted for "an extended period." Surprisingly, over this period, the market appeared to continually believe that liftoff was just around the corner, as evidenced from the Survey of Professional Forecasters and also from the fact that two-year

\footnotetext{
${ }^{6}$ Indeed long-term interest rates should, if anything, increase with higher inflation expectations.
} 
Treasury yields remained quite sensitive to macroeconomic news (Swanson and Williams (2014)). Swanson and Williams conclude from the sensitivity of Treasury yields to macroeconomic news surprises that the more explicit date-based forward guidance that came in August 2011, coupled with the introduction of the dot plot the following January, was effective in pushing the expected time of liftoff back to around two years from then. Femia, Friedman and Sack (2013) reach a similar conclusion using survey evidence.

The theoretical concept of forward guidance is a commitment to allow an inflationary boom in the future (Eggertsson and Woodford (2003)). This is very powerful in standard DSGE models, arguably implausibly so (Del Negro, Giannoni and Patterson (2012)). Campbell et al. (2012) refer to this as Odyssean forward guidance. However, neither the Federal Reserve nor any other central bank has given this kind of forward guidance, and indeed Kohn (2009) stated that this was not the intention of FOMC forward guidance. A planned overshoot of inflation as in Eggertsson and Woodford is not envisioned in the current monetary policy framework.

\subsection{Summary of Economic Projections}

One of the transparency initiatives of the FOMC over the past decade or so has been the introduction of the summary of economic projections (SEP) and its expansion to include forecasts of interest rates in 2012. The hope was that market expectations would move in line with the SEP and give them more of a hold on longer-term interest rates.

The SEP interest rate projections, viewed as the Committee's forecasts, have turned out to be quite poor, perhaps in part because they represent up to 19 different views many of which are quite distinct. Federal Reserve Chairs have noted that the dot plot is not a consensus forecast of the FOMC and that the statement is the mechanism that the Committee uses to express its collective judgement about the likely future path of rates. Nonetheless, the dot plot gets a lot of attention and is, not surprisingly, viewed by markets and the press as a Committee forecast, notwithstanding instance to the contrary. This is especially true since the statement does not normally include much explicit guidance about future interest rates.

Faust (2016) argues that the dot plot conveys the diversity of views on the Committee but fails to represent how the Committee is likely to aggregate those views into a consensus. Consequently, he argues the dot plot gives the illusion of transparency but adds to public confusion. He cites a political science literature that maximal apparent transparency can actually be counterproductive (Stasavage (2007), Sunstein (2016)). 
In any event, the SEP receives considerable attention and affects market expectations. We ran a simple event study regression aimed at identifying the causal effect of the SEP on market interest rate expectations. Since September 2015, the Federal Reserve Bank of New York Primary Dealer Survey has asked primary dealers for their expectations of what the SEP will predict at the upcoming meeting. This represents their expectations just a few days before the FOMC announcement. Define $S_{y, t}$ to be the median SEP path for the funds rate at the end of year $y$ at meeting $t$ less the expectation for that prediction coming from the Primary Dealer Survey taken shortly before the meeting. Define $\Delta E D_{y, t}$ as the intradaily change in the Eurodollar futures contract rate expiring in December of year $y$ from 15 minutes before the announcement for FOMC meeting $t$ until 15 minutes afterwards (tight window) or until 1 hour and 45 minutes afterwards (wide window). Then consider the simple event-study regression,

$$
\Delta E D_{y, t}=\beta S_{y, t}+\varepsilon_{y, t} .
$$

There are 15 FOMC meetings with SEP releases in the sample, and at each meeting there are forecasts at 3 or 4 horizons. The coefficient $\beta$ tells us the effect of a surprise in the SEP on the Eurodollar futures rate which, in the absence of shifts in risk premia, should represent expected short-term interest rates at a comparable horizon. The wide window includes the press conference, which was always held over this sample period, whereas the tight window does not. However, the SEP was released with the FOMC statement at $2 \mathrm{pm}$, so its impact should be reflected in the tight window. ${ }^{7}$

Table 1. Regression of Intraday Eurodollar Futures Rate Changes on SEP Interest Rate Surprises

\begin{tabular}{lll}
\hline \hline & Tight window & Wide window \\
\hline$\beta$ & $0.18^{* * *}$ & $0.19 * *$ \\
& $(0.05)$ & $(0.09)$ \\
\hline \hline
\end{tabular}

This table reports the slope coefficients in regressions of intradaily changes in December Eurodollar futures rates onto the surprises in SEP interest rate projections at the same maturities. Observations are pooled across SEP forecast dates and horizons. The sample period is all SEP forecasts from September 2015 to March 2019 inclusive. Standard errors, clustered by forecast date, are reported in parentheses.

The results are shown in Table 1. Standard errors are clustered by FOMC meeting. The conclusion is that SEP surprises do have a statistically significant effect on a proxy for market rate expectations. The coefficient estimate is approximately 0.18 , indicating that a one percentage point

\footnotetext{
${ }^{7}$ The definitions of tight and wide windows follows Gürkaynak, Sack and Swanson (2005).
} 
higher-than-expected SEP number for the federal funds rate increases Eurodollar futures rates by 18 basis points. Although statistically significant, this estimated effect is not very large. Presumably if the track record of the SEP relative to other real-time alternatives improves over time, then the impact of the SEP will increase.

\subsection{Macroeconomic effects}

By the standards of time series macroeconometrics, the data span available for studying the macroeconomic effects of slope policies is relatively short, so it is perhaps not surprising that the literature has obtained a wide range of results. Using a Bayesian VAR identified via sign and zero restrictions, Weale and Wieladek (2015) found that asset purchases of 1 percent of GDP, in the US, led to a peak increase in both real GDP and CPI of 0.6 percentage points. These are very large estimated effects---the size of the Fed balance sheet increased by nearly 20 percentage points of GDP. Hesse, Hofmann and Weber (2018) use a similar Bayesian VAR methodology but get somewhat smaller, though still very positive, effects on both economic activity and inflation. In subsample analysis, they find that the effects of asset purchases were stronger in the early stages, right after the crisis, than later on.

Nakamura and Steinsson (2018a) identify a policy news shock as the first principle component of the jump in five short-term interest rates around FOMC announcements and find that surprise tightening of policy is associated with an increase in growth expectations. This exercise does not attempt to split out shocks to the level of funds rate from shocks to the slope of the yield curve. They interpret this as owing to the possibility that tighter monetary policy reveals Federal Reserve information about the state of the economy, along the lines also indicated by Campbell et al. (2012, 2017).

Several authors have identified forward guidance, or path surprises, in structural VARs using high frequency financial variables around announcements as instruments, with mixed results. These papers interpret shocks to the slope of the yield curve as forward guidance surprises, but they may also include elements of LSAPs, especially since the two kinds of announcements often came out concurrently. Bundick and Smith (2018) find that forward guidance shocks that lower the path of expected policy rates lead to moderate increases in output and inflation, but Kim (2017) and Lakdawala (2019) find that these forward guidance shocks are contractionary, which they see as supporting the information signaling view of Nakamura and Steinsson (2018a). 
A number of authors use either DSGE or the FRBUS models to simulate the effects of LSAPs and forward guidance. These papers have found that LSAPs and forward guidance have modest but beneficial effects on both economic activity and inflation. We return to these papers in Section 6 .

\section{The Economic Expansion Following the Financial Crisis}

The expansion that began in the second quarter of 2009 exhibited steady improvement in the labor market, on pace with previous expansions despite the severity of the recession, but historically slow growth of GDP and quiescent rates of price inflation and wage growth. As shown in Figure 4, the unemployment rate fell from its peak of $10.0 \%$ in October 2009 at an average rate of 0.74 percentage points per year, crossing the CBO NAIRU in the first quarter of 2017. This peak-to-NAIRU rate of decline was faster than in the previous two business cycles, but slower than the recovery following the severe recession of 1981-82. The decline in the unemployment rate has been matched by the steady addition of jobs to the economy: since the peak of unemployment in October 2009, the economy has added, on average, approximately 175,000 jobs per month.

Figure 4. The unemployment rate, the CBO NAIRU, and the average decline of the unemployment rate from its business cycle peak to when it hits the NAIRU, for the current and prior three expansions.

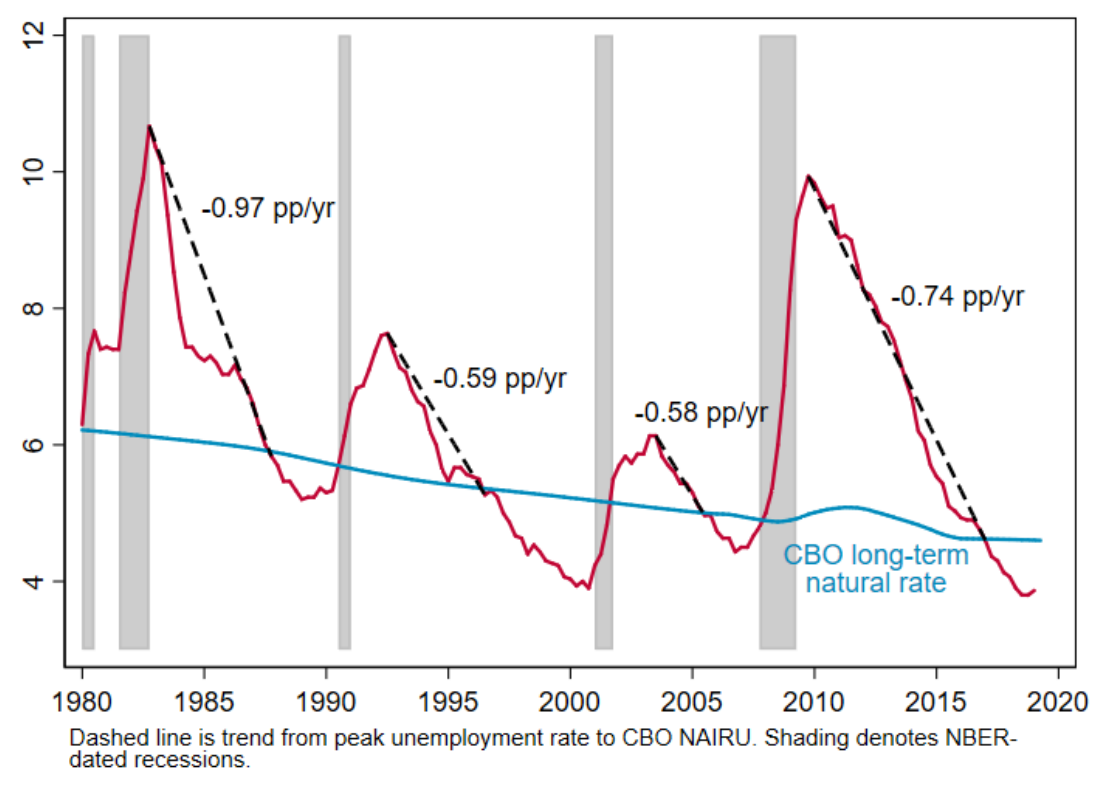


Figure 5. Four-quarter growth of GDP and its mean value over the current and prior three expansions.

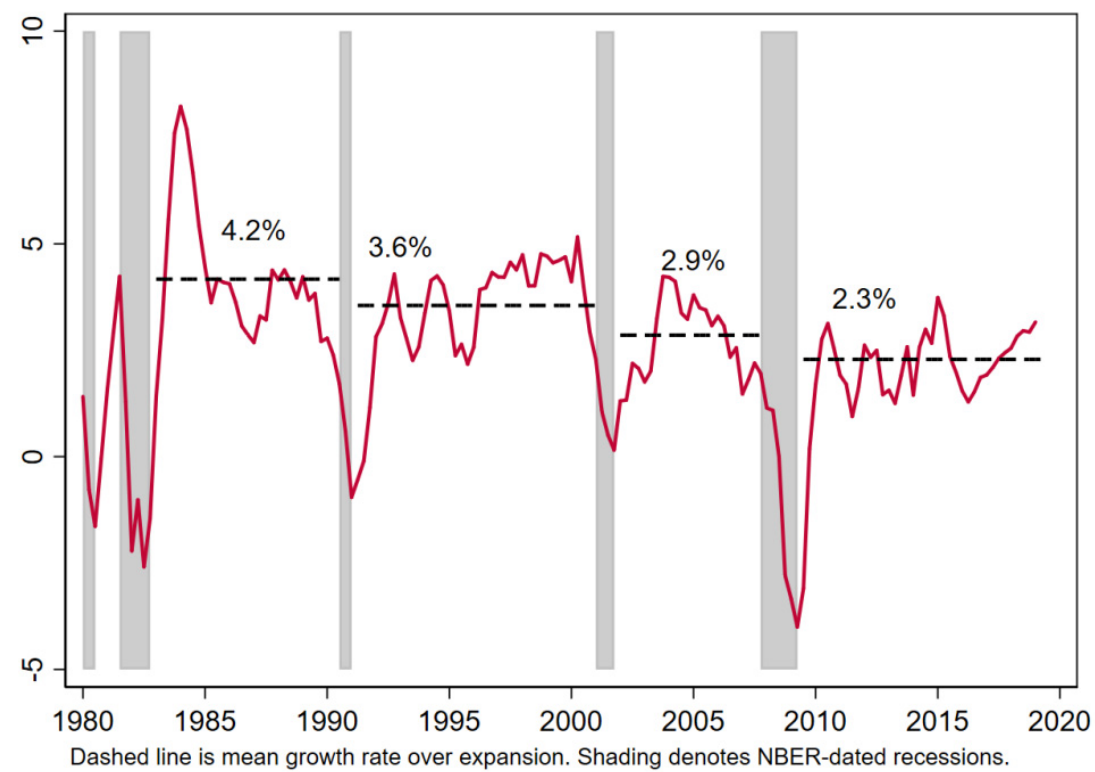

In contrast to this recovery of the unemployment rate, GDP growth over the recovery has been historically slow: over the expansion GDP growth has averaged only $2.3 \%$ annually. The slowing growth of U.S. output over this recovery is a continuation of a preexisting trend. As shown in Figure 5, the growth rate of GDP during expansions has fallen over each of the current and past three expansions.

The reasons for the slow growth in GDP, despite the recovery of the labor market as measured by the unemployment rate, has been the subject of a great deal of debate by economists. ${ }^{8}$ Although there are many open questions, two key proximate reasons for the decline are a slowdown in the growth rates both of the number of available workers and in output per worker, which in turn is driven by a decline in total factor productivity.

Although the rate of unemployment declined at a rate equal, on average, to that of the past three recessions, the fraction of adults in the labor force - that is, the labor force participation rate - fell substantially over the recession and early recovery, from $66.0 \%$ at the cyclical peak of December 2007 to $62.9 \%$ in January 2015 , and has been approximately stable since. This decline is, in large part, a continuation of historic trends in the working patterns of adult Americans. As shown in Figure 6, the labor force participation rate for men has been falling steadily over the past four decades. Starting in the 1960s, women entered the labor market at increasing rates, with female labor force participation rising

\footnotetext{
${ }^{8}$ See for example Fernald et al. (2017), Farhi and Gourio (2018), Gutiérrez and Philippon (2017), McGrattan and Prescott (2012) and other contributions to Ohanian, Taylor, and Prescott (2012).
} 
Figure 6. Male and female labor force participation rate, ages $16+$

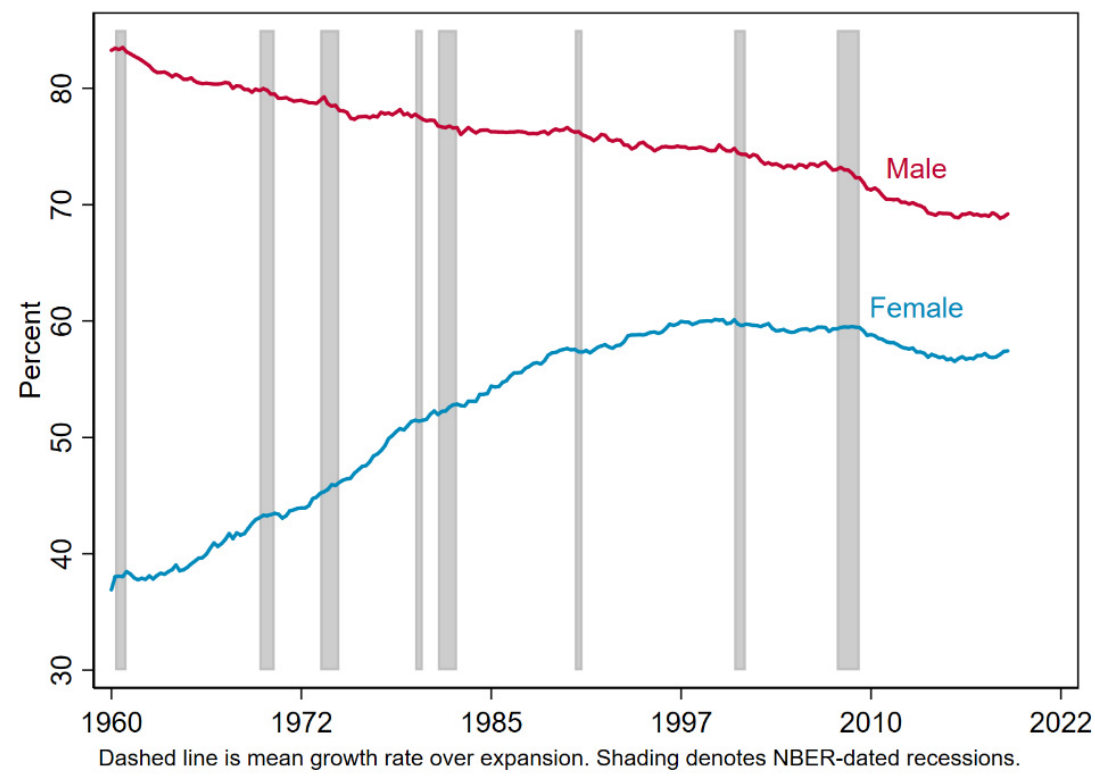

Figure 7. Overall labor force participation rate, ages $16+$, and demographic trend

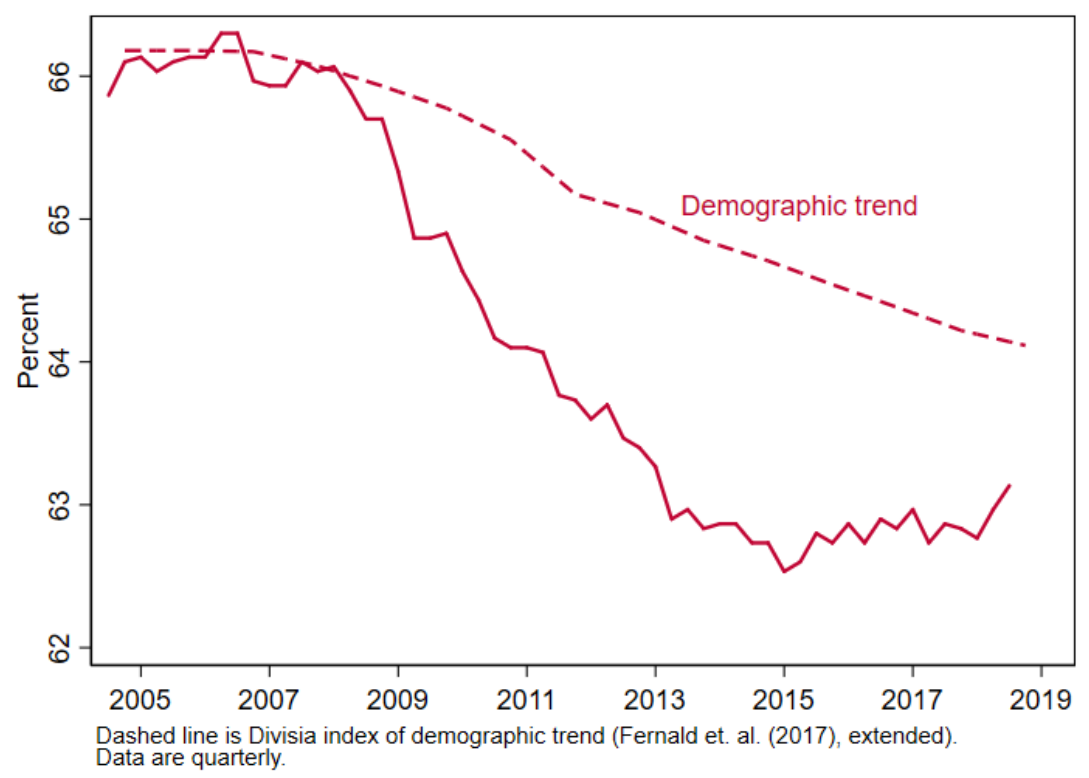


to a peak of $60 \%$ in 1999. A major factor in the decline in the LFPR since 2000 is the aging of the labor force. The earliest members of the baby boom generation reach the Social Security early retirement age of 62 in 2008. The retirement of baby boomers has led to a demographically-induced decline in the LFPR. As shown in Figure 7, the estimated demographic component of the decline accounted for twothirds of the 3.3 percentage point decline in the overall LFPR since 2006. The remaining one-third of the decline - the amount not explained by demographic factors - appears partly to be the consequence of other structural factors and partly the persistent effects of the severe recession. The prime-age male LFPR (which partially adjusts for demographics) has been falling for decades, and the prime-age female LFPR is now declining like the prime-age male LFPR. ${ }^{9}$ This said, the slow recovery of the labor force participation rate suggests that there has been hysteresis in the labor market, which potentially could have been averted by a faster recovery (e.g., Reifschneider, Wascher, and Wilcox (2015), Aaronson, Daly, Wascher, and Wilcox (2019)).

The decline in the LFPR over the recovery slowed the growth of available workers and, for a given level of the unemployment rate, slowed the growth rate of employment over the recovery. As shown in Figure 8, the growth of employment over the current recovery, 1.4\% per year, has been slower than during the recoveries of the 1980s and the 1990s, even though the annual decline in the unemployment rate was approximately the average of the corresponding declines in those two recoveries. A key reason for this slower rate of job growth in the current recovery is changes in the demographics of work: during the 1980s and, to a lesser extent, the 1990s, women surged into the labor force, especially during expansions (Fukui, Nakamura and Steinsson (2019)) and the LFPR rose. During the current recovery, however, the demographics pushed the other way as baby boomers retired and the LFPR declined.

The second factor contributing to the slow growth of GDP during the recovery, conditional on the decline in the unemployment rate, is the slow growth of total factor productivity (TFP) shown in Figure $9 .{ }^{10}$ From 1995 to 2004 , total factor productivity grew at $1.6 \%$, but since 2005 TFP growth has slowed to $0.4 \%$ per year, an even slower rate than during the late 1980 s and early 1990 s. As can be seen in Figure 9 (and as confirmed by regressions), TFP growth is cyclical, and some of those cyclical effects

\footnotetext{
${ }^{9}$ Abraham and Kearney (2018) review the evidence on the factors driving the trend decline in the male and female LFPR and suggest that long-term demand factors, in particular trade and automation, are important factors in the decline in addition to aging and factors that affect labor supply, such as increased participation in disability programs.

${ }^{10}$ The growth rate of TFP is the growth rate of output minus the growth rate of quality-adjusted factor inputs. TFP grows because of new inventions, improvements in production, and improvements in the efficiency with which businesses are managed.
} 
Figure 8. Quarterly growth of payroll employment (at an annual rate) and its mean value over the current and prior three expansions.

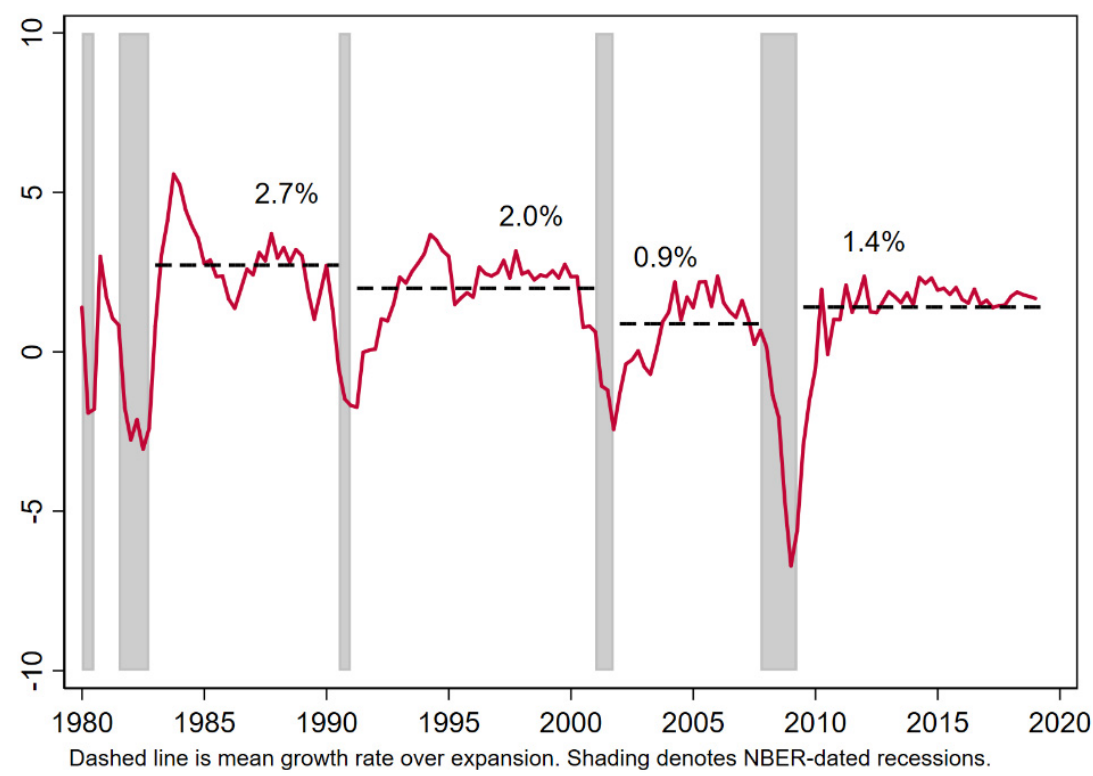

Figure 9. Four-quarter growth of total factor productivity in the nonfarm business sector, with low-frequency trend

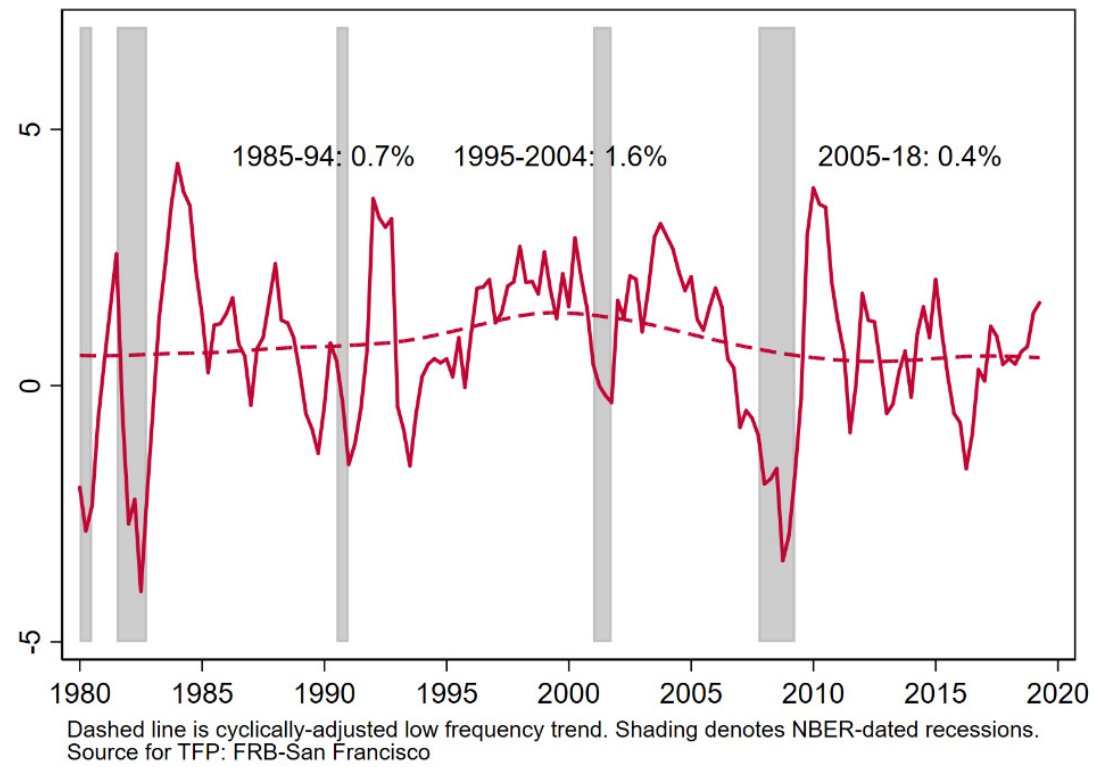


can have long lags. ${ }^{11}$ Still, the slowdown in TFP growth has been highly persistent. Despite its importance to growth over the medium and long run, economists still have much to learn about what drives TFP and why it has been depressed since approximately 2005. Multiple explanations have been proposed, ranging from increasing firm concentration to the aging of the labor force to a dearth of, or increasing difficulty of producing, new ideas and technologies. ${ }^{12}$ The common thread of these explanations is that substantial parts of this decline in TFP growth do not arise from the recession and instead reflect deeper structural trends in the U.S. economy, with roots that predate the recession. ${ }^{13}$ Fernald et al. (2017) use a growth accounting framework to decompose the decline in the growth rate of output, after cyclically adjusting for the decline in the unemployment rate, over the current and previous three expansions. They estimated that, through 2016, the slow growth of TFP explained just more than half the 1.8 percentage point annual shortfall in business output per capita from 2009:Q2 to 2016:Q2, relative to the three prior recoveries, with the decline in the LFPR essentially explaining the rest. Other potential factors, such as potentially slow growth of investment that would slow the growth in capital per worker, made only small contributions to the gap between the current recovery and previous recoveries, and were themselves rooted in trends that predate the crisis.

The secular forces slowing the growth of the labor force and productivity do not preclude important roles for demand during the recovery. Fernald et al. (2017) stress the importance of fiscal drag associated with the unwinding of the American Recovery and Reinvestment Act, with the Federal sequester, and with constraints on State and local spending stemming in part from its reliance on property tax receipts (which fell sharply after the fall in housing prices during the recession), combined with balanced budget requirements. More recently, CBO (2018) estimated that the Job Creation and Tax Act of 2017, the Bipartisan Budget Act of 2018, and the Consolidated Appropriation Act of 2018 together would add 0.6 percentage points to GDP growth in 2018 and 0.9 percentage points in 2019, mainly through additional fiscal stimulus during those years. ${ }^{14}$ Shifts in aggregate demand, including from monetary and fiscal policy, affect the rate of decline of the unemployment rate and the growth rate of

\footnotetext{
${ }^{11}$ For example, Anzoategui, Comin, Gertler, and Martinez (2016) provide evidence that technology diffusion depends on aggregate demand, inducing cyclical behavior in TFP with long lags because of the slow diffusion process.

${ }^{12}$ See, for example, Gordon (2016), Byrne, Fernald and Reinsdorf (2016), Alon et al. (2018), Bloom et al. (2017), Farhi and Gourio (2018), and Karahan et al. (2019).

${ }^{13}$ Oliner, Sichel and Stiroh (2007), Jorgenson, Ho and Stiroh (2008).

${ }^{14}$ Source: For the combined effect of the Bipartisan Budget Act of 2018 and the Consolidated Appropriation Act of 2018, CBO (2018), p.13; for the JCTA, CBO (2018), Table B-2.
} 
Figure 10. Four-quarter rates of PCE inflation: core (excluding food and energy) and overall.

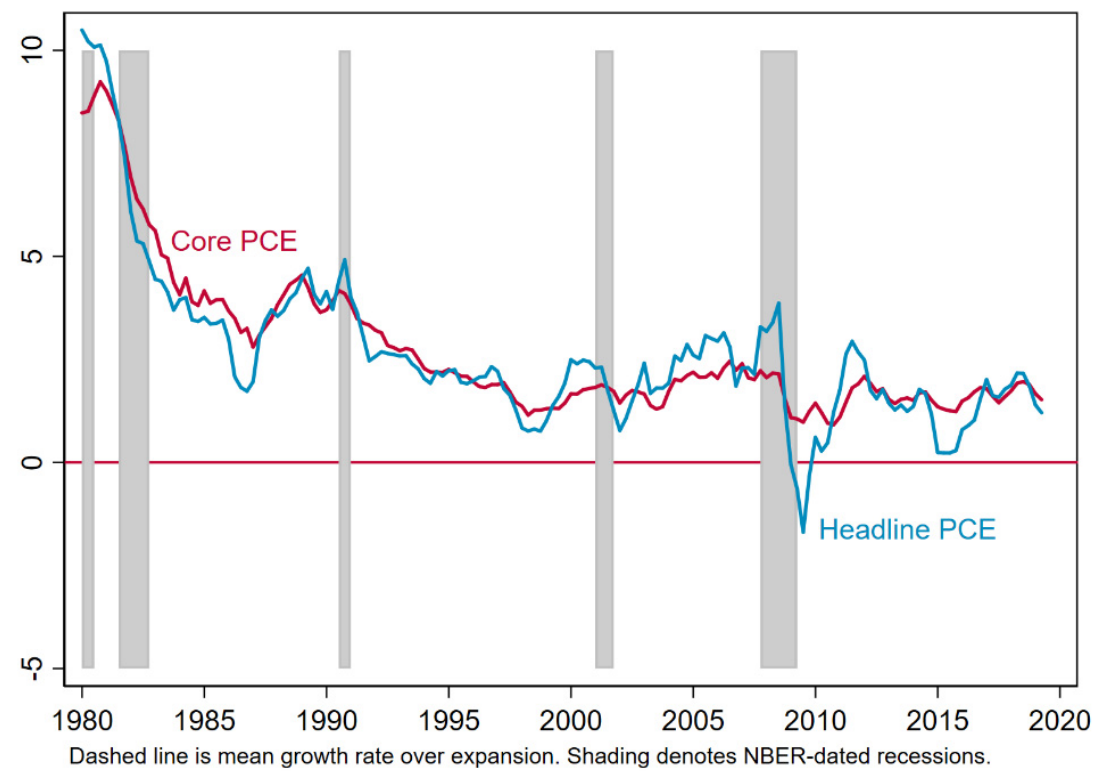

output, within the constraints on long-term growth rates imposed by demographics and other secular trends.

One of the most salient features of the recovery is quiescence of inflation in the face of the very large changes in labor market slack. As shown in Figure 10, core inflation, as measured by the Personal Consumption Expenditure price index excluding food and energy (core PCE), fell during the recession, largely in keeping with declines in previous recessions (Stock and Watson (2010)). But core inflation rose through the second half of 2011 into 2012, despite rates of unemployment still exceeding 8\%. From 2013 to 2018, core inflation has increased by only one-half percentage point despite the unemployment rate falling by four percentage points. ${ }^{15}$

As the unemployment rate reached and passed the NAIRU, wages have risen more than prices. As shown in Figure 11, wages - both average hourly earnings and the economy-wide Employment Cost Index, which is adjusted for compositional changes - grew at an annual rate of $2.2 \%$ from 2011 through 2018 , and both grew at an annual rate of approximately $2.8 \%$ during 2017-2018.

\footnotetext{
${ }^{15}$ A number of candidate explanations have been suggested for the "missing disinflation" during the early recovery. Gilchrist et al. (2017) suggest that it is because firms with liquidity problems raised prices in the downturn even at the expense of future market share. Coibion and Gorodnichenko (2015) attribute the missing disinflation to rising household inflation expectations, as household inflation expectations are very sensitive to oil prices.
} 


\section{Figure 11. Four-quarter rates of wage growth: average hourly earnings and the Employment Cost Index.}

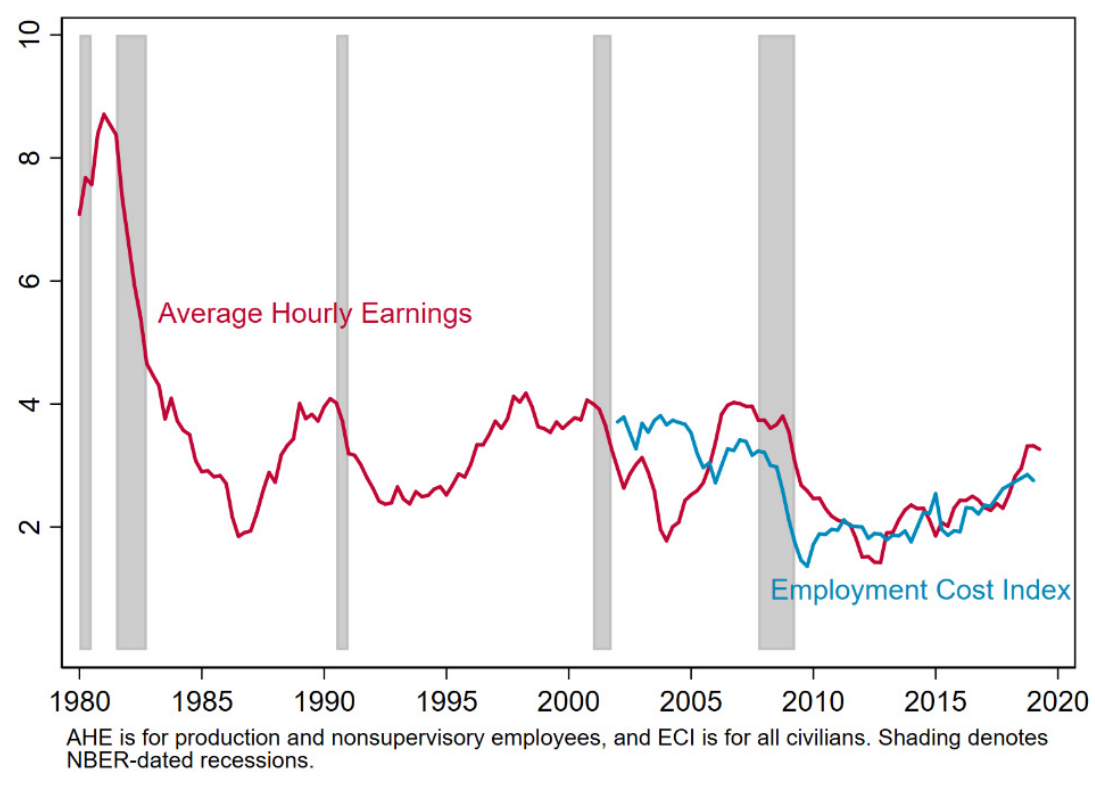

One way to restate the faster increase of wages than prices over the recovery is that the shortrun wage Phillips Curve is steeper than the short-run price Phillips Curve. ${ }^{16}$ This is illustrated in Figure 12 , which plots the rate of four-quarter price inflation (as measured by core PCE) and wage inflation (as measured by the economy-wide Employment Cost Index) against the 4-quarter lag of the CBO unemployment gap. As the regression lines illustrate, the slope of the wage Phillips curve is three times that of the price Phillips curve. This is consistent with the clear cyclical pattern of wage inflation since the 1980s in Figure 11, in contrast to the limited cyclical variation of price inflation evident in Figure 10.

A potentially complicating factor for monetary policy arises from longer-run trends in the real rate of interest. Over the past 15 years, nominal interest rates have fallen by more than the rate of inflation, suggesting that the long-run equilibrium real rate of interest has declined. Figure 13 shows the yield on 10-year inflation-protected Treasury securities (TIPS), along with two estimates of the equilibrium rate of interest, which are updated estimates based on Holston, Laubach, and Williams (2017) and on Del Negro et al. (2017). Although the numerical values differ, all three series point to a decline both in the real rate, as measured by the return on TIPS, and on the underlying long-run

\footnotetext{
${ }^{16}$ See Galí (2011), Galí and Gambetti (2019), Stock and Watson (2018b), McLeay and Tenreyro (2019), Hooper, Mishkin, and Sufi (2019).
} 
Figure 12. Phillips Curve scatterplot of four-quarter wage and price inflation vs. the unemployment gap, $2001-2018$.

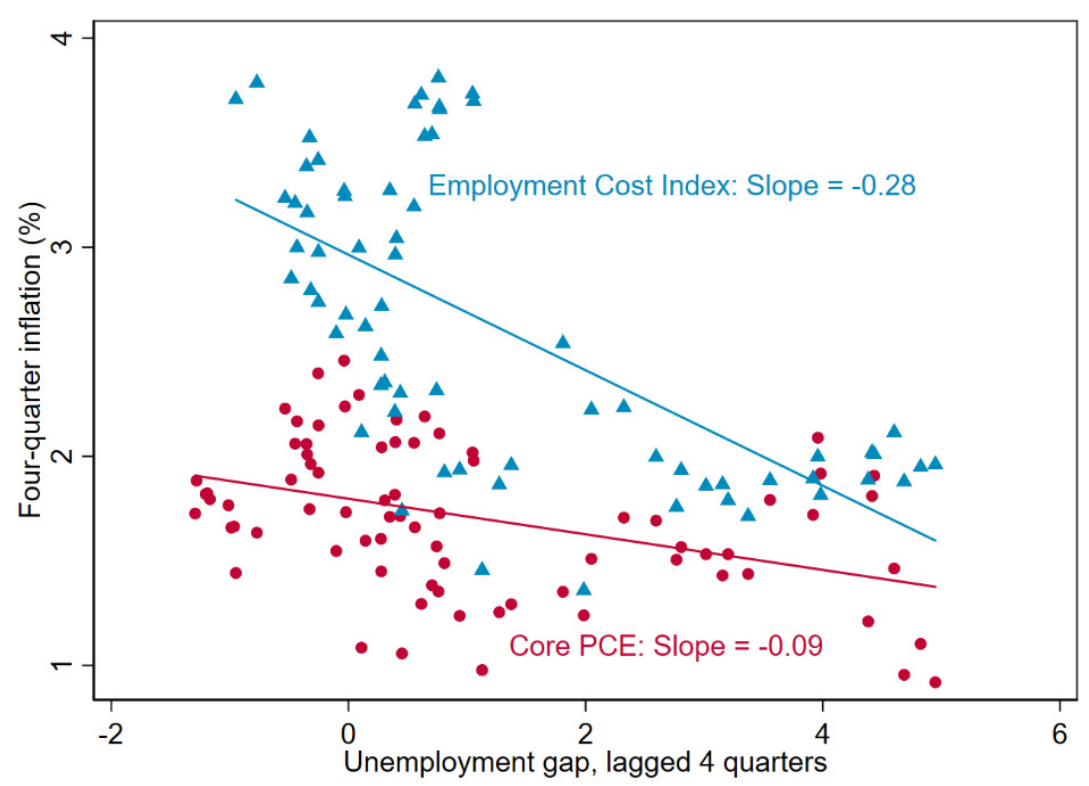

equilibrium real rate, which is unobserved. The estimated equilibrium rate using the Holston, Laubach, and Williams (2017) method is approximately 50 basis points over 2017-2018. The current Summary of Economic Projections has a long-run projection for the federal funds rate of 2.8 percent, implying an equilibrium real interest rate of 80 basis points. Chung et al. (2019, Figure 1$)$ plot the range of seven different estimates of $r^{*}$. While there is disagreement about the precise value of $r^{*}$ currently, there is broad agreement that it has declined by one percentage point, or perhaps more, since the early 2000 s. This decline is an international phenomenon, shared by all developed economies (Obstfeld (2019), Rachel and Summers (2019)).

Economists have suggested multiple explanations for the decline in $r^{*}$, including the aging of the population (increasing the demand for savings), an increasing premium for safety and liquidity (perhaps due to greater global demand for safe assets), and a lower trend rate of growth of productivity; see Andrade et al. (2019) and Rachel and Summers (2019) for a discussion of these forces and relevant references. Most of these forces represent low-frequency trends that are not affected by monetary policy and can reasonably be expected to persist for an extended period of time. All else equal, a lower equilibrium real rate implies a lower equilibrium nominal rate, which (holding constant the inflation target) implies a higher probability of hitting and staying at the zero lower bound as a result of 
countercyclical monetary policy. ${ }^{17}$

Figure 13. Two estimates of the long-term equilibrium real rate of interest $\left(r^{*}\right)$ and the yield on 10-year TIPS

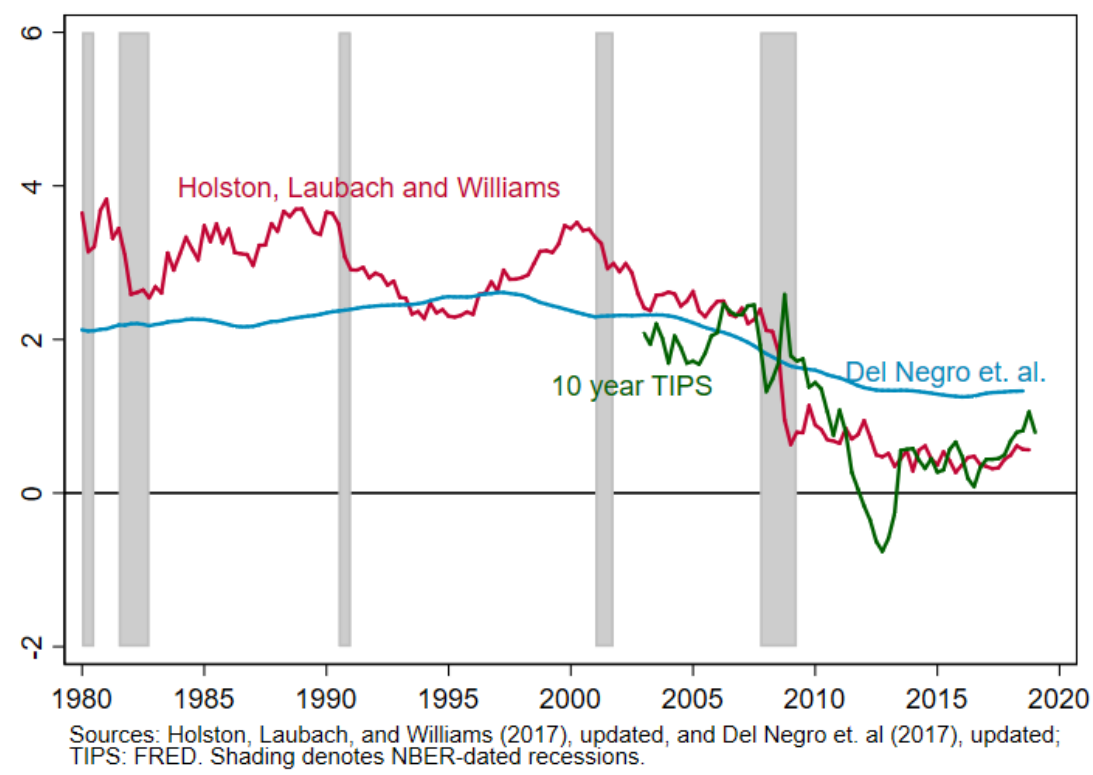

This overview of the recovery has two implications for assessing the performance of monetary policy under the current monetary policy framework.

First, much of the slow growth in GDP, given the unemployment rate, stems from factors that have little to do with monetary policy. The decline in the LFPR is driven in large part by demographic factors, in particular the plateau of women entering the labor force in the 1990s and the subsequent decline of overall labor force participation as the baby boom retires. Although there are open questions about the drivers of the productivity slowdown and the one-third of the decline in the LFPR not explained by demographics, only some of those explanations are cyclical and thus could plausibly be affected by monetary policy. As a result, the scope for alternative monetary policies to effect large improvements in GDP growth rates is significantly circumscribed, even if those policies somehow led to faster declines in the rate of unemployment and thus smaller cyclical movements in TFP growth and the LFPR.

\footnotetext{
${ }^{17}$ For example, Kiley and Roberts (2017) estimate that the zero lower bound (ZLB) will bind about one third of the time in the future.
} 
Second, that the rate of decline of the unemployment rate during this recovery was the same, on average, as over the previous three recoveries suggests that monetary policy (including alternative policy tools) remained effective despite the binding zero lower bound. This observation does not control for the many factors that made the financial crisis and the subsequent expansion unique, as well as the extraordinary tools marshalled to fight the crisis. To see whether this qualitative observation holds up empirically requires a model that can provide quantitative estimates of the effect of alternative policy paths, the topic to which we now turn.

\section{Simulation Model}

Our assessment of the performance of Fed policy over the expansion uses a model of monetary policy, interest rates, the unemployment rate, and price inflation. Section 5.1 provides an overview of the model, and Sections 5.2 and 5.3 provide econometric details.

\subsection{Overview of the simulation model}

The simulation model groups monetary policy actions into two categories: traditional monetary policy circa 2000, in which the FOMC sets a range for the Fed funds rate, and slope policy, which explicitly aims to affect the slope of the Treasury yield curve.

Slope policy is comprised of the multiple additional tools or actions of the current monetary policy framework, including forward guidance, SEPs, LSAPs, and maturity management. The common feature of these tools is that they affect the slope of the safe-asset term structure, either by providing information about future policy and, thus, changing expectations of future short rates, or by directly affecting the value of current long rates. As discussed in Section 2, these policies are nuanced, interact, and have evolved over time. Instead of trying to estimate their effects separately, we quantify the collective effect of this new suite of policies through their combined effect on the slope of the term structure, which in our base model is measured by the spread between the yield on 10-year Treasuries and the Fed funds rate.

The simulation model quantifies the response of the unemployment gap and the rate of inflation over time to Fed funds and/or slope monetary policy shocks. The simulation model merges two separate models, one of the CBO unemployment gap and another of core PCE inflation.

For the unemployment gap, we use a monthly structural vector autoregression (SVAR) to estimate the separate effects of Fed funds and slope policy. These effects are identified using an instrumental variables strategy that exploits Kuttner's (2001) insight that, in a tight window around an 
FOMC announcement, the predominant reason for a change in interest rates or Treasury bond prices is the information about policy revealed by the announcement. From these announcement-window changes we construct two instrumental variables, one for the Fed funds shock and one for the slope shock, which we use in conjunction with a vector autoregression to estimate the separate effects of Fed funds and slope policy on the unemployment rate over time.

These announcement-window changes in interest rates are directly attributable to policy shifts that are at least partially unexpected and comprise part of the overall monthly change in interest rates. We use this policy-related exogenous variation in rates to identify the impact effect of policy changes on relevant macroeconomic variables. With this impact effect in hand, we trace out the dynamic effect of the Fed funds or slope policy on the unemployment gap using a vector autoregression, using the Structural Vector Autoregression-Instrumental Variables (SVAR-IV) method, as used with a single shock by Gertler and Karadi (2015).

The simulation model merges this response of the unemployment gap to Fed funds and slope monetary policy with a hybrid New Keynesian Phillips curve, which relates the rate of inflation to past inflation, expected future inflation, and inflationary pressure exerted by the unemployment gap. In the combined model, a contractionary Fed funds policy -that is, a tightening of monetary policy through a higher Fed funds rate, holding constant the 10 year-Fed funds spread-implies a contractionary path of the unemployment gap. The increase in the expected discounted value of the unemployment gap then exerts negative pressure on inflation, which falls somewhat at first, then more as the inertial effects of the initial inflation rate wear off. Similarly, a contractionary slope shock - an increase in the 10 year-Fed funds spread, holding constant the Fed funds rate - leads to an expected deterioration of macroeconomic conditions which also results in a decline in current and future rates of inflation. Thus, the simulation model can be used to compute counterfactual paths for the rates of unemployment and inflation under policies that differ from those actually implemented.

There are other useful frameworks that are widely used for evaluating monetary policy counterfactuals. The Fed's main macro model, FRBUS, is routinely used for this purpose by, see Bernanke, Kiley and Roberts (2019) and Chung et al. (2019) for recent examples. Another approach is to use a dynamic stochastic general equilibrium (DSGE) model, such as recently used for related simulations by Debortoli, Galí, and Gambetti (2019). An advantage of our approach is its transparency and simplicity. We view these approaches as complementary, and in Section 6 we compare our results to those obtained by other researchers using other methods. 


\subsection{Identification and estimation of the effects of Fed funds and slope policy on the unemployment} rate

We use the SVAR-IV method to estimate the dynamic effect of a Fed funds shock and a slope shock on the unemployment gap. ${ }^{18}$ Gertler and Karadi (2015) use announcement-window changes and the SVAR-IV method to identify the dynamic effect of a Fed funds shock, and our model of the unemployment gap can be seen as an extension of their approach to include both a Fed funds and slope shock. $^{19}$

In our base model, the vector autoregression consists of five monthly variables: the unemployment gap, the Federal Funds rate, the spread between the yield on 10-year Treasury bonds and the Federal Funds rate, the Gilchrist and Zakrajšek (2012) excess bond premium, and the inflation rate as measured by core PCE. The two instruments are drawn from a panel of changes in interest rates of maturities from overnight (the Federal Funds rate) through 10 years around FOMC monetary policy announcements. The full balanced panel of these announcement-window changes runs from 1994m2 $2019 \mathrm{~m} 2 .^{20}$

For the Fed funds shock, the instrument is the difference between the target decision and the expectation implied by current-month (and potentially next-month) Federal funds futures contracts, constructed as described by Kuttner (2001). The impact effect of a Fed funds shock is then estimated by instrumental variables regression of the VAR variables on the federal funds rate.

For the slope shock, the instrument identifies policy-induced changes in the slope of the Interbank/Treasury term structure, holding constant changes in the Fed funds rate. To this end, the

\footnotetext{
${ }^{18}$ The SVAR-IV method (Stock (2008), Stock and Watson (2012), Mertens and Ravn (2013)) consists of two steps. In the first, a reduced-form VAR is estimated, yielding the VAR innovations (residuals). In the second, instrumental variables regression is used to estimate the causal impact effect of a shock by regressing the other VAR innovations (e.g., the unemployment gap innovation) on the causal variable of interest (e.g. the Fed funds rate) using instrumental variables regression. The resulting IV coefficients estimate the impact effect of a monetary policy shock, which is traced out dynamically using the VAR. See Stock and Watson (2018a) for an overview and a discussion of the relation between SVAR-IV and local projections-IV (LP-IV).

${ }^{19} \mathrm{Kim}$ (2017) and Lakdawala (2019) both use a 2-instrument/2-shock identification approach with announcementwindow changes, however they focus on forward guidance shocks and shorter ends of the term structure.

${ }^{20}$ The data are from Gürkaynak, Sack and Swanson (2005), as updated by Federal Reserve staff. The data are announcement-window changes, computed using two-hour windows, in the following interest rates: the first six Federal Funds futures contracts, the front eight Eurodollar futures contracts, on-the-run three and six-month bill yields and on-the-run two-, five-, ten- and thirty-year Treasury coupon yields. The data also include announcement-window changes in S\&P500 futures contracts. In months with no announcement, the value of the announcement-window change is zero. In months with multiple announcements, the announcement-window changes were summed over that month for the total monthly announcement-window change. Otherwise, the monthly observation is the single announcement-window change in that month.
} 
slope instrument is the residuals from a regression of announcement-window changes in the ten-year on-the-run Treasury yield onto the Kuttner shock. This residual is similar in spirit to the path surprise of Gürkaynak, Sack and Swanson (2005), but using a much longer maturity concept of the slope. The impact effect of the slope shock is then estimated by instrumental variables regression of the VAR variables on the 10 year-Fed Funds spread, using the slope instrument.

The SVAR-IV method permits different estimation samples to be used for the VAR and the instrumental variables regressions. The (reduced-form) monthly vector autoregression is estimated with four lags ${ }^{21}$ over the period $1990 \mathrm{~m} 1-2019 \mathrm{~m} 2$, a period that omits the Great Inflation and its immediate aftermath. The IV regression that estimates the impact effect of the Fed funds shock is estimated over the period 1994m2-2007m12, which avoids the zero lower bound period during which there were no Fed funds policy changes. The IV regression that estimates the effect of the slope shock is estimated over 2008m1-2019m2, the period during which the instruments of slope policy were refined and implemented. ${ }^{22}$

The estimated impulse response functions are summarized in Figure 14. First consider the Fed funds shock. The instruments are strong, with a heteroskedasticity-robust first-stage F-statistic of 17.0. A one percentage point monetary-policy increase in the Fed funds rate, holding the slope of the term structure constant, is estimated to increase the unemployment rate by approximately 0.6 percentage points after 18 months, however this effect is imprecisely estimated. ${ }^{23}$

\footnotetext{
${ }^{21}$ The AIC selects 4 lags and BIC selects 2 lags, and the unemployment gap IRFs are insensitive to using either the AIC or BIC choice.

${ }^{22}$ As noted in section 2, the first use of slope policy in the modern era was the appearance of forward guidance in 2003; SEPs, LSAPs, and maturity policy were not developed until the crisis. Thus the period prior to 2003, and arguably prior to 2007, was one in which there was little or no reliance on slope policy. Because our instruments start in $1994 \mathrm{~m} 2$, this provides a period for a placebo test of our scheme for identifying the effect of slope policy prior to 2007. Our method should not detect slope policy during that early period, and as is reported in the Supplement, indeed it does not. (The Supplement is available from the authors upon request.)

${ }^{23}$ Many monetary SVARs use quarterly data and/or a flow activity variable, such as industrial production, instead of the unemployment rate, complicating a direct comparison. Two papers that consider monthly monetary VARs with the response of the unemployment rate to a Fed funds shock are Coibion (2012) and Ramey (2016). Ramey's Figure 2(c) proxy VAR (SVAR-IV) estimate of the unemployment rate impulse response function is very close to ours, including the initial dip and a maximum value of approximately 0.4 percentage points attained after approximately two years, despite important differences (different sample period and she uses the Romer and Romer (2004) monetary policy shock as an instrument, not announcement-window changes). Coibion (2012) treats the Romer and Romer (2004) monetary policy shocks as shocks not as instruments, which in the SVAR-IV framework is the reduced form response to the instrument. Despite this and other important differences, Coibion's (2012, Figure 7 and Table 2) estimates of the peak response of the unemployment rate bracket our estimates.
} 


\section{Figure 14. Estimated response of the unemployment gap to unit Fed funds and slope monetary policy shocks}
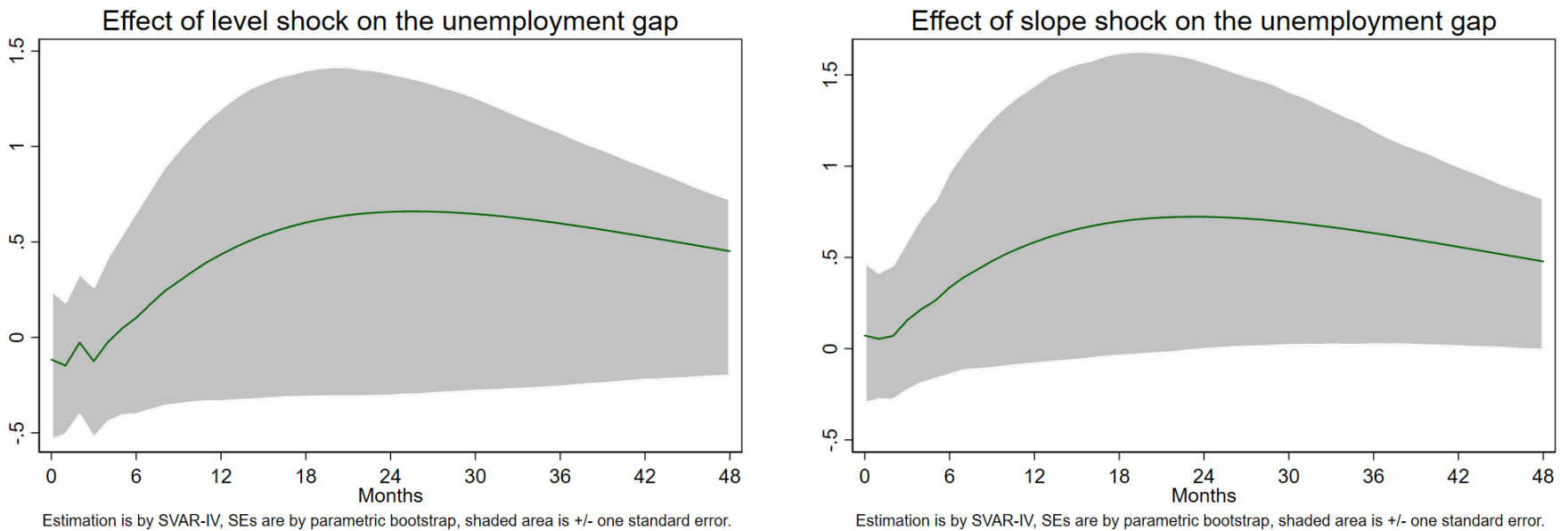

Notes: The Fed funds shock increases the Fed funds rate by one percentage point. The slope shock increases the 10 year Treasury-Fed funds spread by one percentage point. The instrument for the Fed funds monetary policy shock is difference between the pre-announcement level of the Fed futures rate and the announced target (the Kuttner shock). The instrument for the slope monetary policy shock is the residual from regressing the announcementwindow change in the ten-year on-the-run Treasury yield on the Kuttner shock. Estimation samples are 1990m1$2019 \mathrm{~m} 2$ for the VAR, 1994m2-2007m12 for the Fed funds shock IV regression, and 2008m1-2019m2 for the slope shock IV regression. Shaded area denotes one standard error bands, computed by parametric bootstrap.

For the slope shock, the instrument is weaker than for the Fed funds shock (first stage $F=5.8$ ). A one percentage point slope shock - that is, a shock that increases the 10-year - Federal funds spread by one percentage point - increases the unemployment rate by a peak of about 0.7 percentage points, attained after 18 to 28 months.

An issue that affects the interpretation of the slope shock impulse response function is the extent to which the elements of slope policy revealed during an announcement convey Fed inside information about the economy, as opposed to information about the future path of policy (see for example Campbell et al. (2012), Nakamura and Steinsson (2018a, b), Kim (2017), and Lakdawala (2019)). If movements in the slope of the term structure around announcement windows reflect news about the economy, rather than a reaction to policy actions and intentions, the impulse response function will be a biased estimate of the dynamic causal effect of slope policy. We do not provide a complete analysis of this issue, but we do offer three observations. First, the sign of the news channel is the opposite of that in Figure 14: to the extent that an announcement of, for example, prolonging a zero Fed funds rate also conveys bad news about the economy, then the announcement-window decline in the 10 year-Fed 
funds spread would be associated with a lower future unemployment gap than expected, the opposite of what we estimate. Second, similar reasoning implies that an announcement that conveys bad economic news would increase the excess bond premium; but our estimated response of the EBP to the slope shock has the opposite sign, with moderate persistence (see Appendix A). Third, if the announcement conveys news, then one would expect bad news (a reduced spread) to be associated with a decline in the stock market. Because our data set contains the announcement-window change in the S\&P 500, we can examine this implication empirically, and it does not hold up in the data: the announcement-window change in the S\&P 500 is negatively correlated with our slope instrument, and indeed is negatively correlated with the residuals from regressions of announcement-window changes against the Kuttner shock at horizons of three or more months over the period 2008m1-2019m2. ${ }^{24}$ While these observations do not rule out some potential bias from announcements having an economic news component, together they suggest that the impulse responses reported here primarily reflect the slope policy channel.

Appendix A shows estimates of these IRFs obtained using local projections with instrumental variables, which (for these instruments) does not require the SVAR assumption of invertibility. Robustness checks of the IRFs in Figure 14 to various modeling assumptions are reported in the Supplement. ${ }^{25}$

\subsection{The Phillips curve}

The second part of the model quantifies the relation between the unemployment gap and inflation, which is quantified using the hybrid Phillips curve,

$$
\pi_{t}=\gamma_{b} \pi_{t-1}+\gamma_{f} \pi_{t+1}^{e}+\kappa U g a p_{t}+e_{t}
$$

where $\pi_{t}$ is quarter-over-quarter core PCE inflation (at an annualized rate), Ugap is the

unemployment gap, and $\pi_{t+1}^{e}$ is expected inflation as measured from the Michigan survey, and $e_{t}$ is the error term. ${ }^{26}$

\footnotetext{
${ }^{24}$ The 18 correlations between the S\&P 500 change and the various orthogonalized interest rate futures or yield changes (excluding the current- and next-month Fed funds futures rates) range from -0.06 to -0.33 , with only four being significant at the $5 \%$ level.

${ }^{25}$ The Supplement is available from the authors upon request.

${ }^{26}$ Because the inflation rate is included in the VAR, one option would be to estimate the effect of the two monetary policy shocks on inflation by SVAR-IV, as we do for the unemployment rate. Doing so, however, has two disadvantages. First, as McLeay and Tenreyro (2019) emphasize, monetary policy has successfully stabilized the inflation rate in a range that is narrow by historical standards, but from an econometric perspective this successful management of inflation confounds the reduced-form relation estimated using a VAR or a conventional Phillips
} 
Because the unemployment gap responds to supply shocks that also affect the rate of inflation (and thus are contained in the error term $e_{t}$ ), the unemployment gap is endogenous and the parameters of Equation (2) cannot reliably be estimated by ordinary least squares. We therefore estimate Equation (2) by generalized method of moments. For instruments, we draw inspiration from Galí and Gambetti (2019) and, more closely, Barnichon and Mesters (2019a). Barnichon and Mesters (2019a) point out that monetary policy shocks, were they observable, would provide valid instruments because they would be uncorrelated with the supply shocks comprising $e_{t}$. Although monetary policy shocks are not observed, observable instruments for those shocks can be used instead. Because monetary policy shocks enter with a lag, a distributed lag of those instruments should be used for if they are to be relevant.

Accordingly, we construct instruments from the panel of announcement-day changes described in footnote 20. Specifically, from the 20 announcement-day interest rate changes (the Kuttner shock and the 19 announcement-day changes with various maturities) we construct the first three principal components. From these, we construct two sets of instruments. The first set consists of exponentially weighted moving averages (EWMA) of each principal component, with EWMA coefficients of 0.9 and 0.7, for a total of 6 instruments. The second set of instruments adopts Barnichon and Mesters' (2019a) approach and uses polynomial distributed lags, here with degree 2 and maximum lag length 12 .

The estimation results are summarized in Table 2. The estimates using the two instrument sets show similar coefficients. The first set (the EWMA instruments) is stronger, and we use those estimates for our base model. ${ }^{27}$

curve that does not take into account the endogeneity of monetary policy. This is the classic problem that, when a variable is controlled, the historical relationship used for that control breaks down (Kareken and Solow (1963), Goldfeld and Blinder (1972)). McLeay and Tenreryo (2019) show that this can manifest as a Phillips curve that appears flat when in reality it is not. The VAR simply estimates a dynamic version of this Phillips curve and thus inherits this endogeneity problem. Second, because the Phillips curve is estimated implicitly in the VAR, it is difficult to use SVAR-IV methods to conduct sensitivity checks to changes in the Phillips curve and/or its lead-lag dynamics. Third, the VAR leaves the role of expectations implicit, but it is useful to know explicitly how important they are in the simulations. Fourth, the VAR covers a long period in which the slope of the Phillips curve is thought to have been flattening, and estimating the Phillips curve separately allows us to do so using more recent data. ${ }^{27}$ Results for alternative specifications, including different sample periods, using core CPI inflation and the Survey of Professional Forecasters expectations method, and different estimators are reported in the Supplement. 
Table 2. Estimated Phillips Curve Coefficients.

\begin{tabular}{|ccccccc|}
\hline $\begin{array}{c}\text { Instrument } \\
\text { set (\# IVs) }\end{array}$ & Ugap $t$ & $\pi_{t+1}$ & $\pi_{t+1}^{e}$ & $\kappa /\left(1-\gamma_{b}-\gamma_{f}\right)$ & $\begin{array}{c}\text { First-stage } \\
\text { F-effective }\end{array}$ & $\begin{array}{c}\text { J-statistic } \\
\text { ( } \boldsymbol{p} \text {-value) }\end{array}$ \\
\hline \multirow{2}{*}{ A (6) } & -0.094 & 0.099 & 0.400 & -0.187 & 43.65 & 4.89 \\
& $(0.024)$ & $(0.049)$ & $(0.092)$ & $(0.054)$ & & $(0.43)$ \\
& & & & & 5.18 \\
B (9) & -0.122 & 0.055 & 0.354 & -0.206 & 6.94 & $(0.74)$ \\
\hline
\end{tabular}

Notes: The unemployment gap is from the CBO. Data are quarterly. Standard errors are strong-instrument NeweyWest (8 lags). All regressions include an intercept. The first-stage $F$ statistic is the Montiel Olea and Pflueger (2013) effective $F$. Instrument set B: polynomial distributed lags of degree 2 of first three principal components of announcement-window changes in the panel of interest rates (including Fed Funds), 1994q2-2018q4 (maximum lag =12). Instrument set B: EWMA of first three principal components using weight coefficients 0.90 and 0.70 .

The estimates in Table 2 are in the range of those in the literature, see for example the estimates in McLeay and Tenreyro (2019, Table 2) and Crump et al. (2019). These estimates imply fairly flat Phillips curves. One measure of the implied Phillips curve slope is the long-run effect of a sustained unit increase in the unemployment gap, which, in terms of the coefficients in (2), is given by $\kappa /\left(1-\gamma_{b}-\gamma_{f}\right)$. This value is reported in Table 2 and is similar, approximately -0.2 , for the two estimates.

\subsection{Combined Simulation Model and Simulation Method}

The unemployment rate impulse responses from Section 5.2 are monthly, which takes advantage of the monthly data on announcement-window changes, while the Phillips curve estimation is quarterly, the frequency of observation of the Michigan inflation expectations survey. To combine the two models, the impulse responses of the unemployment gap to the two monetary shocks were temporally aggregated by averaging the unemployment rate responses for the months within the quarter. Given these two quarterly impulse responses, the hybrid Phillips curve is solved forward. ${ }^{28}$ Doing so yields two mutually consistent pairs of impulse responses of the inflation rate and the unemployment gap first to the Fed funds shock, and second to the slope shock.

\footnotetext{
${ }^{28}$ The forward solution of Equation (2) involves a variant of the Blanchard and Kahn (1980) method. Assume that $\gamma_{f}>0, \gamma_{b}>0$ and $\gamma_{f}+\gamma_{b} \leq 1$. Define $z_{t}=\pi_{t}-\theta \pi_{t-1}$ and guess that $z_{t}=\zeta E_{t} z_{t+1}+\phi U g a p_{t}$ for unknown parameters $\theta, \zeta$ and $\phi$. We verify that this guess satisfies Equation (2) if $\zeta=\gamma_{f} / \lambda, \phi=\kappa / \lambda$ and $\lambda \theta=\gamma_{b}$ where $\lambda=1-\theta \gamma_{f}$. Solving the third of these equations gives $\theta=\left(1-\sqrt{1-4 \gamma_{b} \gamma_{f}}\right) / 2 \gamma_{f}$. Then solve forward to write $z_{t}=(\kappa / \lambda) \sum_{j=0}^{\infty}\left(\gamma_{f} / \lambda\right)^{j} E_{t} \operatorname{Ugap}_{t+j}$ and hence $\pi_{t}=\theta \pi_{t-1}+(\kappa / \lambda) \sum_{j=0}^{\infty}\left(\gamma_{f} / \lambda\right)^{j} E_{t} \operatorname{Ugap}_{t+j}$.
} 
The model for the Fed funds shock is completed by augmenting the unemployment gap and inflation rate impulse responses by the dynamic response of the Federal funds rate to the Fed funds shock. Given this trio of impulse response functions, we follow Sims (1986) and compute the sequence of Fed funds shocks that would deliver a specified path of the Federal funds rate, and then compute the effect of that sequence of Fed funds shocks on the unemployment gap and the rate of inflation. Similarly, by augmenting the slope shock pair of impulse responses by the dynamic response of the 10 year-Fed funds spread to a unit slope shock, we can compute the sequence of slope shocks to obtain a stipulated path of this spread and thus their effect on the unemployment gap and the rate of inflation.

Both trios of impulse response functions imply a dynamic reduced-form Phillips relation, that is, the cumulative change in the rate of inflation divided by the cumulative change in the rate of unemployment. Because the two shocks have different dynamics, these two ratios differ for the two shocks, however they turn out to be numerically close. For our base model after 24 months, this Phillips slope is -0.188 for the Fed funds shock and -0.185 for the slope shock. The 24-month Phillips multiplier is approximately $\kappa /\left(1-\gamma_{b}-\gamma_{f}\right)$, which is reported in Table 2. The estimates of McLeay and Tenreyro (2019), using pooled OLS estimation with metro area data (their Table 3) imply an estimate of $\kappa /\left(1-\gamma_{b}-\gamma_{f}\right)$ of -0.308 . Barnichon and Mesters (2019b) using high-frequency instruments get a post1990 Phillips multiplier of about -0.15 at three to four years, but they estimate a steeper Phillips curve using Romer and Romer (2014) shocks as instruments. Appendix B and the Supplement explore the sensitivity of our counterfactual estimates to using a more responsive Phillips curve.

\section{Performance Under Counterfactuals}

We use this simulation model to assess how the U.S. economy would have performed under alternative monetary policies implemented using the tools of the current monetary policy framework. This analysis takes full advantage of the benefits of hindsight and as such care must be taken in interpreting the results. For example, several of our counterfactuals are infeasible hypothetical cases, and all our simulations rely on ex-post data that were unavailable to Fed decision-makers in real time. Thus, finding that macroeconomic performance is better under a given counterfactual does not imply that the Fed should or could have taken different decisions in real time. Rather, such a finding, based on what we know now, can inform future Fed policy as it navigates the next recession and recovery.

We begin by describing the counterfactuals, then turn to the results. 


\subsection{Counterfactuals}

No ZLB. Our first counterfactual supposes that there is no zero lower bound on interest rates and that the Fed had followed a Taylor rule for the Federal funds rate, with no LSAPS. Here and subsequently, the Taylor rule we use is $F F_{t}=2+\pi_{t-1}^{(12)}+0.5\left(\pi_{t-1}^{(12)}-2\right)-2 * U g a p_{t-1}$, where $F F, \pi^{(12)}$, and Ugap are respectively the Federal funds rate, the 12-month rate of core PCE inflation, and the unemployment gap. This is based on the Taylor (1999) rule, which uses the output gap as the slack measure, with a coefficient of 1 . Yellen (2012) uses this version of the Taylor rule, and refers to it as the "balanced approach" rule, and this output gap coefficient of 1 is also used by Chung et al. (2019). We translate the coefficient on the output gap into a coefficient of -2 on the unemployment gap, using an Okun's law coefficient of $2 .^{29}$ This counterfactual does not, of course, simulate a feasible policy path; like Christiano, Eichenbaum, and Trabant (2015) and Gust et al. (2017), we use it to calibrate the macroeconomic cost of the zero lower bound on interest rates. ${ }^{30}$

Follow Taylor (1999) rule (constrained by ZLB) with no LSAPs. This counterfactual is like the "No ZLB" counterfactual, except that the ZLB is imposed and there are no LSAPs, as discussed in footnote 30.

\footnotetext{
${ }^{29}$ Our Taylor rule has no interest rate inertia as we want to focus on how the FOMC responds to inflation and the unemployment gap. Historically, the FOMC has moved quickly to cut rates in downturns.

${ }^{30}$ As discussed in Section 5.4, alternative policy scenarios are implemented as a sequence of unanticipated level and slope monetary policy shocks to provide a specified path for observable variables. We provide details here for the "No ZLB" scenario; the calculations for the other scenarios are similar. For the "No ZLB" scenario, the Taylor rule determines the value of the Fed Funds rate in the next period and thus the value of the Fed funds shock, which in turn affects the realized values of inflation and unemployment and, via the Taylor rule, the subsequent value of the Fed funds rate. Solving forward recursively yields the paths of the observable variables. The "No LSAP" hypothetical is implemented by calculating the sequence of slope shocks that remove the historical effect of LSAPs on the 10 year-FF spread. To assess the effects of LSAPs, we take the change in SOMA ten-year equivalents as a share of nominal GDP, relative to December 2008, and multiply this by an assumed elasticity of ten-year yields of 6 basis points per percentage point of GDP (Belton et al. (2018)). This assumes that LSAPs work through the stock of purchases, rather than the flow. There likely were transitory flow effects, especially in disrupted financial markets in 2009, but we omit these for the purposes of our working calibration. Our no-LSAP scenario adds slope shocks to steepen the yield curve by the required amount. Because this negation of historical slope policy is calibrated by a no-LSAPs scenario, it does not necessarily remove the effects of forward guidance. The effect of the sequence of Fed funds shocks on interest rates, the unemployment gap, and inflation are computed using the IRFs for those series with respect to the levels shock, and similarly the slope shock IRFs are used for the sequence of slope shocks. The combined effect on all variables (interest rates, unemployment, and inflation) is the sum of the level and slope effects for each variable. For scenarios below that specify "historical slope policy," no changes are made to historical slope shocks, so the counterfactual paths for interest rates, inflation, and the unemployment gap arise solely from the Fed funds shock and the Fed funds shock IRFs. Slope shocks are allowed to affect the level of the funds rate after liftoff in December 2015, but not during or before December 2015 when the economy was stuck at the ZLB. Finally, for plotting purposes, results are reported in terms of the unemployment rate by adding the CBO natural rate of unemployment to the simulated path of the (CBO) unemployment gap, under the assumption that the monetary policy counterfactuals do not affect the natural rate of unemployment.
} 
Earlier/later liftoff. These counterfactuals imagine that the observed path of increases in the Fed funds rate started, alternatively, one year earlier or one year later. For these counterfactuals, slope policy is unchanged, that is, the realized historical slope shocks are used.

Alternative 10 year-Fed funds slope policies. We consider several counterfactuals in which Fed funds policy is the same as it was historically, but slope policy differs. Specifically, we consider four such counterfactuals that focus on the 10 year-Fed funds spread: no LSAPs (computed as described in footnote 30); a slope policy that flattened the 10 year-Fed funds slope by 1 percentage point for 2 years; an earlier and stronger slope policy flattened the slope by 2 percentage points for 18 months beginning December 2008; and a slope policy that fixed the 10 year-Fed funds spread at 2 percentage points for 5 years starting in December 2008.

Historical $\pi^{*}=\mathbf{3} \%$ or $\mathbf{4 \%}$. This hypothetical supposes, counterfactually, that entering the recession, the Fed had inherited nominal interest rates, raters of inflation, and an inflation target either one or two percentage points higher than actual. For example, for the ten years through 2000, core PCE inflation averaged $2.1 \%$, essentially at the $2 \%$ target. Under the $\pi^{*}=3 \%$ counterfactual, inflation hypothetically would have averaged $3.1 \%$, essentially at a $3 \%$ target. More generally, we quantify the concept of inheriting an inflation target that is $x$ percentage points higher by increasing the values of all nominal variables (interest rates and inflation) by $x$ percentage points at an annual rate, while leaving real variables unchanged. These higher nominal rates are then combined with various policy rules or targets to provide counterfactuals. For example, one such counterfactual is inherited nominal rates one percentage point higher and an inherited 3\% inflation target, historical Fed funds policy (still driving the Fed funds rate to the ZLB), and historical slope policy (historical slope shocks). Another counterfactual specifies a $3 \%$ inflation target coupled with no slope policy, which is implemented as an absence of LSAPs as described in footnote $30 .{ }^{31}$

\footnotetext{
${ }^{31}$ A mechanical alternative interpretation of the higher-inflation steady state counterfactual is that the Fed could drive nominal rates below zero by the difference between $2 \%$ and the hypothesized rate. We do not endorse this interpretation however because such a policy would go sufficiently beyond the scope of historical experience that we would not consider our simulation model to be reliable were nominal rates to be reduced below zero by more than a small amount. Moreover, the literature that has studied negative rates concludes that when rates are negative, further cuts are less stimulative than in normal times, and may even be contractionary. Negative interest rates have been in Europe and in Japan. No country has set a policy rate below - 75 basis points, and only Switzerland has gone this low. The ECB has set its deposit facility rate at -40 basis points. However, deposit rates have however generally been bounded at zero, and bank profits may be hurt by negative rates. Brunnermeier and Koby (2017) considered the idea of a reversal interest rate at which further cuts would hurt bank profitability, and might be contractionary. Consistent with this, whereas event-study evidence has typically found that monetary policy raises bank equity returns, Ampudia and Van Den Heuvel (2018) find that surprise monetary policy easing lowers bank equity prices at negative interest rates. Eggertsson et al. (2019) document that in Swedish data, for negative policy rate, cuts in policy rates have no effect on bank deposit rates and if anything increase bank lending
} 
Temporary Price Level Targeting. Temporary price level targeting involves the Fed committing to makeup shortfalls in inflation when at the zero lower bound. The simplest form of temporary price level targeting would commit the Fed to remain very accommodative until cumulative average inflation since hitting the zero lower bound reaches the target. Conventional inflation targeting (which references only the rate of inflation, not the price level) would resume once away from the ZLB. In unreported results, we simulated this version of temporary price level targeting, however the magnitude of disinflation in the recession was such that it would take quite extreme policies to hit the temporary price level target by 2019, and inflation would have to go considerably above 2 percent. This finding is broadly consistent with findings in Bernanke, Kiley and Roberts (2019), so we examine instead their proposal for temporary price level targeting with a one-year lookback, which is equivalent to average inflation targeting where the average is computed over the prior 12 months. This policy would commit the Fed to maintain very accommodative policy until inflation over the previous year averages 2 percent. We consider two forms of temporary price level targeting with this one-year lookback period. One promises Fed funds shocks to keep the funds rate at zero until the target is reached; the other instead promises slope shocks to achieve the same effect.

Makeup rule. Reifschneider and Williams (2000) propose that, if the Fed Funds rate hits the zero lower bound, the Fed would keep the rate at the zero lower bound for an additional period after the Taylor rule rate rises above zero, where the additional time is enough to make up for the excursion of the Taylor rule rate below zero. (This makeup rule is the third rule listed on page 37 of the February 2019 Monetary Policy Report).

\subsection{Results}

The results of each counterfactual are summarized in four-panel figures, which depict the actual and counterfactual paths of the nominal Fed funds rate or 10 year-Fed funds spread (upper left), the real Fed funds rate (upper right), the unemployment rate (lower left), and the 12-month rate of core PCE inflation (lower right).

Figure 15 shows the results for the Taylor (1999) rule with no-ZLB counterfactual. Absent the ZLB, the Taylor rule would have prescribed a nominal funds rate of -5.5 percent in 2009 and 2010,

rates. Eggertsson et al. (2019) and Ulate (2018) both study the effects of negative interest rates on economic activity in DSGE models. Ulate finds that interest rate cuts are less stimulative than when rates are positive; Eggertsson et al., who do not incorporate bank monopoly power, find that they are outright contractionary. Burke et al. (2010) concluded that, in the United States, a rate below about -35 basis points might lead banks to switch reserves into physical currency. 
resulting in a much faster decline of the unemployment rate. ${ }^{32}$ However, the funds rate would have returned to being positive in 2012 which would have slowed the pace of progress on unemployment during the second half of the recovery, and the unemployment rate would have stabilized approximately at the CBO NAIRU. These results are very similar to the findings of Gust et al. (2017) who consider a DSGE model where the federal funds rate is the only instrument of monetary policy (no forward guidance, LSAP or other slope policy). Their monetary policy reaction function calls for a nominal funds rate falling to -5.5 percent. In their model, the inability to drive the funds rate below zero accounts for 30 percent of the fall in output in 2009 and most of the subsequent slow recovery.

Figure 15. Counterfactual with unconstrained Taylor (1999) rule
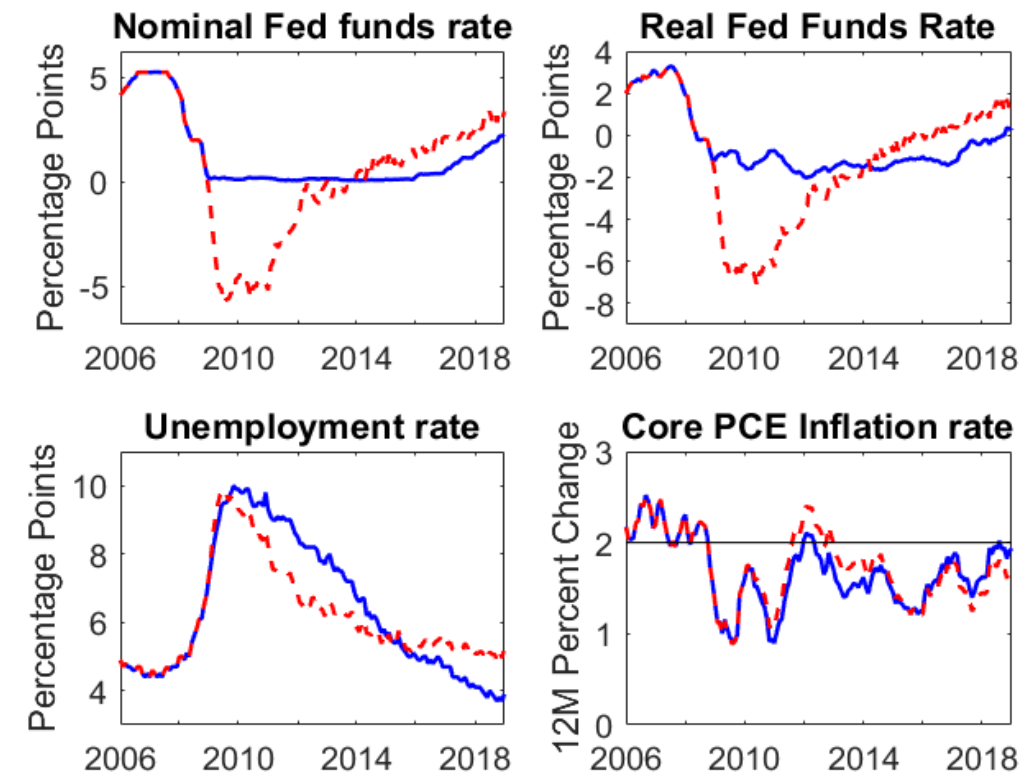

Notes: Actual is blue solid line, counterfactual is red dashed line.

Figure 16 shows the results for the Taylor rule incorporating the ZLB and undoing the effects of LSAPs, as discussed in footnote 30 . The Fed funds rate would have been at the ZLB until liftoff in late 2015 . Progress on the unemployment rate would have been slower than was actually observed, especially later in the recovery, initially as a result of the steeper yield curve in the absence of LSAPs then compounded by a steeper pace of tightening after liftoff. The unemployment rate would remain

\footnotetext{
32 The original Taylor (1993) rule has coefficient of 0.5 on the output gap, which translates into -1 on the unemployment gap, with the conventional Okun's coefficient. This would prescribe a funds rate of -2 percent in 2009 with a slower recovery than we obtain with the Taylor (1999) rule. We show this counterfactual in the Supplement.
} 
over 5 percent in early 2019, and the slow progress on unemployment would have further reduced the inflation rate, relative to what was actually observed.

Figure 17 and Figure 18 envision a liftoff from the ZLB that is respectively one year earlier and one year later than actual, with no change in slope policy (same slope policy shocks as historical). Specifically, in the early liftoff simulation, we use Fed funds shocks to get the funds rate starting in December 2014 to where it actually was one year later, and likewise for late liftoff. An earlier liftoff slightly slows progress on unemployment, but it has virtually no effect on inflation. Later liftoff would lower the unemployment rate at the end very slightly, but because of the lags the effect is negligible as of the end of the sample in February 2019.

Figure 16. Counterfactual with Taylor (1999) rule incorporating ZLB and no LSAPs
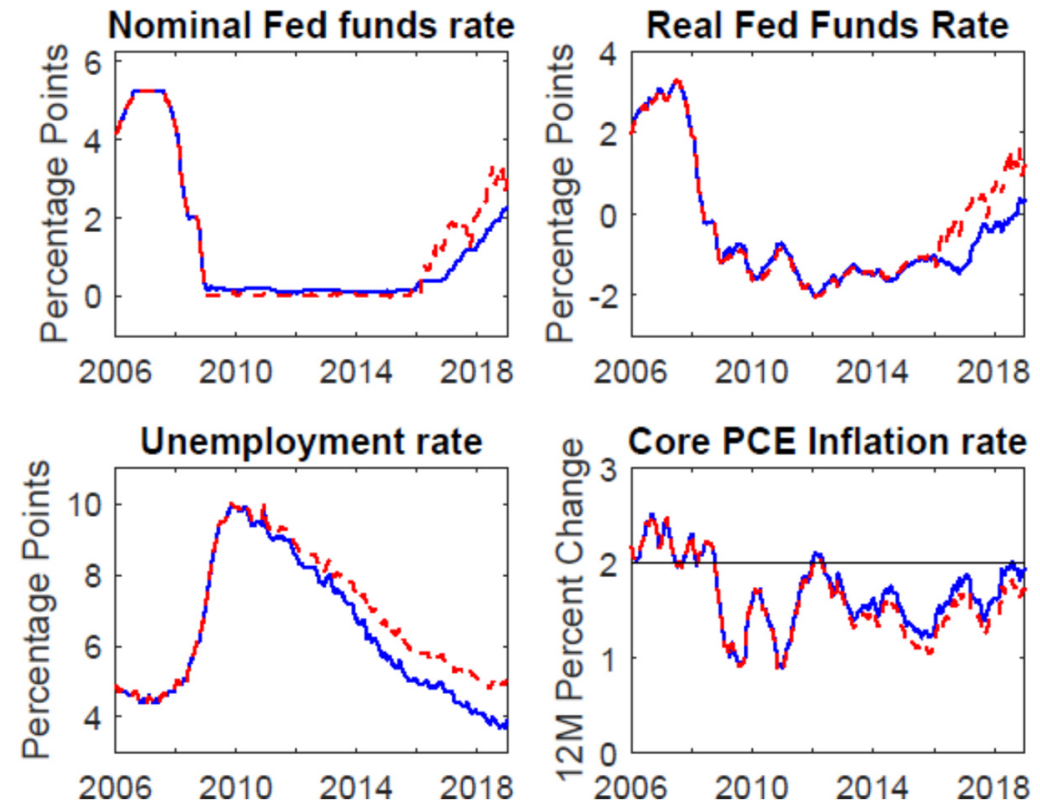

Notes: Actual is blue solid line, counterfactual is red dashed line. 
Figure 17. Early Liftoff
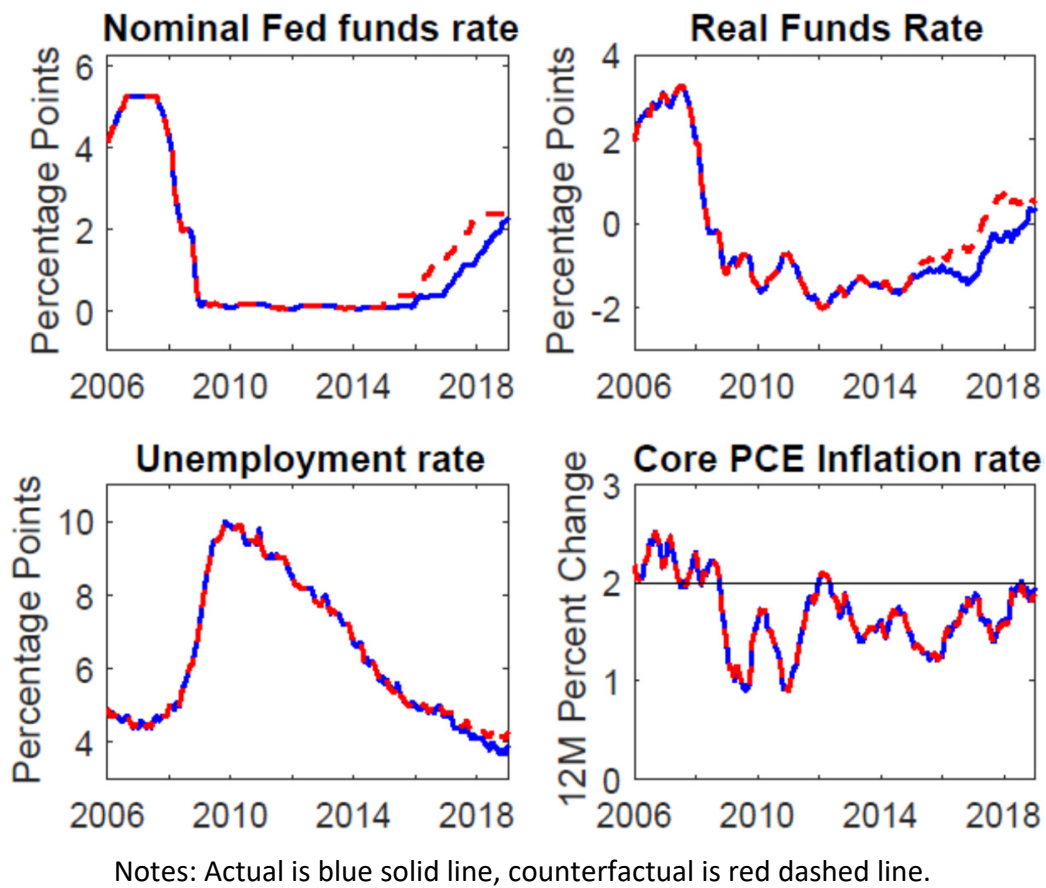

Figure 18. Late Liftoff
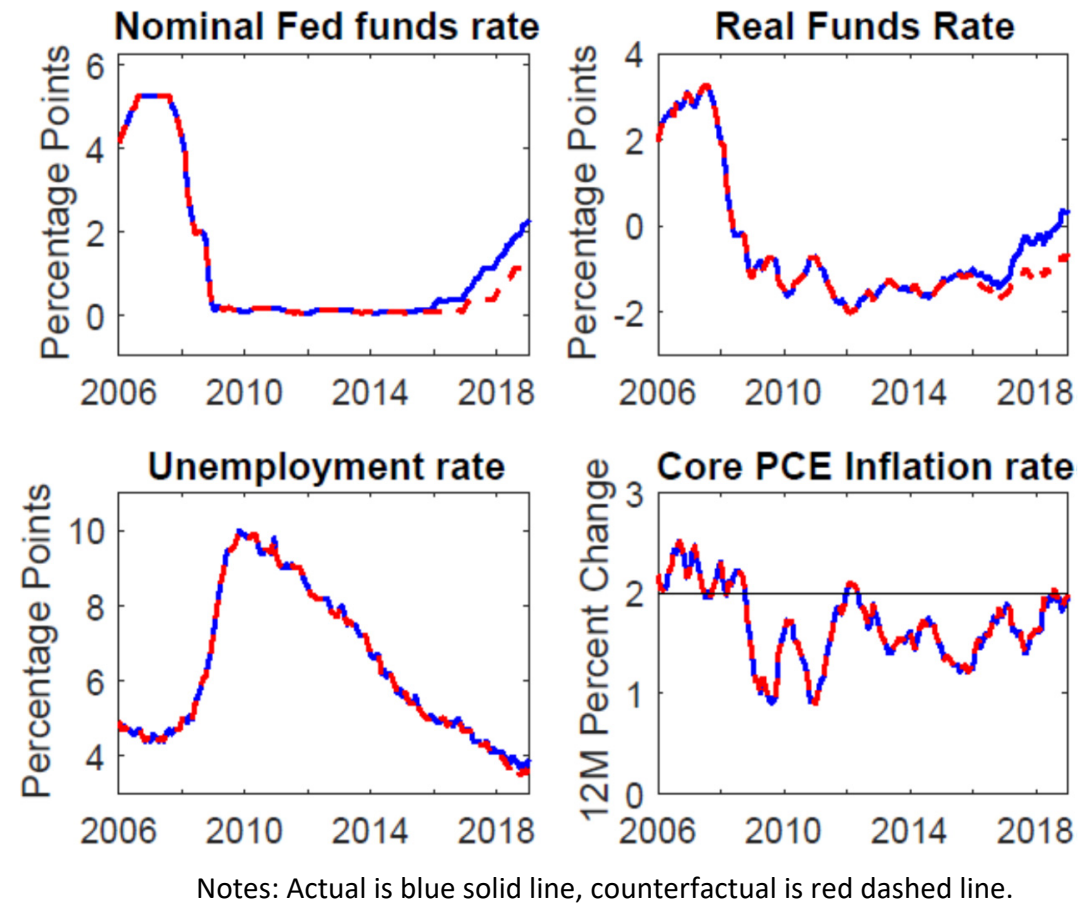
Figure 19 through Figure 23 simulate various alternative slope policies, combined with the actual historical Fed funds policy. These counterfactuals are organized as a progression with increasingly aggressive slope policy.

The first of these, in Figure 19, contemplates a less aggressive slope policy than actual, calibrated to correspond to an absence of LSAPs. This counterfactual has a steeper yield curve, especially after 2012. ${ }^{33}$ The steeper yield curve would have slowed the improvement in the unemployment rate by more than a year, keeping the unemployment rate around 5 percent at the end of the sample, and the rate of inflation would have been even lower than it actually was.

Figure 19. No LSAPs
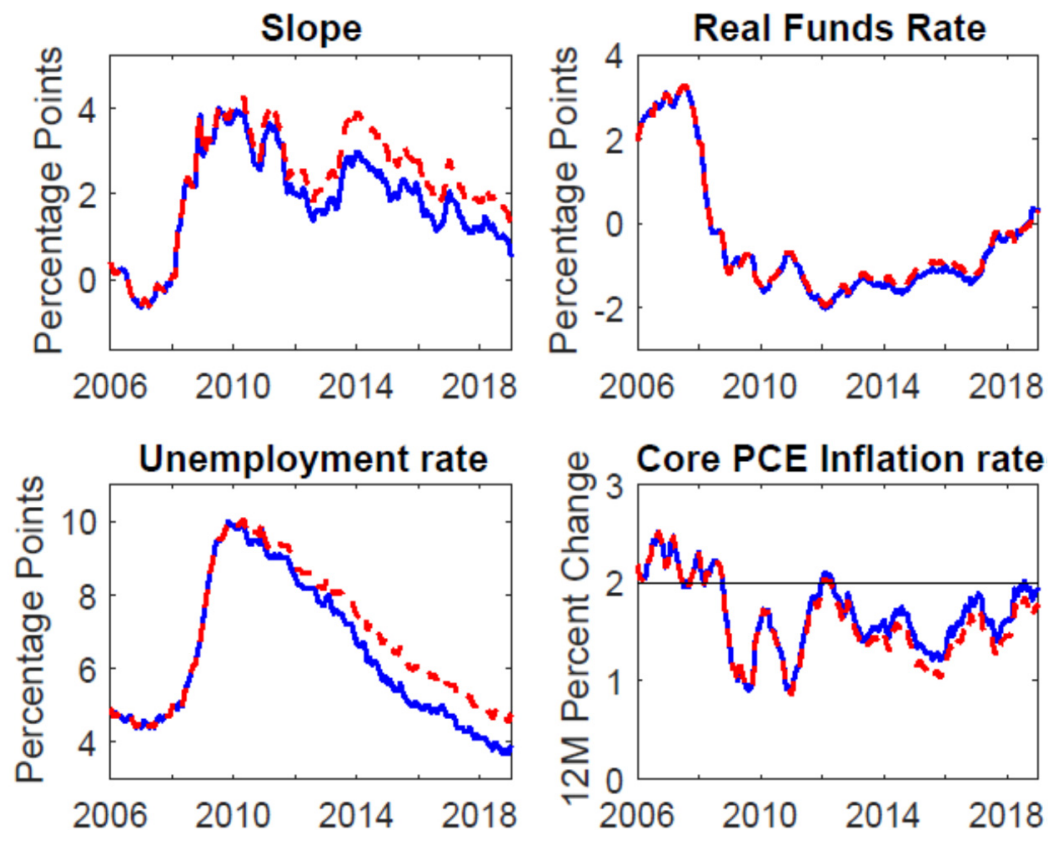

Notes: Actual is blue solid line, counterfactual is red dashed line.

Figure 20 through Figure 23 consider more aggressive counterfactual slope policies. The first of these, in Figure 20, counterfactually supposes a slope policy that flattens the yield curve by an additional 1 percentage point for 5 years, relative to the actual historical outcomes, starting in December 2008. Assuming an elasticity of 6 basis points per percentage point of GDP ten-year equivalents, this

\footnotetext{
${ }^{33}$ The reason why the effect on slope is largest after 2012 is that we assume that the effect of LSAPs is proportional to the stock of ten-year Treasury equivalents in the SOMA portfolio, as a share of nominal GDP, which peaked in 2014. To the extent that LSAPs might have had transitory flow effects, which might have been particularly large when financial markets were disrupted in 2009, this assumption could understate their effects in 2009 and overstate their effects later in the sample.
} 
corresponds to additional LSAPs of about $\$ 2.5$ trillion over and above the LSAPs that were actually implemented, although the slope shock could also be implemented in part by forward guidance. This slope shock would have closed the unemployment gap two years earlier, and raised inflation a bit.

Figure 21 considers a threshold (state-dependent) version of the previous calendar (timedependent) policy, in which the yield curve is flattened by 1 percentage point until either the unemployment gap falls to 1 percent or inflation exceeds 2.5 percentage points. The outcome is very similar to the simulation in Figure 20, as the slope shocks get turned off after about five years.

Figure 22 considers a "stronger sooner" front-loaded version of slope policy, in which slope policy flattens the yield curve by 2 percentage points but only for 18 months starting in December 2008, relative to the actual historical outcomes. It is particularly hard to know what kind of asset purchases would have been needed to achieve this outcome. Our working assumption from footnote 30 of the effects of the stock of asset purchases on ten-year yields would indicate that about $\$ 5$ trillion of additional LSAPs would have been needed. In the disrupted financial markets of 2009 and 2010,

Figure 20. Counterfactual of five-years of additional flattening
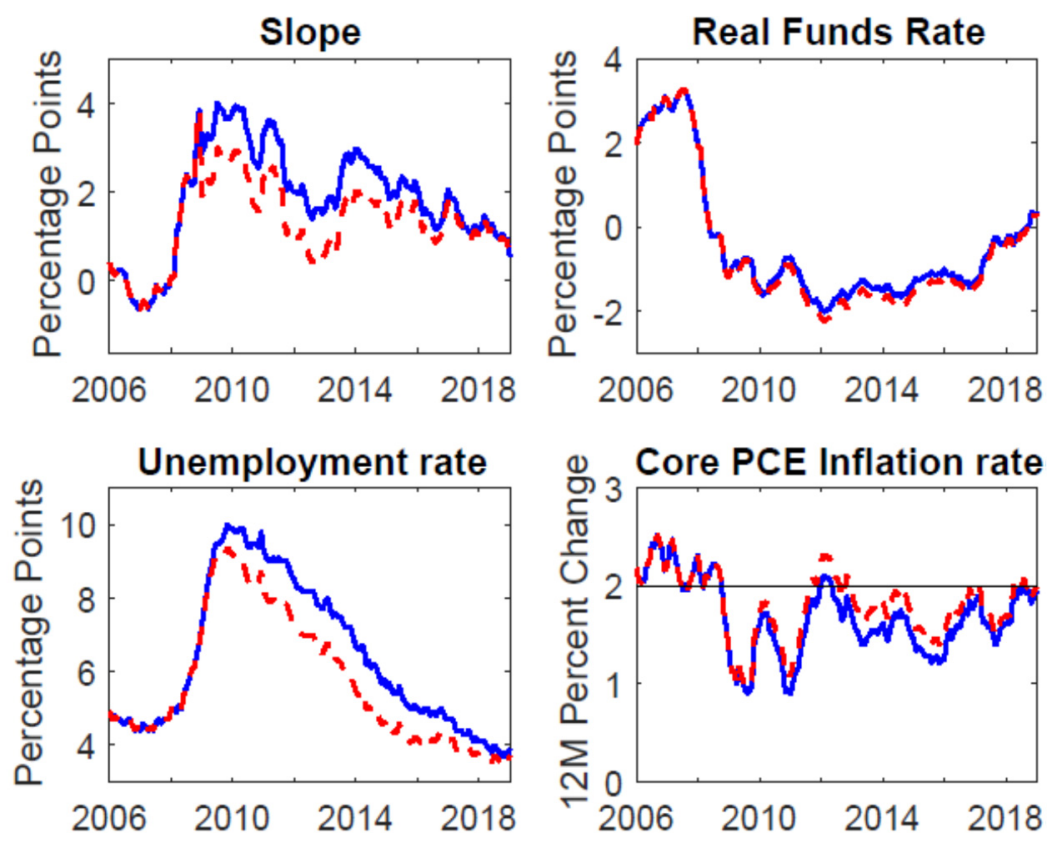

Notes: Actual is blue solid line, counterfactual is red dashed line. 
Figure 21. Counterfactual of additional flattening until threshold achieved
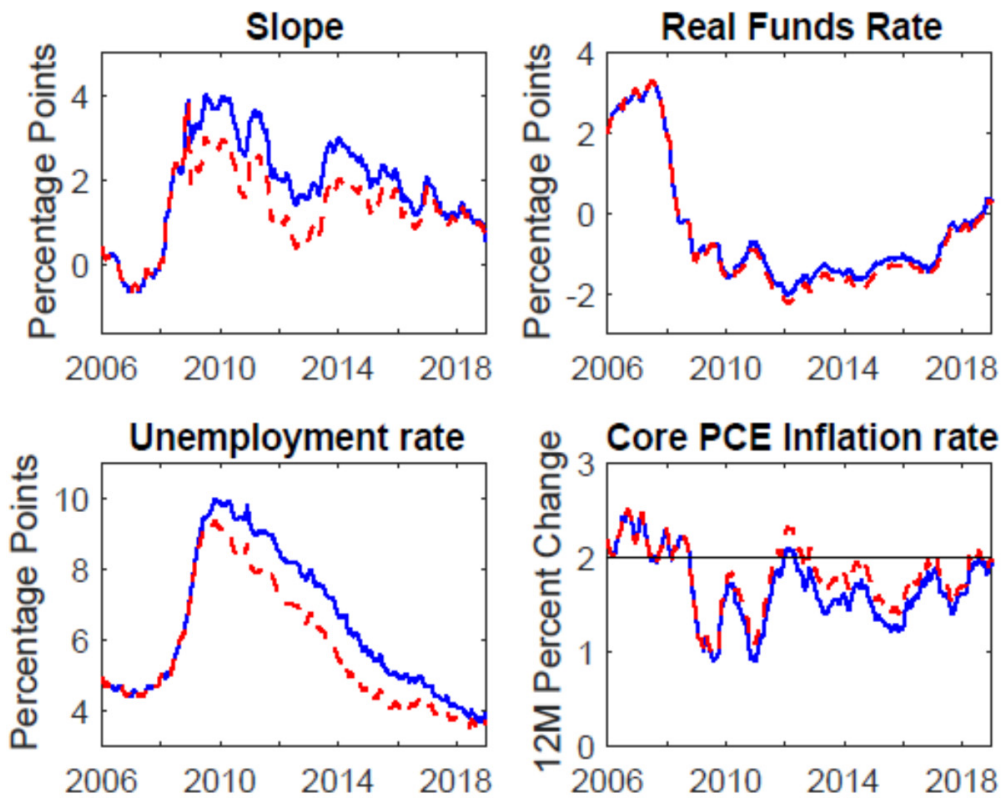

Notes: Actual is blue solid line, counterfactual is red dashed line.

Figure 22. Frontloaded additional LSAPs:

Yield Curve Flattened by an Additional 2 Percentage Points for 18 Months
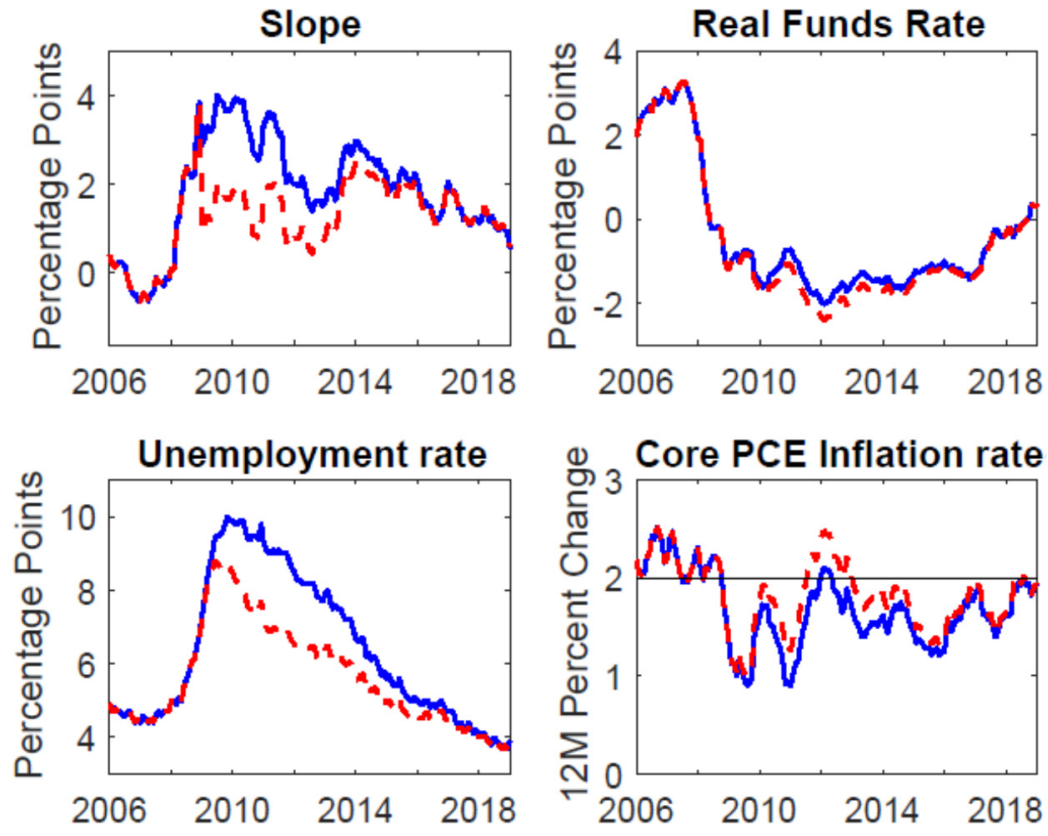

Notes: Actual is blue solid line, counterfactual is red dashed line. 
however, it might have been possible to achieve such a flattening of the yield curve with smaller asset purchases. Additional forward guidance might also play a role in reducing the requisite volume of LSAPs. In our simulation, this early aggressive slope policy would have shaved slightly more than one percentage point off the cyclical peak of the unemployment rate, would have reduced the unemployment gap by an average of 1.7 percentage points over the first four years of the recovery, and Inflation would have been materially higher, though still below the 2 percent target on average over the last decade.

Figure 23 considers an alternative version of front-loaded policy, which pins the slope to 2 percentage points for 5 years. With the funds rate at the ZLB, this is equivalent to pinning the ten-year yield to two percent. ${ }^{34}$ With our illustrative assumption of the effects of the stock of asset purchases on ten-year yields, this would have required very large purchases. However, as pointed out by Bernanke (2016), such a policy might not need such large purchases if it were fully credible. In our simulations, this slope shock would again have brought the unemployment rate down much faster early in the recovery.

Figure 23. Yield Curve Slope Set to 2 Percentage Points for 5 Years
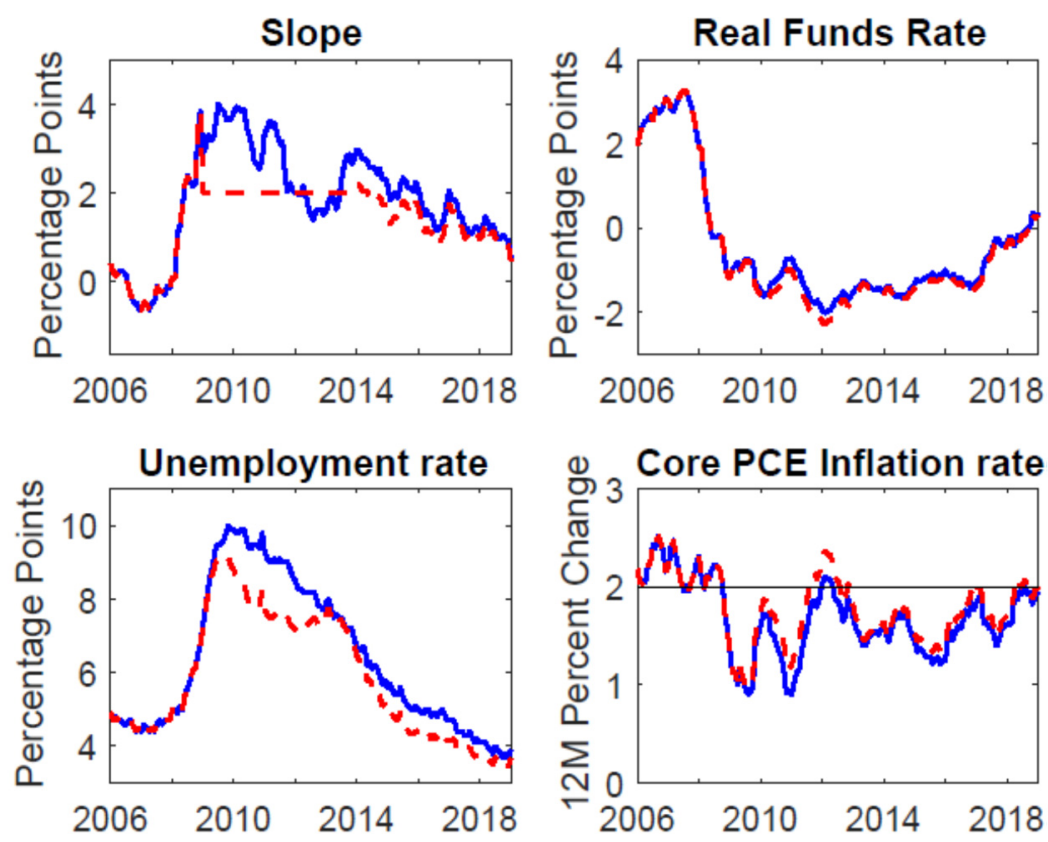

Notes: Actual is blue solid line, counterfactual is red dashed line.

\footnotetext{
34 There are precedents for policies of this sort. The Federal Reserve enforced a ceiling of 2-1/2 percent on longterm Treasury yields during and immediately after World War 2 (Hetzel and Leach (2001)). The Swiss National Bank has long targeted three-month interest rates as a tool of policy, which goes slightly out the term structure. And the Bank of Japan is currently using a "yield curve control" policy that simultaneously targets short- and long-term interest rates.
} 
Figure 24 through Figure 27 consider counterfactuals in which the Fed had, prior to the recession, inherited a higher inflation target and, with it, initial higher rates of inflation and nominal rates of interest, without changing initial values of all real variables including real rates. These counterfactuals postulate that inflation and all nominal interest rates came into the financial crisis recession shifted up by either one or two percentage points. These are not simulations of transitioning from a lower to a higher inflation target during the recession or recovery.

The first of these exercises, shown in Figure 24, considers inheriting a 3 percent inflation target, combined with policy that (like actual policy) goes to the ZLB after December 2008. Under this counterfactual, Fed funds policy lifts off when either of two conditions are met: the unemployment gap falls to 1 percent or the inflation rate exceeds target by 0.5 percentage points. The historical slope shocks are preserved, so implicitly the Fed conducts the same LSAPs and forward guidance policy as it did historically. In this simulation, the inherited extra percentage point of headroom allows the real funds rate to fall by a further percentage point. In this counterfactual, liftoff comes when the unemployment gap falls to 1 percent, which happens in 2014. The unemployment gap closes seven quarters earlier than in the actual data, and inflation averages 1.1 percentage points higher---the 1 percent assumed nominal starting point plus a small boost from the stronger economy. Inflation still falls just short of the 3 percent hypothetical inflation target.

Figure 24. 3 percent Inherited Inflation Target with historical slope shocks counterfactual
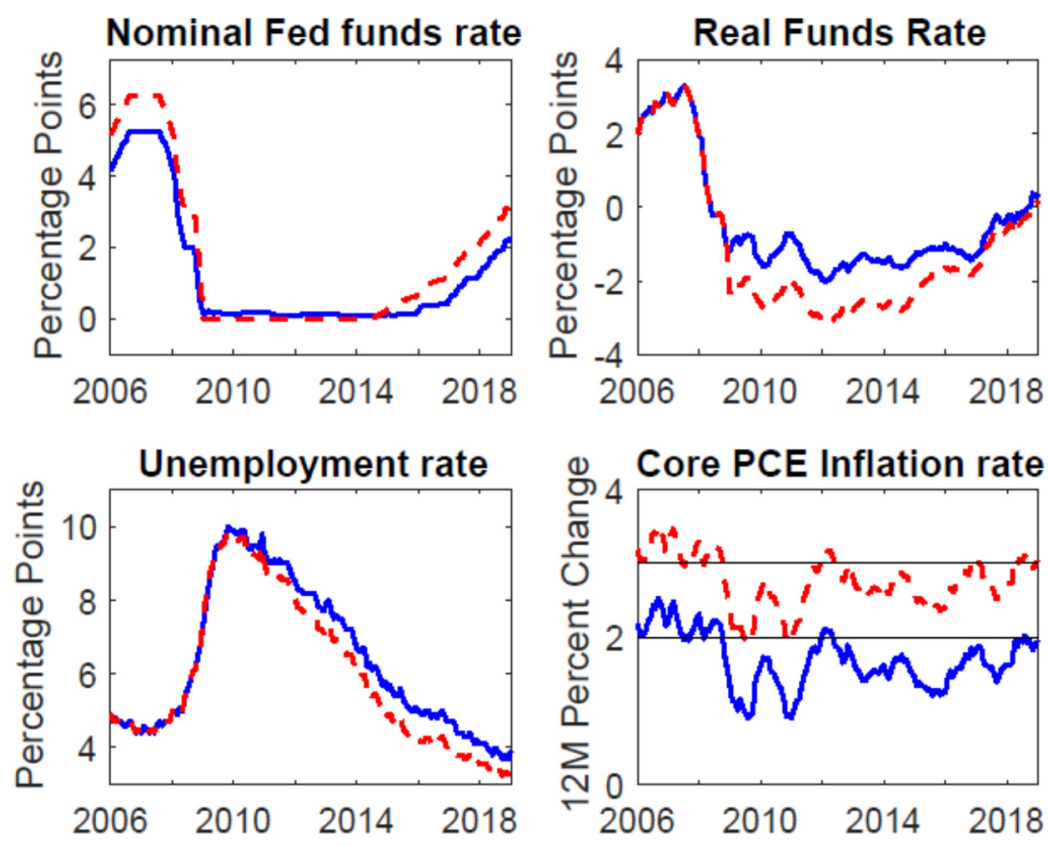

Notes: Actual is blue solid line, counterfactual is red dashed line. In the bottom right panel, horizontal lines denote 2 percent and 3 percent inflation levels. 
Figure 25 repeats the hypothetical of a 3 percent inflation target but removes historical LSAPs. Specifically, Fed funds policy drops the Fed funds rate to the ZLB in December 2008, where it stays until the unemployment gap falls to 1 percent or inflation exceeds the target by 0.5 percentage points. However, this simulation adds in slope shocks to reverse the effects of LSAPs. The real funds rate is reduced, but the outcome for the unemployment rate is almost identical to that actually observed in the data. The path of inflation is also almost identical to that observed in the data, except that it is shifted up by a percentage point. This simulation implies that the LSAPs that were actually conducted have about the same ability to stimulate the economy as an additional percentage point cut in the real funds rate. Alternatively, had the Fed inherited a 3\% inflation target, it could achieved the same outcomes as were actually observed without any LSAPs.

Figure 25. 3 percent Inherited Inflation Target with no LSAPs
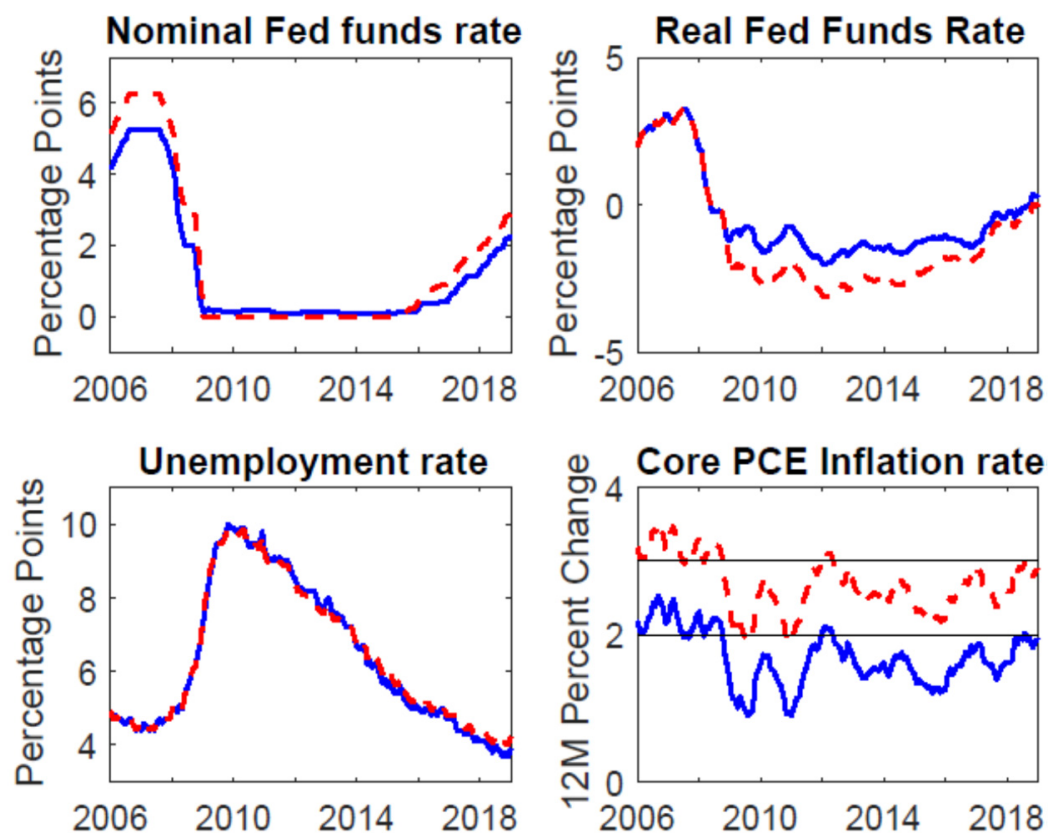

Notes: Actual is blue solid line, counterfactual is red dashed line. In the bottom right panel, horizontal lines denote 2 percent and 3 percent inflation levels.

Figure 26 and Figure 27 repeat the previous two counterfactuals, but now with an inherited 4 percent inflation target. Figure 26 keeps the historical slope shocks, while Figure 27 reverses the slope shocks from LSAPs. Inheriting a 4 percent inflation target in combination with historical slope shocks would have given a much faster recovery, with liftoff arriving in early 2014 and the unemployment gap closing in the third quarter of 2014. But, because of the historically flat Phillips curve, even this would 
not have been enough to quite hit the 4 percent target, on average, over the last decade. A 4 percent target with no LSAPs (Figure 27) would have given a slightly faster recovery than was actually observed. In theory, another possibility for achieving a lower real Fed funds rate is to push the Fed funds rate below zero, as has been done for short rates by the ECB and by the Swiss National Bank without changing the inflation target. Figure 28 considers the counterfactual of setting the Fed funds rate to -25 basis points during the period that it was, in fact, at the ZLB. This would amount to more than 35 basis points of additional accommodation, as the effective funds rate was never quite at zero. We estimate the macroeconomic effect of this policy to be small, lowering the unemployment rate by at most two tenths of a percentage point and having virtually no effect on inflation. Moreover, this counterfactual is done in the context of a linear model in which an easing of policy has, by assumption, the same incremental effect when rates are positive or negative. Easing, however, is arguably less effective when rates are negative, because of the effect on the banking system (see footnote 31 ). Thus, even the small effects that we find arguably overstate the benefits of cutting the federal funds rate to -25 basis points.

Figure 26. 4 percent Inherited Inflation Target with historical slope shocks
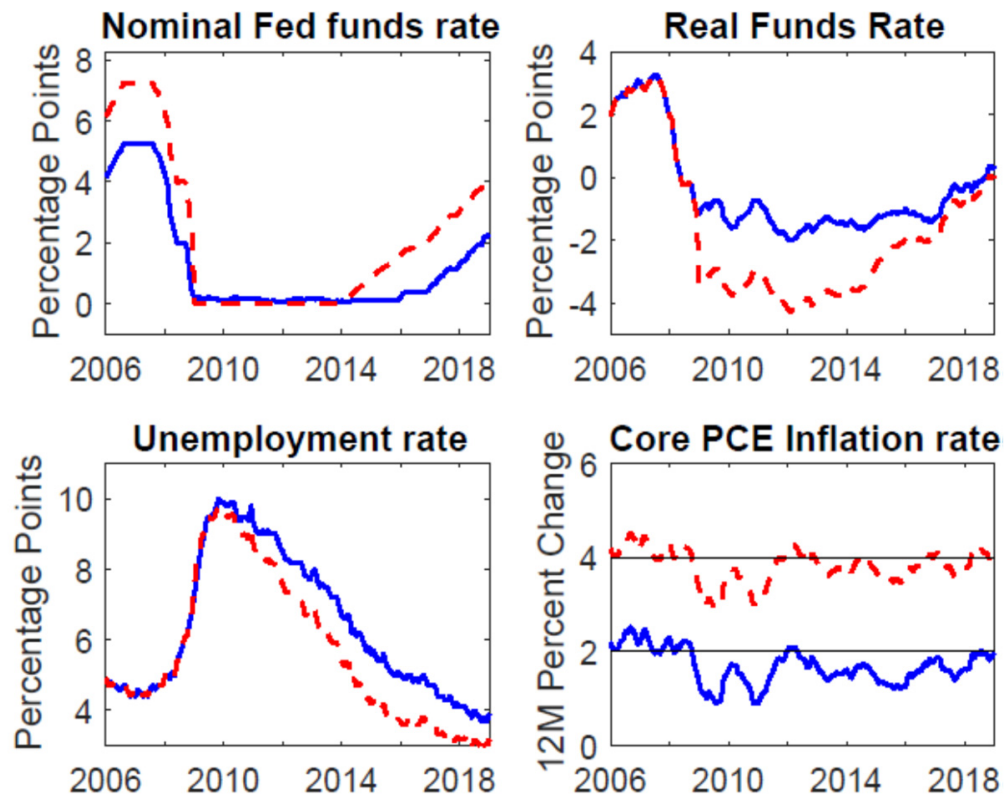

Notes: Actual is blue solid line, counterfactual is red dashed line. In the bottom right panel, horizontal lines denote 2 percent and 4 percent inflation levels. 
Figure 27. 4 percent Inherited Inflation Target with no LSAPs
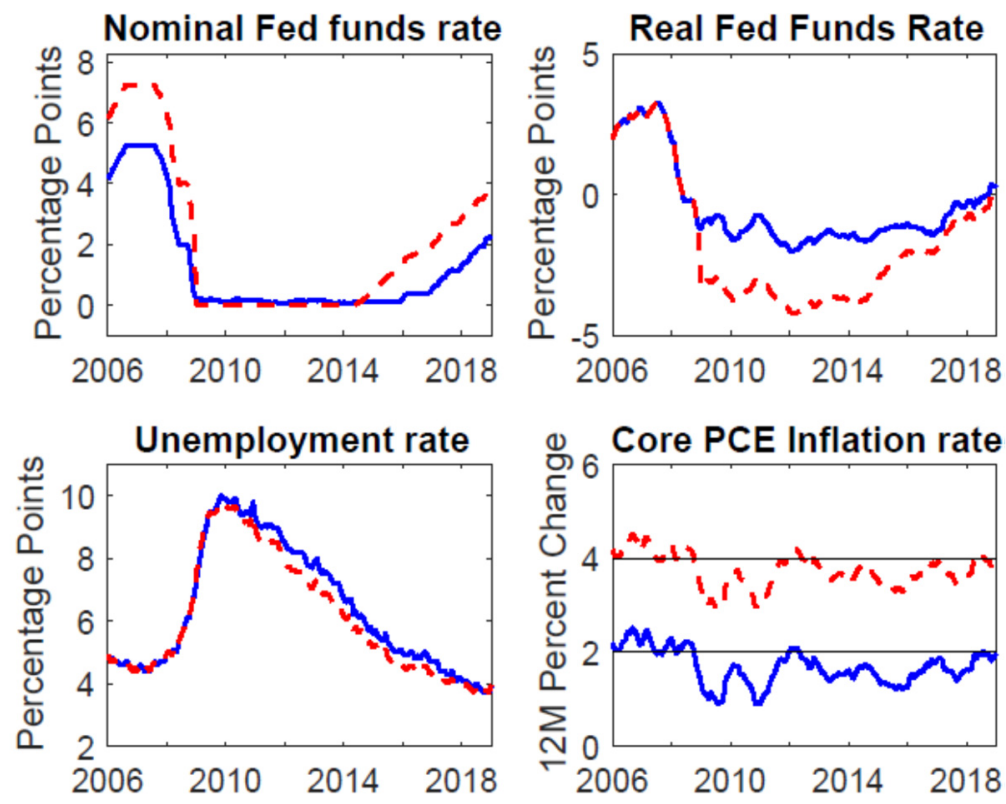

Notes: Actual is blue solid line, counterfactual is red dashed line. In the bottom right panel, horizontal lines denote 2 percent and 4 percent inflation levels.

Figure 28. Fed Funds rate of $-\mathbf{2 5 b p}$
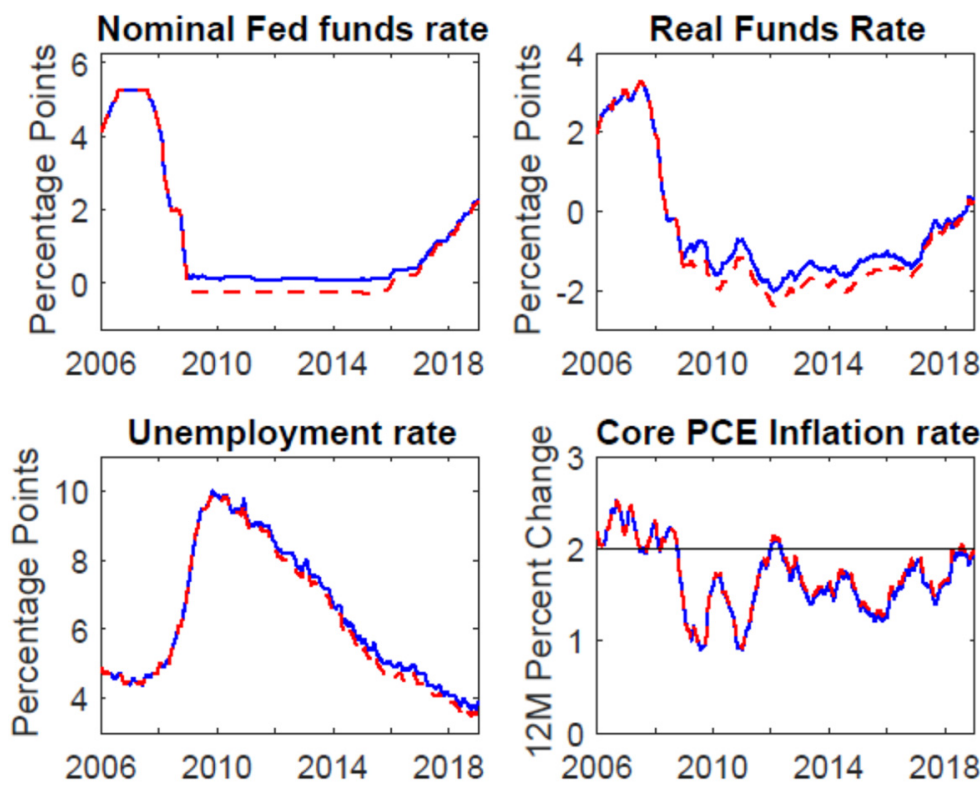

Notes: Actual is blue solid line, counterfactual is red dashed line. 
The next two figures examine a form of temporary price level targeting. Figure 29 adopts a rule of adding Fed funds shocks to keep the funds rate at zero from December 2008 until the temporary price level target with a 2 percent inflation rate and a one-year lookback period has been reached. This ends up implying a liftoff from the zero lower bound that does not come until 2018. Inflation is slightly higher at the end, and the unemployment rate falls a bit faster, but the difference is small. The disinflationary forces from the recession were too big to be easily addressed by Fed funds shocks alone, even with temporary price level targeting.

Figure 30 adopts a rule of adding slope shocks to keep the slope of the yield curve at 2 percent from December 2008 until the same temporary price level target has been reached. This enables a faster recovery, and the target is reached in 2012.

Figure 29. Temporary Price Level targeting via Fed funds shocks
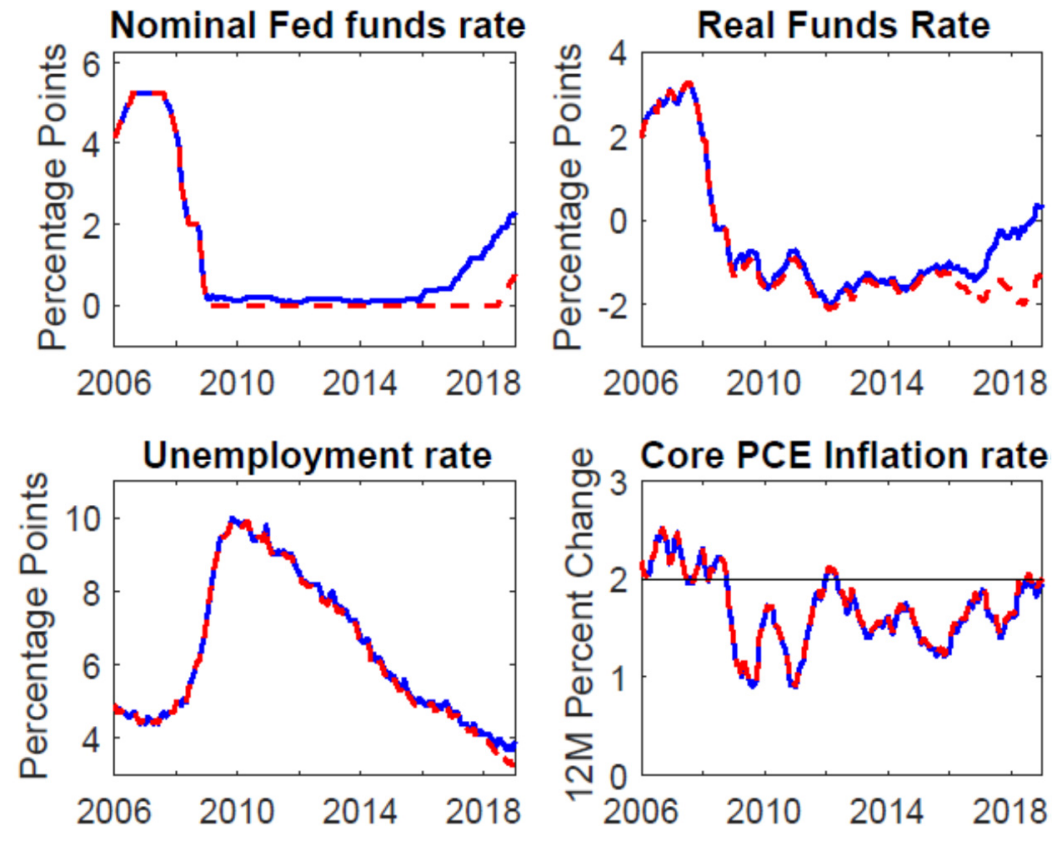

Notes: Actual is blue solid line, counterfactual is red dashed line. 
Figure 30. Temporary Price Level Targeting via slope shocks
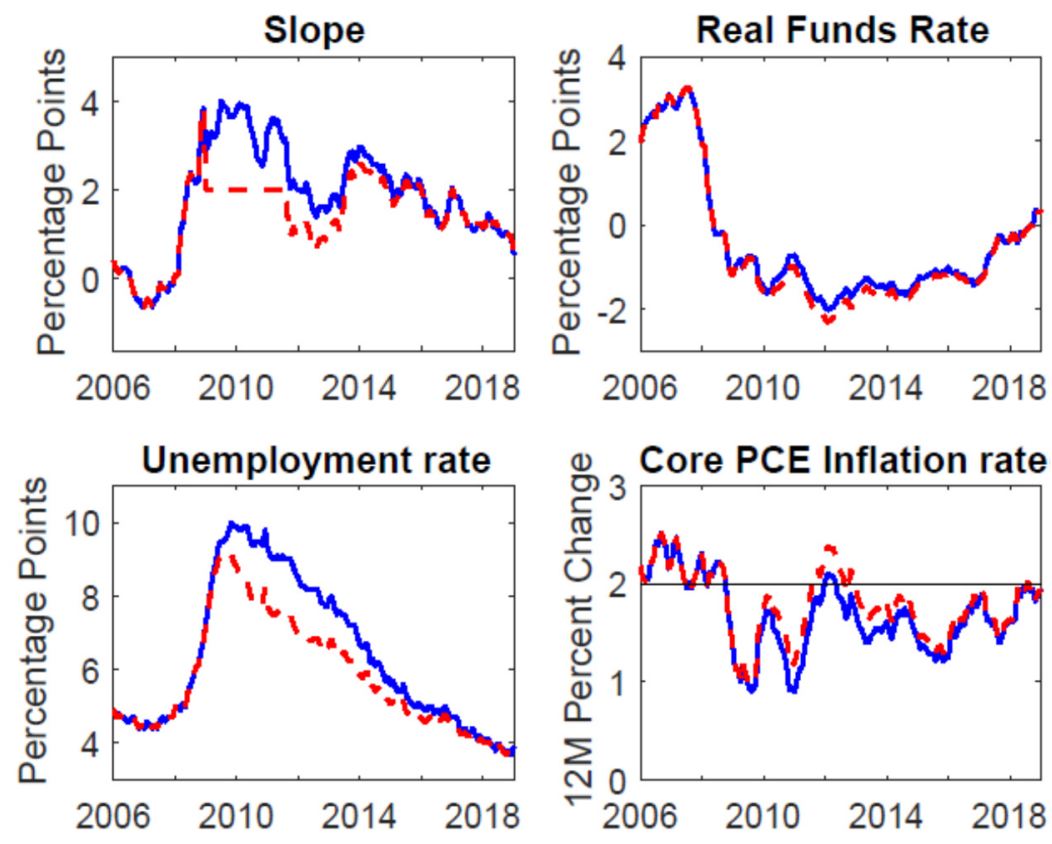

Notes: Actual is blue solid line, counterfactual is red dashed line.

We conclude this section with two simulations that examine the Reifschneider and Williams (2000) makeup rule, where the Fed funds rate stays remains at zero long enough to make up for the cumulative miss of the Funds rate from the Taylor (1993) rule rate created because of the zero lower bound. We consider two cases: in Figure 31, with $r^{*}=2 \%$, and in Figure 32, modifying the Taylor (1993) rule to have $r^{*}$ take on the Holston-Laubach-Williams (2017) value. Both cases are illustrated for the case of no LSAPs, so that the makeup rule is the only adjustment the Fed makes to policy as a result of the zero lower bound. Comparing the two figures, the liftoff date depends heavily on the value of $r$ * used to implement the makeup rule, with the $2 \%$ value leading to higher Fed funds rates after 2015 than actual, and the Holston-Laubach-Williams (2017) $r^{*}$ leading to staying sat the zero lower bound longer than actual. The main feature of both of these simulations, however, is that the policy does not compensate for the effect of shutting down LSAPs; that is, the makeup policy alone prolongs the recession, and suppresses inflation, relative to actual historical policy.

Expectations and a caveat. In principle much of the potential advantage of average inflation targeting and makeup rules arises because the rule changes agents' expectations of future Fed policy, which is then reflected in lower medium- and long-term interest rates. In addition, these policies have the potential to affect inflation expectations directly. Because we implement these policies through a 
sequence of unanticipated Fed funds shocks, these channels are shut down in our SVAR counterfactuals. As a result, our estimates could understate the effects of temporary price level targets. This said, those expectational channels require the Fed to have a credible ability to commit to future policy and for that commitment to be well understood by markets and, in the case of price expectations, price-setters. Because of these commitment and informational challenges, expectational mechanisms that are powerful in theory may be less so in reality.

Figure 31. Makeup rule, with $r^{*}=2 \%$
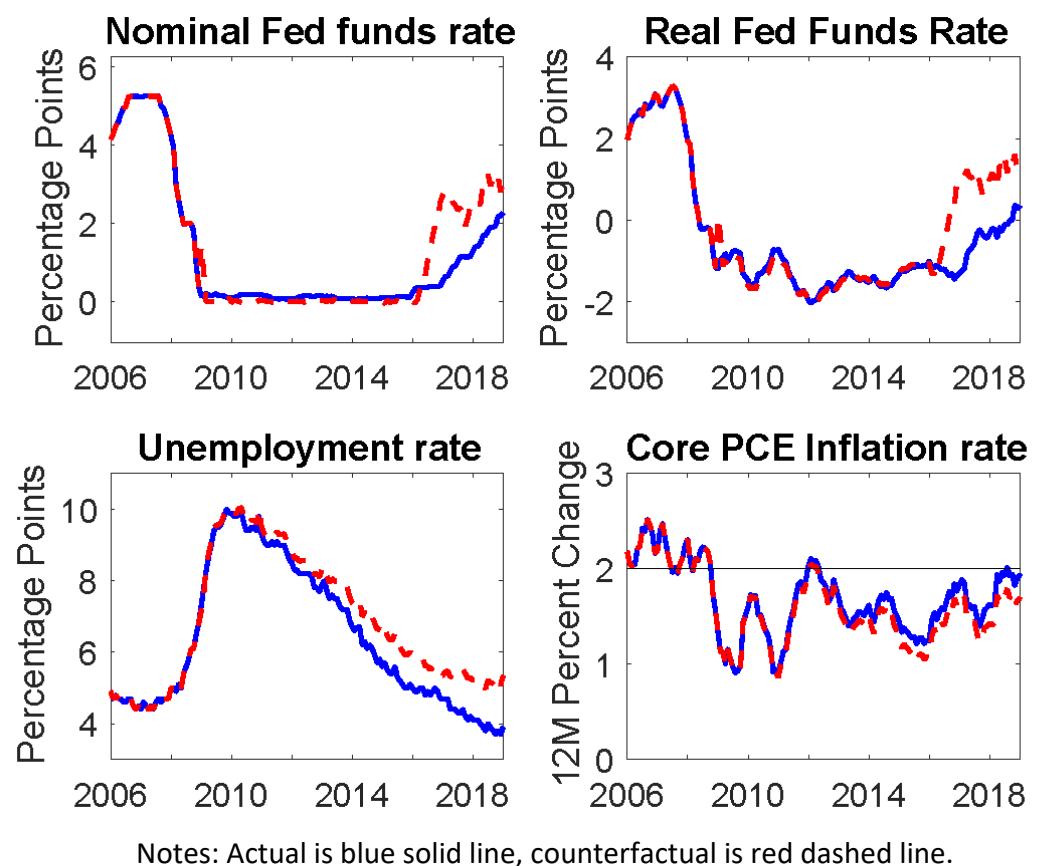
Figure 32. Makeup rule, with Holston, Laubach and Williams (2017) value of $r *$
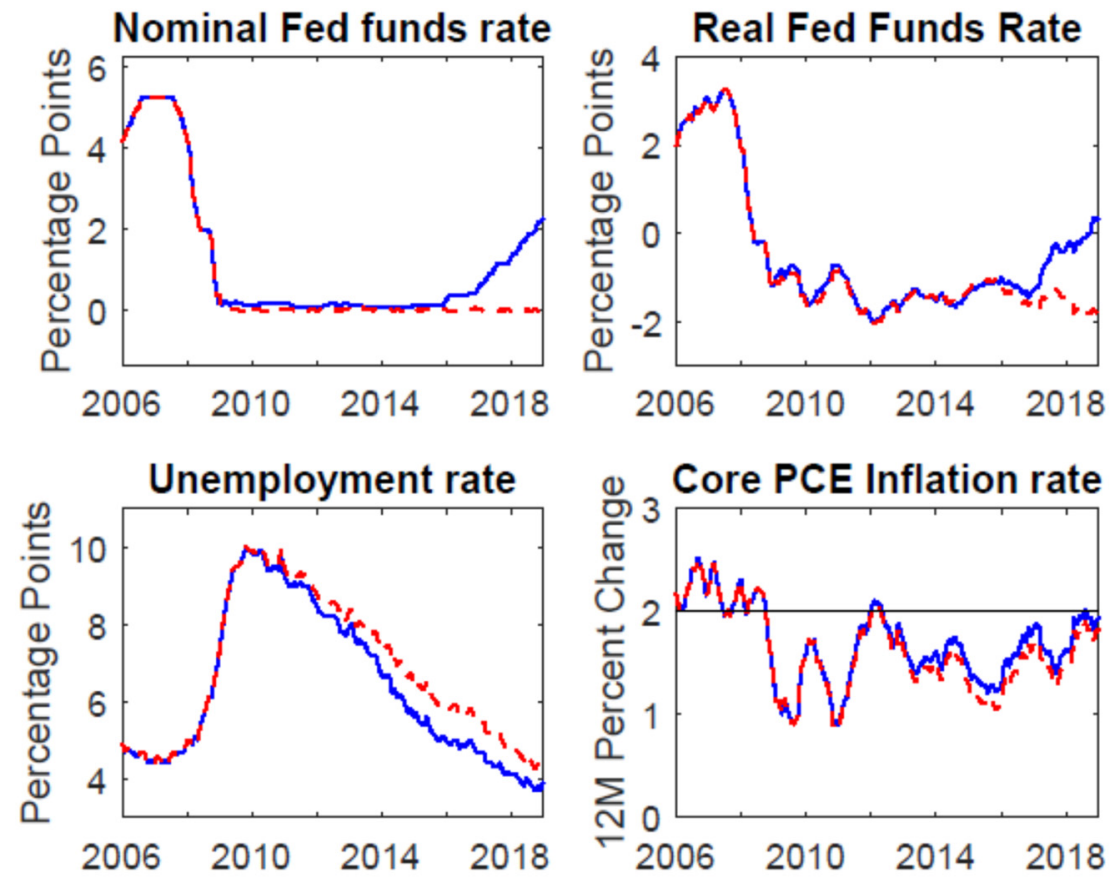

Notes: Actual is blue solid line, counterfactual is red dashed line.

\subsection{Comparison to other simulations}

A number of authors have considered the effects of asset purchases in the FRBUS model. Engen, Laubach and Reifschneider (2015) simulate the effects of all the quantitative easing programs from the financial crisis till the end of $2014 .{ }^{35}$ Their results come from an entirely different methodology, and yet are quite close to ours. They find that the peak effect of asset purchases on the unemployment rate is to lower it by $1 \frac{1}{4}$ percentage points, while the peak effect on inflation is to raise it by $1 / 2$ a percentage point. We get almost exactly the same effect on unemployment, but our effect on inflation is only $1 / 4$ percentage point, because of our flat Phillips curve. Our estimated effect of a slope shock on the unemployment rate comes faster than in the FRBUS simulations, perhaps because of sluggish adjustment of real variables in FRBUS. This comes notwithstanding the fact that we are modeling policies by a sequence of unanticipated shocks which shut down expectational mechanisms in FRBUS which allow term premium effects to be frontloaded.

${ }^{35}$ Earlier FRBUS analyses of LSAPs include Chung et al. (2012) and Durdu et al. (2013). 
Chung et al. (2019) consider balance sheet and other policies in FRBUS in a hypothetical future zero lower bound scenario, and Chen, Curdia and Ferrero (2012) simulate the effects of the QE2 program specifically in a DSGE model. Our counterfactuals are not directly comparable to the specific counterfactuals considered in these two papers. However, our conclusions are qualitatively consistent with theirs. Shocks that flatten the yield curve move unemployment and inflation in the right direction, but even very large balance sheet actions have quite limited macroeconomic impact. For example, Chung et al. consider an expansion of the balance sheet to 33 percent of GDP in a future fairly severe downturn and find that this balance sheet policy would close the output gap just four quarters earlier and raise inflation by $1 / 2$ a percentage point. Our estimated responses to slope policy are comparable in magnitude to those in FRBUS, but take effect more quickly.

Our counterfactual simulations also relate to the question of the relevance or irrelevance of the ZLB over the period since the financial crisis. Different authors have posed this question somewhat differently. Gust et al. (2017) compares scenarios with an unconstrained federal funds rate with that incorporating the ZLB, but where there are no policy alternatives like forward guidance or LSAPs. They find that macroeconomic conditions would have improved more rapidly with the ability to drive rates below zero, and we find something very similar in Figure 15. Swanson (2018) argues that the Fed always had room to drive intermediate-term interest rates lower by additional forward guidance and asset purchases, and in this sense argues that the Fed never really hit the limits of unconventional monetary policy. This too is consistent with our simulations, especially in Figure 22, in which a "stronger sooner" slope policy would have fostered a quicker recovery. Debortoli, Galí and Gambetti (2019) provide evidence that the ZLB did not change the time series properties of key economic variables, which theory suggests should change if the ZLB was a substantial constraint on monetary policy. We interpret this finding as consistent with the evidence in Figure 25, which indicates that actual slope policy provided roughly the equivalent of one percentage point of easing of the ZLB. While the Fed, through its new tools of slope policy, was able to offset partially the effect of the ZLB, the presence of the ZLB did constrain the macroeconomic outcomes the Fed was able to achieve.

\section{Caveats and Discussion}

The results presented in Section 6 are subject to important caveats. First, the proper interpretation of the counterfactuals in Section 6 is not as second-guessing the decisions of the Fed, but rather informing Fed decision-making going forward about the efficacy of its monetary policy tools in a low-inflation environment, calibrated to the experience of the current recovery. Indeed, the 
counterfactual simulations in Section 6 are conducted with the benefit of hindsight and many of the scenarios would not or might not have been feasible in real time. For example, some of the scenarios consider more aggressive slope policy than was actually taken. But the macroeconomic effects of those policies were not known at the time, and are still quite uncertain. Some observers of monetary policy as well as some members of the FOMC expressed concerns that the expansion of the balance sheet was setting the stage for a surge in inflation. That this surge never transpired is only known with the benefit of hindsight. Another potential concern was that the size of the balance sheet would make it difficult for the Fed to control short-term interest rates, although in hindsight this fear also was not realized.

Second, because the model is estimated on historical data, there is uncertainty about the responses of both the unemployment gap and inflation to monetary policy interventions. The dynamic response of the unemployment gap to a Fed funds shock has been well studied, and our estimate is consistent with other estimates in the literature. The history available to study slope shocks is shorter. Our estimated effect of a slope shock is consistent with that in FRBUS, although our estimates suggest shorter lags than in FRBUS. Perhaps the greatest source of uncertainty in our estimates concerns the response of inflation to changes in slack. Our Phillips curve is consistent with others estimated using time series data, and this flat Phillips curve is consistent with the small fluctuations in the rate of inflation that has been observed over the past twenty years despite large fluctuations in slack. Against this aggregate evidence, regional evidence on price inflation, as well as national evidence on wage inflation, suggests that that the Phillips curve could be steeper than estimated using aggregate time series price data. The simulations in Appendix B consider a Phillips curve estimated from regional data, with a long-run response of inflation to a change in the unemployment gap twice as large as in our base model. With this steeper Phillips curve, the more expansionary policies considered in Section 6 result in higher rates of inflation, but even so, those rates generally remain at or below the Fed's inflation target.

Third, in our model, expectations of future policy affect the inflation process through their effect on expected future unemployment gaps. We do not, however, consider mechanisms whereby expectations change about the target rate of inflation. Bernanke, Kiley and Roberts (2019) and Bernanke (2019) point out that imperfect credibility of the Fed can constrain the sorts of policies it undertakes and in particular motivates temporary price level targeting with a short and rolling lookback period, which is the version of temporary price level targeting we consider here.

Fourth, several of our counterfactuals posit using slope policy more aggressively. Doing so, however, so comes with potential risks that are not in our model. As discussed in Carpenter et al. (2013), if the Federal Reserve has a portfolio of long duration assets, then its remittances to the Treasury will 
decline as short-term interest rates increase; the larger the balance sheet, the bigger is this effect. While a period of zero remittances is operationally possible, it could pose other institutional challenges. Unconventional monetary policy also had international spillover effects. ${ }^{36}$ Announcements of easing of monetary policy by the U.S. led to sharp drops in foreign yields but also depreciation of the dollar relative to foreign currencies. They also lead to portfolio inflows into emerging markets where interest rates remained well away from the zero lower bound. These international spillovers are relevant because international financial markets can in turn affect US economic conditions. Another concern associated with very low interest rates (both short and long) is that financial institutions will be led to take on more risk. To some degree, more risk-taking is the intended consequence of monetary policy easing (e.g., Chodorow-Reich (2014)). But very low rates could lead institutions to invest in riskier assets than is socially optimal in order to achieve a target promised return. ${ }^{37}$

With these caveats in mind, we draw six conclusions from our analysis.

First, the current monetary policy framework, in particular its new suite of slope policies, played an important role in supporting the recovery. Absent slope policy, the recovery of the labor market would have been slower, and the rate of inflation lower, than it was. The magnitude of the effect is substantial: absent slope policy, we estimate that the unemployment rate would have crossed the NAIRU more than one year later than it did, and the rate of inflation would have been approximately 0.2 percentage points lower than it was during the latter part of the recovery. As was pointed out in Section 4 , the recovery of the labor market, as measured by the unemployment rate, was faster following the financial crisis than during the previous two recessions, and our estimates suggest that the Fed's use of its suite of tools for slope policy were an important reason for this relatively fast recovery of the labor market.

Second, the main forces behind the slow growth of GDP over this recovery are trends that predate the recession, mainly the retirement of the baby boom, the trend non-demographic decline in the labor force participation rate, and the productivity slowdown that started in the early or mid-2000s. These trends are largely outside the reach of monetary policy, as are other lesser factors behind the slow growth of GDP, such as the fiscal drag from 2012 to 2016 arising from the sequester and the slow

\footnotetext{
${ }^{36}$ See, for example, Ait-Sahalia et al. (2012), Rogers, Scotti and Wright (2014), Bowman, Londono and Sapriza (2015), Fratzscher Lo Duca and Straub (2017), Dell'Ariccia, Rabanal, and Sandri (2018), Bhattarai and Neely (2018). ${ }^{37}$ Some evidence for this "reach for yield" behavior was found by Becker and Ivashina (2015) for insurance companies and Di Maggio and Kacperczyk (2017) for money market mutual funds. Chodorow-Reich (2014) also found evidence for some "reach for yield" behavior for money market mutual funds and private defined benefit pension funds, but argued that it was modest and short-lived.
} 
recovery of state and local spending. In some of our counterfactuals with more aggressive slope policies, the unemployment rate would have reached the CBO NAIRU a year earlier than it did, and (using an Okun's law calculation) this faster decline would have been associated with perhaps 0.3-0.4 percentage points faster annual growth of GDP during the middle and late recovery. But even with this boost, the demographic and other headwinds would have produced a growth rate of GDP below that of the 20012007 expansion, and well below that of the expansions of the 1980s and 1990s.

Third, despite the efficacy of slope policy, the zero lower bound significantly restricted the scope of monetary policy during the recovery. Absent the ZLB, we (and others) estimate that normal Fed funds policy would have led to a Fed funds rate of approximately $-5 \%$. Our estimates suggest that the suite of Fed slope policies was able to offset perhaps one percentage point of the ZLB constraint. Although we do not undertake any probability estimates ourselves, simulation evidence in the literature suggests a high probability of hitting the ZLB in future recessions. ${ }^{38}$ In short, the ZLB imposes significant constraints on the efficacy of Fed policy, and our estimates suggest that those constraints are only partially offset by the new slope policies.

Fourth, small changes in the policy stance would have produced small changes in realized outcomes. For example, speeding up or delaying liftoff of the Fed funds rate by one year would have changed the unemployment gap, relative to actual, by a few tenths of a percentage point, and would have had a negligible effect on the inflation rate. Similarly, even if a negative Fed funds rate could be implemented, and putting aside the many risks of doing so, sustaining a negative rate (we consider -25 basis points) for the entire ZLB episode would have had only small effects on the speed of the recovery and negligible effects on the rate of inflation.

Fifth, of the counterfactuals we consider, the policies with the largest effect are ones with early and aggressive slope policy, undertaken roughly when the Fed funds rate hits the ZLB. Our model estimates that such policy has a relatively quick effect on the economy, with major impacts in less than one year, and as a result early aggressive action to flatten the term structure could substantially speed the recovery in the labor market and support reflation. This could be particularly true if there is some nonlinearity that makes policy more effective during or immediately after a recession. We do not model

\footnotetext{
${ }^{38}$ Kiley and Roberts (2017) conclude that with a 1 percent neutral real rate and 2 percent inflation target, FRBUS would imply that the effective lower bound will bind 30 percent of the time. Bernanke, Kiley and Roberts (2019) find that it binds between 15 and 40 percent of the time, depending on the monetary policy reaction function, with temporary price level targeting being effective at keeping the economy away from the ZLB. Chung et al. (2019) find a probability between 20 and 50 percent of the ZLB binding at some point with in the next decade. The model of Mertens and Williams (2018) has a probability of being at the ZLB of at least 30 percent.
} 
the combination of forward guidance, LSAPs, and maturity policies that would accomplish such a "stronger sooner" policy, and arguably the best mix would depend on financial market conditions. In addition, as discussed above, more aggressive use of slope policy comes with a number of concerns and potential channels that we do not model, which could constrain the Fed's ability to implement them in practice.

Sixth, the current suite of policies would have led to a substantially faster recovery had the Fed inherited higher nominal interest rates and inflation consistent with a higher inflation target. For example, we estimate that an inherited inflation target of $3 \%$, combined with the historical use of slope policy, would have resulted in the unemployment rate falling below NAIRU seven quarters earlier than it did; had all nominal rates and the inflation rate been two percentage points higher and had the inherited inflation target been $4 \%$, the unemployment rate would have crossed NAIRU ten quarters earlier than it did, allowing liftoff to occur in 2014. Under both the $3 \%$ and $4 \%$ scenarios, the rate of inflation gets closer to the target rate.

Our conclusion that the tools in the current monetary policy framework would have been more effective over the past decade had the Fed inherited a higher inflation target raises the question of how the Fed might reach a higher inflation target, should it choose to do so. We do not model such a transition process, but offer some thoughts based on historical experience. The decline in inflation from 1985 through 2005 was gradual, with the rate of core PCE inflation falling from an average of $3.6 \%$ in the second half of the 1980 s to $1.7 \%$ in the first half of the 2000 s. This decline was largely a result of policy of opportunistic disinflation (Orphanides and Wilcox (2002)), in which the Fed did not actively use monetary policy to lower inflation but at the same time did not seek to reverse declines in inflation when they occurred. During this period of opportunistic disinflation, inflation expectations of both professionals and the public also fell gradually, tracking the slow decline in inflation: from the first half of the 1990s through the first half of the 2000s, the Survey of Professional Forecasters expected 10-year rate of $\mathrm{CPI}$ inflation gradually declined from $3.6 \%$ to $2.5 \%$, and the Michigan survey measure of inflation expectations fell from $3.2 \%$ to $2.6 \%$. This period of slowly falling rates of inflation and inflation expectations was accompanied by historically low inflation volatility. Moreover, from 1990 to 2005, inflation expectations also exhibited low volatility, with quarterly standard deviations of 0.2 percentage points and 0.4 percentage points for the long-term SPF and Michigan survey measures, respectively, around their slowly declining trend.

In the same way, the Fed might now accept opportunistic reflation (Brainard (2019)), where it does not seek to reverse increases in inflation coming from, for example, a tight labor market or supply- 
side price shocks. A policy of opportunistic reflation could have challenges. Given the flat Phillips curve that has been observed over the past two decades and which is the source of the sluggish response of inflation to slack in our simulations, sustained unemployment rates below current estimates of the natural rate could, by themselves, have modest and slow effects in raising the inflation rate to a higher target: like the disinflation, the reflation would likely be slow. The policy would need to be clearly communicated so that inflation expectations could adjust accordingly, as they did during the period of opportunistic disinflation. Sustained low interest rates could raise other potential concerns such as asset bubbles (Brainard (2017)). These and other potential challenges warrant additional study. 


\section{References}

Aaronson, Stephanie R., Mary C. Daly, William Wascher, and David W. Wilcox. "Okun revisited: Who benefits most from a strong economy? Brookings Papers on Economic Activity (2019), forthcoming.

Abraham, Katharine, and Melissa S. Kearney. "Explaining the decline the U.S. employment-to-population ratio: A review of the evidence." National Bureau of Economic Research working paper 24333 (2018).

Ait-Sahalia, Yacine, Jochen Andritzky, Andreas Jobst, Sylwia Nowak, and Natalia Tamirisa. "Market response to policy initiatives during the global financial crisis." Journal of International Economics 87.1 (2012): 162-177.

Alon, Titan, David Berger, Rob Dent, and Benjamin Pugsley. "Older and Slower: The Startup Deficit's Lasting Impact on Productivity Growth" Journal of Monetary Economics, 93 (2018): 68-85.

Ampudia, Miguel, and Skander Van den Heuvel. "Monetary policy and bank equity values in a time of low interest rates." Working Paper (2018).

Andrade, Philippe, Jordi Galí, Hervé Le Bihan, and Julien Matheron. "The optimal inflation target and the natural rate of interest." Working Paper (2019).

Anzoategui, Diego, Diego Comin, Mark Gertler, and Joseba Martinez. "Endogenous technology adoption and R\&D as sources of business cycle persistence." American Economic Journal: Macroeconomics (2019), forthcoming.

Barnichon, Regis and Geert Mesters. "Identifying the Phillips curve from shifts in demand." Working Paper (2019a)

Barnichon, Regis and Geert Mesters. "The Phillips multiplier." Working Paper (2019b).

Becker, Bo, and Victoria Ivashina. "Reaching for yield in the bond market." The Journal of Finance 70.5 (2015): 1863-1902.

Belton, Terry, Kristopher Dawsey, David Greenlaw, Huachen Li, Srini Ramaswamy and Brian Sack. "Optimizing the maturity structure of U.S. Treasury debt: A model-based framework." Hutchins Center Working Paper 46 (2018).

Bernanke, Ben S. "What tools does the Fed have left? Part 2: Targeting longer-term interest rates Brookings Institution (2016) at https://www.brookings.edu/blog/benbernanke/2016/03/24/what-tools-does-the-fed-have-left-part-2-targeting-longer-term-interestrates/.

Bernanke, Ben S., "Evaluating longer-for-lower policies: Temporary price-level targeting." Brookings Institution (2019) at https://www.brookings.edu/blog/ben-bernanke/2019/02/21/evaluatinglower-for-longer-policies-temporary-price-level-targeting/.

Bernanke, Ben S., Michael T. Kiley and John M. Roberts. "Monetary policy strategies for a low-rate environment." Finance and Economics Discussion Series 2019-09 (2019).

Bhattarai, Saroj, and Christopher J. Neely. "An Analysis of the Literature on International Unconventional Monetary Policy." FRB St. Louis Working Paper 2016-21 (2016).

Blanchard, Olivier J., and Charles M. Kahn. "The solution of linear difference models under rational expectations." Econometrica 48 (1980): 1305-1311. 
Bloom, Nicholas, Charles I. Jones, John Van Reenan, and Michael Webb. "Are ideas getting harder to find?" NBER Working Paper 23782 (2017).

Bowman, David, Juan M. Londono, and Horacio Sapriza. "US unconventional monetary policy and transmission to emerging market economies." Journal of International Money and Finance 55 (2015): 27-59.

Brainard, Lael. "The disconnect between inflation and employment in the new normal." National Tax Association Spring Symposium (2019).

Brainard, Lael. "Rethinking Monetary Policy in a new normal." Peterson Institute of International Economics (2017).

Brunnermeier, Markus K., and Yann Koby. "The reversal interest rate." National Bureau of Economic Research working paper 25406 (2018).

Bundick, Brent and A. Lee Smith. "The dynamic effects of forward guidance shocks." Working paper (2018).

Burke, Chris, Spence Hilton, Spence Hilton, Ruth Judson, Kurt Lewis, and David Skeie. "Reducing the IOER rate: An analysis of options." Federal Reserve Memorandum (2010).

Byrne, David M., John G. Fernald, and Marshall B. Reinsdorf. "Does the United States have a productivity slowdown or a measurement problem?" Brookings Papers on Economic Activity, Spring (2016): 109-182 (with discussion).

Campbell, Jeffrey R., Charles L. Evans, Jonas D.M. Fisher and Alejandro Justiniano, "Macroeconomic effects of Federal Reserve forward guidance." Brookings Papers on Economic Activity 1 (2012): 1-80.

Campbell, Jeffrey R., Jonas D.M. Fisher, Alejandro Justiniano, and Leonardo Melosi. "Forward guidance and macroeconomic outcomes since the financial crisis." NBER Macroeconomics Annual 31.1 (2017): 283-357.

Carpenter, Seth B., Jane E. Ihrig, Elizabeth C. Klee, Daniel W. Quinn and Alexander H. Boot. "The Federal Reserve's balance sheet and earnings: A primer and projection." Finance and Economics Discussion Series 2013-01 (2013).

Chen, Han, Vasco Cúrdia, and Andrea Ferrero. "The macroeconomic effects of large-scale asset purchase programmes." Economic Journal 122 (2012): F289-F315.

Chodorow-Reich, Gabriel. "Effects of unconventional monetary policy on financial institutions." Brookings Papers on Economic Activity 1 (2014): 155-204.

Christiano, Lawrence J., Martin S. Eichenbaum, and Mathias Trabandt. "Understanding the Great Recession." American Economic Journal: Macroeconomics 7.1 (2015): 110-67.

Chung, Hess, Etienne Gagnon, Taisuke Nakata, Matthias Paustian, Bernd Schlusche, James Trevino, Diego Vilán and Wei Zheng. "Monetary policy options at the effective lower bound: Assessing the Federal Reserve's current policy toolkit." Finance and Economics Discussion Series 2019-03 (2019).

Chung, Hess, Jean-Philippe Laforte, David Reifschneider, and John C. Williams. "Have we underestimated the likelihood and severity of zero lower bound events?" Journal of Money, Credit and Banking 44 (2012): 47-82.

Coibion, Olivier. 2012. "Are the effects of monetary policy shocks big or small? American Economic Journal-Macroeconomics, 4 (2), 1-32. 
Coibion, Olivier, and Yuriy Gorodnichenko. "Is the Phillips curve alive and well after all? Inflation expectations and the missing disinflation." American Economic Journal: Macroeconomics 7.1 (2015): 197-232.

Crump, Richard K., Stefano Eusepi, Marc Giannoni, and Aysegul Sahin. "A unified approach to measuring u*." Brookings Papers on Economic Activity (2019), forthcoming.

D’Amico, Stefania, William English, David López-Salido, and Edward Nelson. "The Federal Reserve's large-scale asset purchase programmes: Rationale and effects." Economic Journal 122 (2012): F415-F446.

D'Amico, Stefania, and Thomas B. King. "Flow and stock effects of large-scale Treasury purchases: Evidence on the importance of local supply." Journal of Financial Economics 108.2 (2013): 425448.

Debortoli, Davide, Jordi Galí, and Luca Gambetti. "On the empirical (ir) relevance of the zero lower bound constraint." NBER Macroeconomics Annual, forthcoming (2019).

Del Negro, Marco, Domenico Giannone, Marc P. Giannoni and Andrea Tambalotti. "Safety, liquidity, and the natural rate of interest." Brookings Papers on Economic Activity 1 (2017): 235-316.

Del Negro, Marco, Marc P. Giannoni, and Christina Patterson. "The Forward Guidance Puzzle." Federal Reserve Bank of New York Staff Report 574 (2012).

Dell'Ariccia, Giovanni, Pau Rabanal, and Damiano Sandri. "Unconventional monetary policies in the Euro Area, Japan, and the United Kingdom." Journal of Economic Perspectives 32.4 (2018): 147-172.

Di Maggio, Marco, and Marcin Kacperczyk. "The unintended consequences of the zero lower bound policy." Journal of Financial Economics 123.1 (2017): 59-80.

DI Maggio, Marco, Amir Kermani, and Christopher Palmer. "How quantitative easing works: Evidence on the refinancing channel." National Bureau of Economic Research working paper 22638 (2016).

Durdu, Bora, Thomas Laubach, David Lebow, Jon Millar and Michael Palumbo. "Evaluating the efficacy of the Federal Reserve's Large Scale Asset Purchases." Memorandum (2013).

Engen, Eric M., Thomas Laubach, and David Reifschneider "The Macro-economic Effects of the Federal Reserve's Unconventional Monetary Policies." Finance and Economics Discussion Series 2015-05 (2015).

Eggertsson, Gauti B., and Michael Woodford. "The Zero Bound on Interest Rates and Optimal Monetary Policy." Brookings Papers on Economic Activity, 1 (2003), 139-235.

Eggertsson, Gaudi B., Ragnar E. Juelsrud, Lawrence H. Summers, and Ella Getz Wold. "Negative nominal interest rates and the bank lending channel." NBER Working Paper 25416 (2019).

Farhi, Emmanuel and François Gourio. "Accounting for macro-finance trends: Market power, intangibles, and risk premia." Brookings Papers on Economic Activity (2018).

Faust, Jon W. "Oh what a tangled web we weave: Monetary policy transparency in divisive times." Hutchins Center Working Paper 25 (2016).

Femia, Katherine, Steven Friedman, and Brian P. Sack. "The effects of policy guidance on perceptions of the Fed's reaction function." Federal Reserve Bank of New York Staff Report 652 (2013).

Fernald, John G., Robert E. Hall, James H. Stock, and Mark W. Watson. "The disappointing recovery of output after 2009." Brookings Papers on Economic Activity 1 (2017): 1-89. 
Foley-Fisher, Nathan, Rodney Ramcharan, and Edison Yu. "The impact of unconventional monetary policy on firm financing constraints: Evidence from the maturity extension program." Journal of Financial Economics 122.2 (2016): 409-429.

Fratzscher, Marcel, Marco Lo Duca, and Roland Straub. "On the international spillovers of US quantitative easing." Economic Journal 128 (2017): 330-377.

Fuhrer, Jeffrey C., Giovanni P. Olivei, Eric S. Rosengren, and Geoffrey M.B. Tootell. "Should the Fed regularly evaluate its monetary policy framework." Brookings Papers on Economic Activity (2018).

Fukui, Masao, Emi Nakamura, and Jón Steinsson. "Women, wealth effects, and slow recoveries." manuscript, University of California-Berkeley (2019).

Gagnon, Joseph, Matthew Raskin, Julie Remache, and Brian Sack. "The financial market effects of the Federal Reserve's large-scale asset purchases," International Journal of Central Banking, 7 (2011): 3-43.

Galí, Jordi. "The return of the wage Phillips curve." Journal of the European Economic Association, 9(3) (2011): 436-461.

Galí, Jordi, and Luca Gambetti. "Has the U.S. wage Phillips curve flattened? A semi-structural exploration." National Bureau of Economic Research working paper 25476.

Gertler, Mark, and Peter Karadi. "Monetary policy surprises, credit costs, and economic activity." American Economic Journal: Macroeconomics 7.1 (2015): 44-76.

Gilchrist, Simon, Raphael Schoenle, Jae Sim, and Egon Zakrajšek. "Inflation dynamics during the financial crisis." American Economic Review 107.3 (2017): 785-823.

Gilchrist, Simon, and Egon Zakrajšek. "Credit spreads and business cycle fluctuations." American Economic Review 102.4 (2012): 1692-1720.

Goldfeld, S.M. and A.S. Blinder (1972). "Some Implications of Endogenous Stabilization Policy," Brookings Papers on Economic Activity 3:1972, 585-644.

Gordon, Robert J. The Rise and Fall of American Growth: The US Standard of Living since the Civil War, Princeton University Press (2016).

Greenlaw, David, James D. Hamilton, Ethan Harris, and Kenneth D. West. "A Skeptical View of the Impact of the Fed's Balance Sheet." National Bureau of Economic Research working paper 24687 (2018).

Greenwood, Robin, and Dimitri Vayanos. "Bond supply and excess bond returns." The Review of Financial Studies 27.3 (2014): 663-713.

Gürkaynak, Refet S., Brian P. Sack, and Eric T. Swanson. "Do actions speak louder than words? The response of asset prices to monetary policy actions and statements." International Journal of Central Banking 1 (2005): 55-93.

Gust, Christopher, Edward Herbst, David López-Salido, and Matthew E. Smith. "The empirical implications of the interest-rate lower bound." American Economic Review 107.7 (2017): 19712006.

Gutiérrez, Germán and Thomas Philippon. "Investment-less growth: An empirical investigation." Brookings Papers on Economic Activity, Fall 2017:89-190 (including discussion).

Hamilton, James D., and Jing Cynthia Wu. "The effectiveness of alternative monetary policy tools in a zero lower bound environment." Journal of Money, Credit and Banking 44 (2012): 3-46. 
Hesse, Henning, Boris Hofmann, and James Weber. "The macroeconomic effects of asset purchases revisited." Journal of Macroeconomics 58 (2018): 115-138.

Hetzel, Robert L. and Ralph F. Leach. "The Treasury-Fed accord: A new narrative account." Federal Reserve Bank of Richmond Economic Quarterly 87.1 (2001): 7-22.

Holston, Kathryn, Thomas Laubach, and John C. Williams. "Measuring the natural rate of interest: International trends and determinants." Journal of International Economics 108 (2017): S59-S75.

Hooper Peter, Frederic S. Mishkin and Amir Sufi: Prospects for inflation in a high pressure economy: Is the Phillips curve dead or is it just hibernating? National Bureau of Economic Research working paper 25792 (2018).

Jorgenson, Dale W., Mun S. Ho, and Kevin J. Stiroh. "A Retrospective Look at the U.S. Productivity Growth Resurgence." Journal of Economic Perspectives 22.1 (2008): 3-24.

Karahan, Fatih, Benjamin Pugsley, and Aysegul Sahin. "Demographic Origins of the Startup Deficit." NBER Working Paper 25874 (2019)

Kareken, J. and R.M. Solow (1963), "Lags in Monetary Policy," in E.C. Brown et al., Stabilization Policies, Prepared for the Commission on Money and Credit, 14-96.

Kiley, Michael T. and John M. Roberts. "Monetary Policy in a Low Interest Rate World." Brookings Papers on Economic Activity 1 (2017): 317-396.

Kim, Kyungmin. "Identification of monetary policy shocks with external instrument SVAR." Finance and Economics Discussion Series 2017-113 (2017).

Krishnamurthy, Arvind, and Annette Vissing-Jorgensen. "The effects of quantitative easing on Interest rates: Channels and implications for policy." Brookings Papers on Economic Activity, 2 (2011): 215-287.

Krishnamurthy, Arvind, and Annette Vissing-Jorgensen. "The aggregate demand for Treasury debt." Journal of Political Economy 120.2 (2012): 233-267.

Kuttner, Kenneth N. "Monetary policy surprises and interest rates: Evidence from the Fed funds futures market." Journal of Monetary Economics 47.3 (2001): 523-544.

Kuttner, Kenneth N. "Outside the box: Unconventional monetary policy in the Great Recession and beyond." Journal of Economic Perspectives 32.4 (2018): 121-46.

Lakdawala, Aeimit. "Decomposing the effects of monetary policy using an external instruments SVAR." Journal of Applied Econometrics (2019), forthcoming.

Li, Canlin, and Min Wei. "Term Structure Modeling with Supply Factors and the Federal Reserve's LargeScale Asset Purchase Programs." International Journal of Central Banking, 9.1 (2013): 3-39.

McGrattan, Ellen R. and Edward C. Prescott. "Delayed Economic Recovery: A Labor Productivity Puzzle?" Ch. 6 in Ohanian, Lee, John B. Taylor, and Ian J. Wright (eds.), Government Policies and the Delayed Economic Recovery. Stanford: Hoover Institution Press (2012).

McLeay, Michael, and Silvana Tenreyro. "Optimal inflation and the identification of the Phillips curve."

Mertens, Karel, and Morten O. Ravn. "The dynamic effects of personal and corporate income tax changes in the United States." American Economic Review 103.4 (2013): 1212-47.

Mertens, Thomas M., and John C. Williams. "What to expect from the lower bound on interest rates: evidence from derivatives prices." Federal Reserve Bank of New York Staff Report 865 (2018).

Montiel Olea, José Luis and Carolin Pflueger. "A Robust Test for Weak Instruments." Journal of Business \& Economic Statistics 31:3 (2013): 358-369. 
Nakamura, Emi, and Jón Steinsson. "High-frequency identification of monetary non-neutrality: the information effect." Quarterly Journal of Economics 133.3 (2018a): 1283-1330.

Nakamura, Emi, and Jón Steinsson. "Identification in macroeconomics." Journal of Economic Perspectives 32.3 (2018b): 59-86.

Obstfeld, Maurice, "Global Dimensions of Monetary Policy," manuscript (2019).

Ohanian, Lee, John B. Taylor, and lan J. Wright (eds.), Government Policies and the Delayed Economic Recovery. Stanford: Hoover Institution Press, 2012.

Oliner, Stephen D., Daniel E. Sichel, and Kevin J. Stiroh. "Explaining a Productive Decade." Brookings Papers on Economic Activity 1 (2007): 81-137.

Orphanides, Athanasios, and David W. Wilcox. "The opportunistic approach to disinflation." International Finance 5.1 (2002): 47-71.

Rachel, Lukasz and Lawrence $\mathrm{H}$. Summers. "On falling neutral real rates, fiscal policy, and the risk of secular stagnation." Brookings Papers on Economic Activity (2019), forthcoming.

Ramey, Valerie A. "Macroeconomic shocks and their propagation." Handbook of Macroeconomics. Vol. 2. Elsevier, 2016. 71-162.

Reifschneider, David, William Wascher, and David Wilcox. "Aggregate supply in the United States: Recent developments and implications for the conduct of monetary policy", IMF Economic Review 63.1 (2015):71-109.

Reifschneider, David, and John C. Williams. "Three lessons for monetary policy in a low-inflation era." Journal of Money, Credit and Banking (2000): 936-966.

Rodnyansky, Alexander, and Olivier M. Darmouni. "The effects of quantitative easing on bank lending behavior." The Review of Financial Studies 30.11 (2017): 3858-3887.

Rogers, John H., Chiara Scotti, and Jonathan H. Wright. "Evaluating asset-market effects of unconventional monetary policy: a multi-country review." Economic Policy 29 (2014): 749-799.

Romer, Christina D. and David H. Romer. 2004. "A new measure of monetary policy shocks: derivation and implications." American Economic Review 94 (4), 1055-1084.

Sims, Christopher A. "Are Forecasting Models Usable for Policy Analysis?", Minneapolis Federal Reserve Bank Quarterly Review 10, (1986): 2-16.

Stasavage, David. "Polarization and publicity: Rethinking the benefits of deliberative democracy." Journal of Politics 69.1 (2007): 59-72.

Stock, James H. (2008). "What's new in econometrics: time series", lecture 7. Short course lectures, NBER Summer Institute. http://www.nber.org/minicourse_2008.html

Stock, James H. and Mark W. Watson. Modeling inflation after the crisis, in "Macroeconomic Challenges: the Decade Ahead", Federal Reserve Bank of Kansas City Economic Policy Symposium (2010).

Stock, James H., and Mark W. Watson. "Disentangling the channels of the 2007-2009 Recession." Brookings Papers on Economic Activity 1 (2012): 81-135.

Stock, James H., and Mark W. Watson. "Identification and estimation of dynamic causal effects in macroeconomics using external instruments." Economic Journal 128 (2018a): 917-948.

Stock, James H., and Mark W. Watson. "Slack and cyclically sensitive inflation." Working Paper (2018b). Sunstein, Cass. "Output transparency vs. input transparency." Working Paper (2016).

Swanson, Eric T. "Measuring the effects of Federal Reserve forward guidance and asset purchases on financial markets." National Bureau of Economic Research working paper 23311 (2017). 
Swanson, Eric T. "The Federal Reserve Is Not Very Constrained by the Lower Bound on Nominal Interest Rates." National Bureau of Economic Research working paper 25123 (2018).

Swanson, Eric T., and John C. Williams. "Measuring the effect of the zero lower bound on medium-and longer-term interest rates." American Economic Review 104.10 (2014): 3154-85.

Taylor, John B. 1993. "Discretion versus Policy Rules in Practice." Carnegie-Rochester Conference Series on Public Policy 39, pp. 195-214.

Taylor, John B. 1999. "The Robustness and Efficiency of Monetary Policy Rules as Guidelines for Interest Rate Setting by the European Central Bank." Journal of Monetary Economics 43(3), pp. 655-679.

Ulate Campos, Mauricio. "Going negative at the zero lower bound: The effects of negative rates on bank profitability." Working Paper (2018).

Vayanos, Dimitri, and Jean-Luc Vila. A preferred-habitat model of the term structure of interest rates. No. National Bureau of Economic Research working paper 15487 (2009).

Weale, Martin, and Tomasz Wieladek. "What are the macroeconomic effects of asset purchases?." Journal of Monetary Economics 79 (2016): 81-93.

Wright, Jonathan $\mathrm{H}$. "What does monetary policy do to long-term interest rates at the zero lower bound?" Economic Journal 122 (2012): F447-F466.

Yellen, Janet. "The Economic Outlook and Monetary Policy." Money Marketeers of New York University (2012). 


\section{Appendix}

\section{Additional Results}

\section{A. Additional impulse response functions}

Figures A-1 and A-2 provide additional results related to the SVAR-IV estimates of the unemployment rate impulse responses to the Fed funds and slope shock.

Figure A-1 shows the local projections-instrumental variables (LP-IV) estimates of the IRFs. Note that these are estimated only over the sample period of the IV regression (1994m2-2007m12 for the Fed funds shock, 2008m1-2019m2 for the slope shock), not the full VAR period used for the SVAR-IV. The LPIV IRFs are generally similar in shape to the SVAR-IV IRFs. For the Fed funds shock, the LP-IV estimates indicate a greater effect of the shocks than the SVAR-IV estimates. For the slope shock, the LP-IV estimates are similar in magnitude, but the LP-IV estimates the impact on the unemployment rate to occur somewhat more quickly than does the SVAR-IV.

Figure A-1. Unemployment gap response to the Fed funds shock (left) and slope shock (right), estimated by by LP-IV.
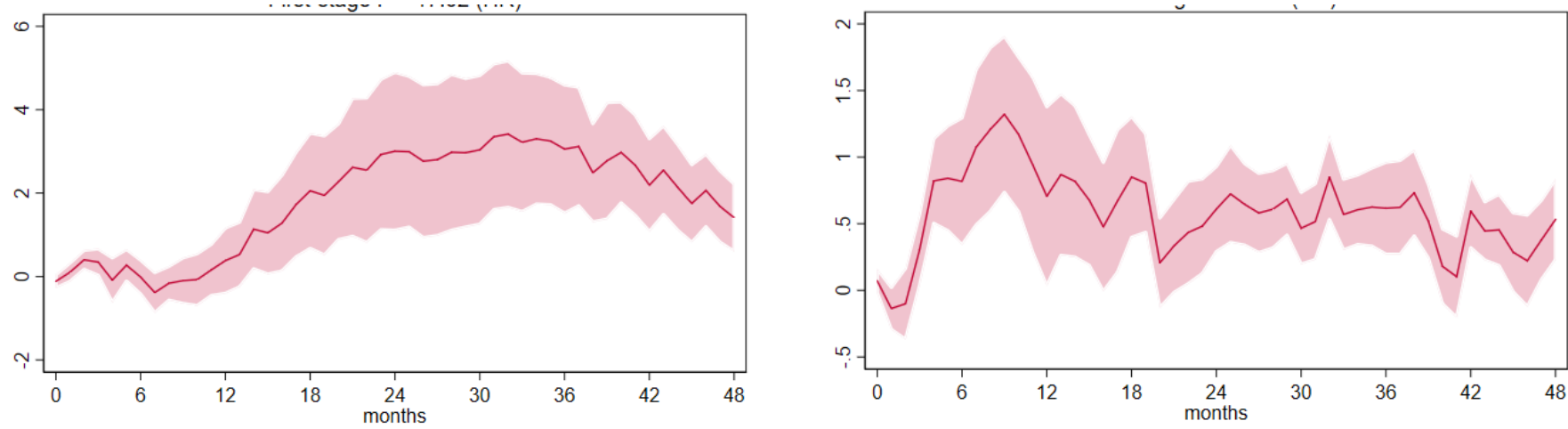

Figures A-2 presents the SVAR-IV estimates of the effect of the two shocks on the GilchristZakrajšek (2012) excess bond premium. The SVAR-IV estimates that both contractionary shocks increase financial market risk premiums, as measured by an increase in the EBP, with an effect that decays within a year. LP-IV estimates (reported in the supplement) are generally similar to the SVAR-IV estimates.

The Supplement reports multiple checks of the robustness of the unemployment rate IRFs to changes in specification, estimation date, and control variables. 
Figure A-2. Response of the Gilchrist- Zakrajšek Excess Bond Premium (EBP) to a Fed funds shock (left) and a slope shock (right), estimated by SVAR-IV

Effect of level shock on the Exess Bond Premium

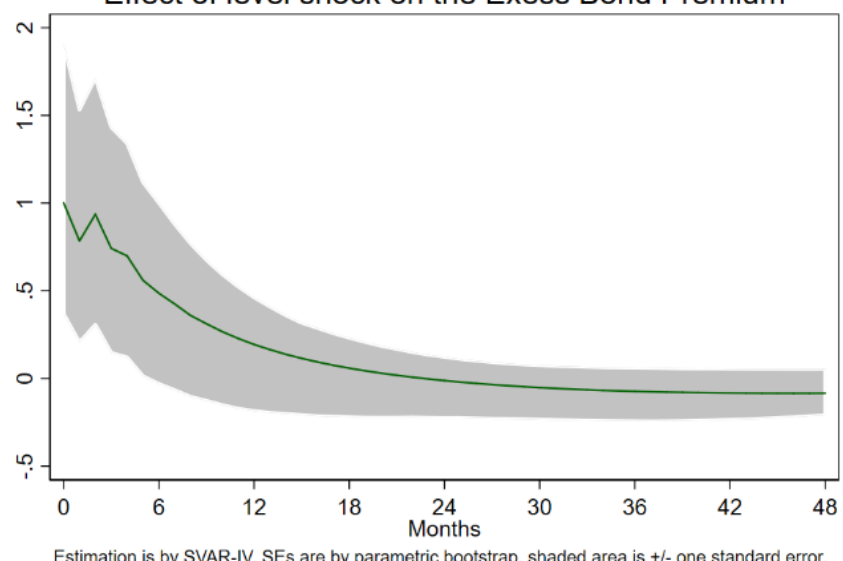

Effect of slope shock on the Exess Bond Premium

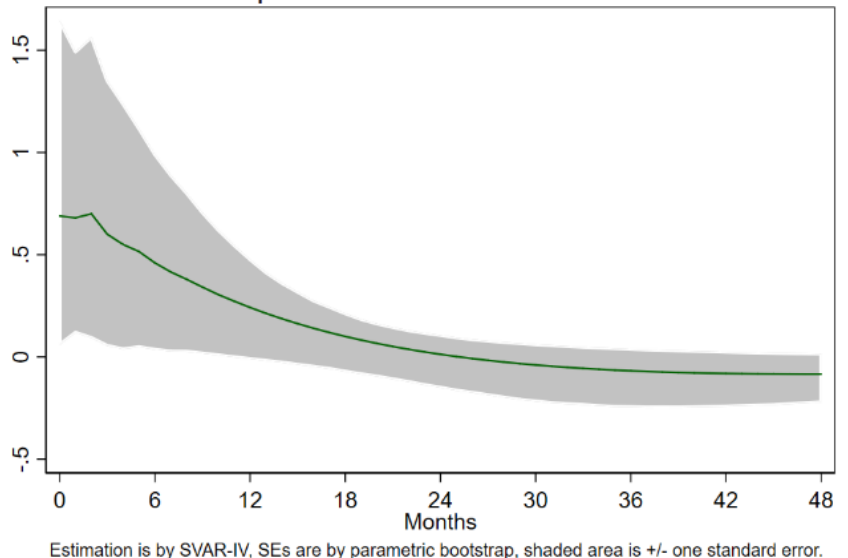

\section{B. Counterfactual simulation results using a steeper Phillips curve}

For these counterfactuals, the Phillips curve in the first line of Table 2 is replaced by a Phillips curve with a greater long-run slope, estimated using MSA-level data. Specifically, we take the estimated coefficients from column 4, Table 3 in MacLeay and Tenreyro (2019), which has the hybrid Phillips curve coefficients $k=-0.367, \gamma_{f}=-0.067$, and $\gamma_{b}-0.073$, which have a long-run slope of $k /\left(1-\gamma_{f}-\gamma_{b}\right)=-0.369$, approximately twice that of the time-series estimate used for the simulations in the paper. Results for selected counterfactuals are shown in Figures B-1 through B-4; a complete set of results for all the counterfactuals is given in the Supplement.

Figure B-1 shows the "No LSAP" counterfactual (compare to Figure 19). Compared to the base model with the flatter Phillips curve, the PCE core inflation rate is estimated to be substantially lower, that is, farther from the $2 \%$ target.

Figure B-2 shows the "stronger sooner" policy counterfactual of Figure 22. With the aggressive early flattening and declining unemployment rate in this scenario, inflation overshoots its target but then returns to $2 \%$. The lack of persistence of shocks to inflation is a consequence of the small dynamic coefficients in the McLeay-Tenreyro MSA-based estimate.

Figure B-3 shows the counterfactual in Figure 24, in which the Fed inherits a 3\% inflation target and additionally uses the slope policies it actually did use. With the steeper Phillips curve, the rate of inflation returns to its $3 \%$ target in the middle of the expansion, then fluctuates around that target. 
Figure B-1: No LSAP Counterfactual: Steeper Phillips Curve
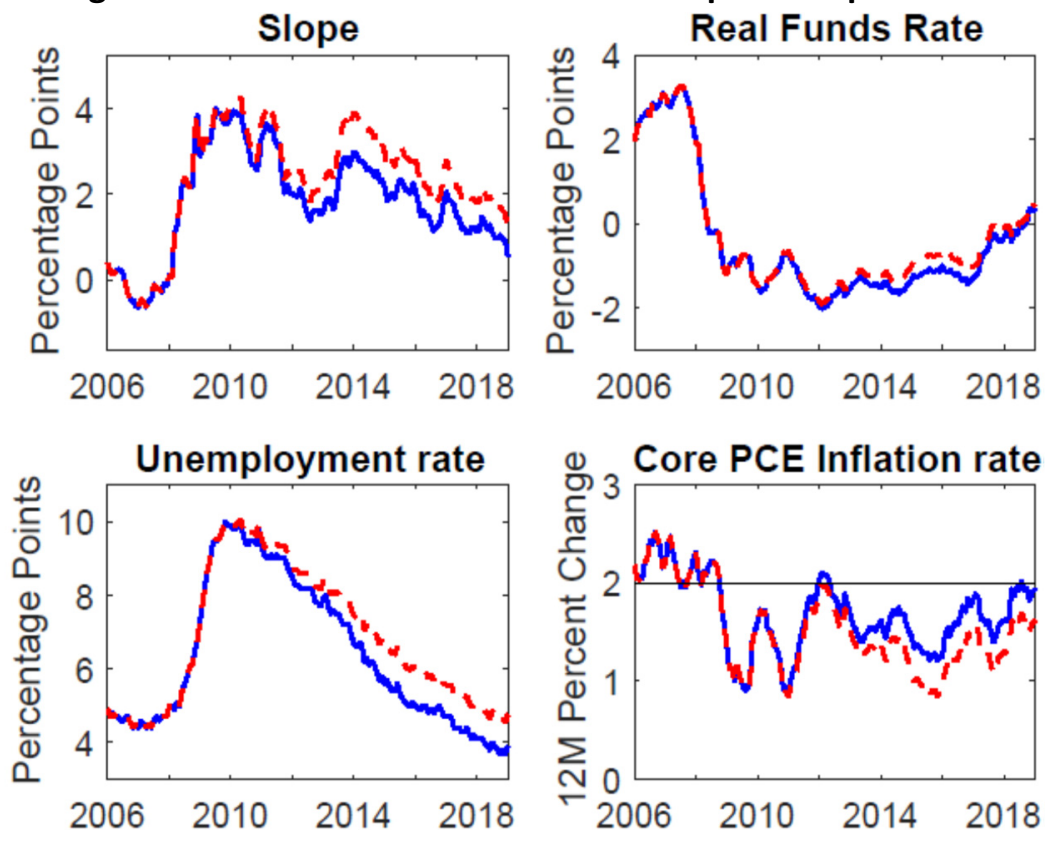

Figure B-2: Frontloaded additional LSAPs:

Yield Curve Flattened by an Additional 2 Percentage Points for 18 Months, Steeper Phillips Curve
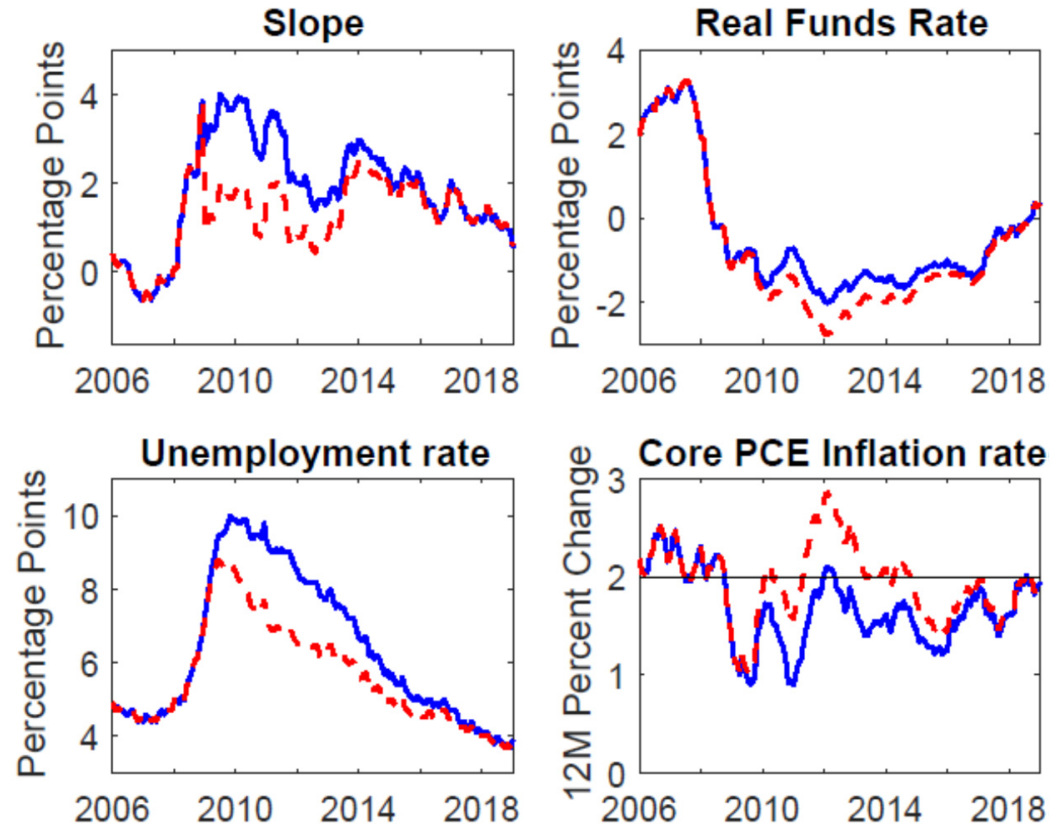
Figure B-3: 3 percent Inherited Inflation Target with historical slope shocks counterfactual: Steeper Phillips Curve
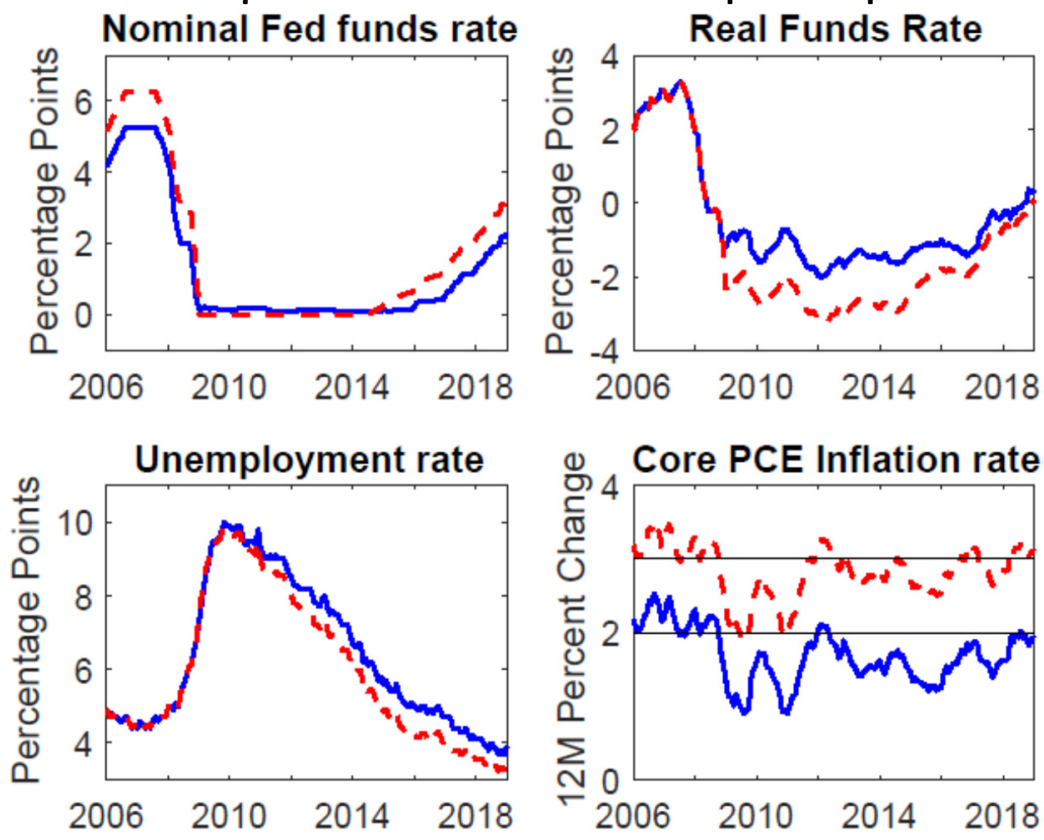